Universidade de São Paulo

Instituto de Física

\title{
APLICAÇÃO DO GEANT4 NO ESTUDO DA INFLUÊNCIA DA RUGOSIDADE DA SUPERFÍCIE DE ÂNODOS DE TUBOS DE RAIOS X UTILIZADOS EM RADIOLOGIA DIAGNÓSTICA
}

\author{
Helio Massaharu Murata
}

Orientador: Prof. Dr. Maurício Moralles

Dissertação de mestrado apresentada ao Instituto de Física para a obtenção do título de Mestre em Ciências

Banca examinadora:

Prof. Dr. Maurício Moralles (IPEN)

Prof. Dra. Cecil Chow Robilotta (IF-USP)

Prof. Dr. Marcelo Baptista de Freitas (UNICAMP)

São Paulo 

FICHA CATALOGRÁFICA

Preparada pelo Serviço de Biblioteca e Informação do Instituto de Física da Universidade de São Paulo

Murata, Helio Massaharu

Aplicação do GEANT4 no estudo da influência da rugosidade da superfície de ânodos de tubos de raios $X$ utilizados em radiologia diagnóstica. São Paulo, 2008.

Dissertação (Mestrado) - Universidade de São Paulo. Instituto de Física - Depto. de Física Nuclear e Instituto de Pesquisas Energéticas e Nucleares/IPEN - Centro de Reator de Pesquisa.

Orientador: Prof. Dr. Maurício Moralles

Área de Concentração: Física

Unitermos: 1. Espectroscopia de raio X; 2. Física médica; 3. Método de Monte Carlo; 4. Física

computacional: 5. Radiografia. 

Aos meus pais, Masaru e Maria e à Christiane, presente em todos os momentos da vida 



\section{Agradecimentos}

Ao Prof. Dr. Maurício Moralles, orientador deste trabalho, pela compreensão, presteza, apoio e contribuições, durante todo o desenvolvimento desta dissertação.

Ao amigo Daniel A. B. Bonifácio, pelas discussões, críticas e sugestões, fundamentais neste trabalho.

Ao amigo Márcio Bottaro, pela colaboração e idealização deste trabalho em seu treinamento na Alemanha.

Ao amigo Dr. Marco Aurélio G. Pereira, pelo apoio e pelas valiosas contribuições.

Aos colegas da CERTUSP do Instituto de Eletrotécnica e Energia da Universidade de São Paulo, em especial ao Prof. Dr. Jean Bodinaud, pelo apoio e oportunidade de concretização deste trabalho.

Aos colegas do STAMH do Instituto de Eletrotécnica e Energia da Universidade de São Paulo, em especial ao amigo Edson Pereira Barbosa, pela grande amizade.

À diretoria do Instituto de Eletrotécnica e Energia da Universidade de São Paulo, pelo apoio na realização deste trabalho.

Ao Instituto de Física da Universidade de São Paulo, pela oportunidade para a realização deste trabalho.

Aos funcionários da secretaria de Pós Graduação do Instituto de Física da Universidade de São Paulo.

À minha família, pelo incentivo e paciência durante o desenvolvimento deste trabalho. 



\section{Resumo}

\section{APLICAÇÃO DO GEANT4 NO ESTUDO DA INFLUÊNCIA DA RUGOSIDADE DA SUPERFÍCIE DE ÂNODOS DE TUBOS DE RAIOS X UTILIZADOS EM RADIOLOGIA DIAGNÓSTICA}

\section{Helio Massaharu Murata}

Estudos recentes utilizaram filtração com absorvedores de W para representar o efeito da rugosidade do ânodo. Para verificar a validade desta metodologia, neste trabalho, foram avaliados espectros de energia na faixa utilizada em radiologia diagnóstica convencional $(40,80$ e $150 \mathrm{kV})$, gerados por tubos de raios X com ânodos rugosos por meio de simulações baseadas no Método de Monte Carlo. Para isto, foi desenvolvido um programa computacional com a ferramenta GEANT4, a qual simula a interação da radiação com a matéria. Neste programa, foram abordados: a modelagem geométrica do sistema, os processos físicos envolvidos e a aplicação de uma técnica de redução de variância baseada no fracionamento (splitting) de bremsstrahlung. Para a modelagem geométrica, as superfícies rugosas dos ânodos foram geradas a partir de um modelo estocástico de crescimento baseado na equação de Edwards-Wilkinson. Os ânodos foram modelados com um ângulo fixo de $16^{\circ}$ e de material constituído de $95 \%$ de tungstênio e $5 \%$ de rênio. As superfícies dos ânodos foram geradas com rugosidades de 0,$0 ; 0,5 ; 1,0 ; 2,0 ; 3,0 ; 4,0 ; 5,0$ e $6,0 \mu \mathrm{m}$.

Também foi realizada a caracterização do feixe de radiação $\mathrm{X}$ pelos parâmetros da energia média e da camada semi-redutora (CSR). Estes parâmetros foram calculados numericamente a partir dos espectros de raios X gerados por simulação de Monte Carlo. Os valores das energias médias sofreram aumentos da ordem de 20 a $30 \%$ e as CSR's entre 11 a 25\% aproximadamente, com o aumento das rugosidades, dependendo da energia máxima do espectro. A comparação entre os espectros produzidos com ânodo rugoso e os espectros gerados com a adição de filtração de $\mathrm{W}$ no feixe primário de radiação $\mathrm{X}$ mostraram que ambos alteram a forma da distribuição espectral, porém de modos distintos. Ou seja, o efeito da rugosidade é diferente do efeito da filtração. 


\section{Abstract}

\section{APPLICATION OF GEANT4 IN THE STUDY OF ROUGHNESS INFLUENCE ON THE ANODE SURFACE FROM X RAY TUBE USED IN RADIODIAGNOSTIC}

\section{Helio Massaharu Murata}

Recent studies employed the filtration with tungsten absorbers to represent the effect of the anode roughness. To verify the validity of this method, in this work, the Monte Carlo method was used to simulate the spectra of $\mathrm{X}$ rays employed in conventional radiodiagnostics $(40,80$ and $150 \mathrm{kV})$, generated by anode roughness. To perform this task, a computational program was developed with the GEANT4 toolkit, which simulates the interaction of radiation with matter. In this program, the geometric modeling of the system, the relevant physical processes and the application of a variance reduction technique based on bremsstrahlung splitting were implemented. In the geometric modeling, the rough surfaces of the anodes were generated from a stochastic model of roughness growth based on the Edwards-Wilkinson equation. The anodes were modeled with a fixed angle of $16^{\circ}$ and material consisting of $95 \%$ tungsten and $5 \%$ of rhenium. The anode surfaces were generated with roughness of $0.0,0.5,1.0,2.0,3.0,4.0,5.0$ and $6.0 \mu \mathrm{m}$.

The $\mathrm{X}$ ray spectra were characterized by the half-value layers (HVL) and mean energies. These parameters were calculated numerically from $\mathrm{X}$ ray spectra generated by the Monte Carlo simulation. The increase in the mean energy values was of the order of 20 to $30 \%$ and in the HVLs between 11 and $25 \%$ approximately growing with the roughness, depending on maximum energy of the spectrum. Comparison between spectra from anodes with roughness and spectra generated by adding tungsten filtration on primary $\mathrm{X}$ ray beam showed that both change the shape of the spectral distribution, but in different ways. In other words, the roughness effect and the filtration effect are not equivalent. 


\section{Sumário}

Resumo

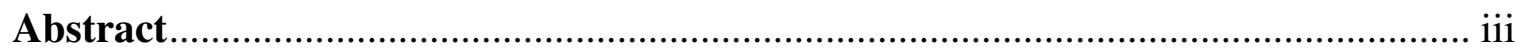

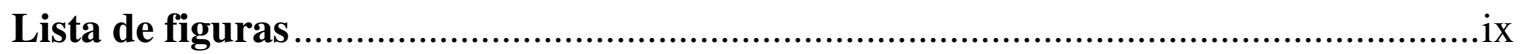

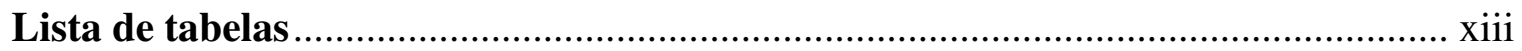

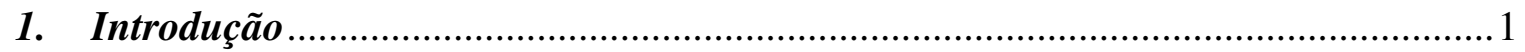

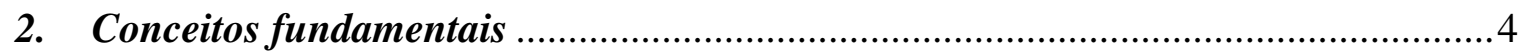

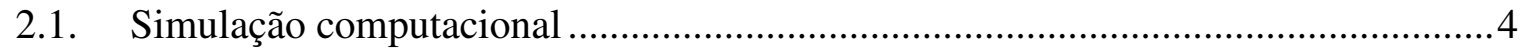

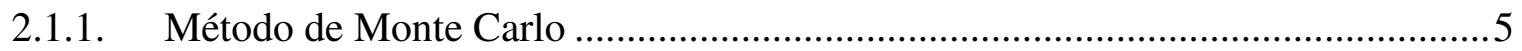

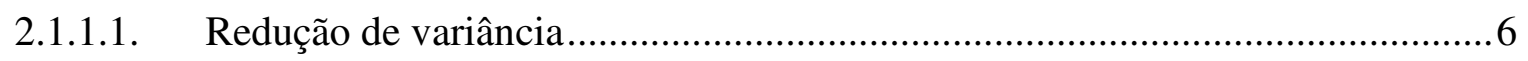

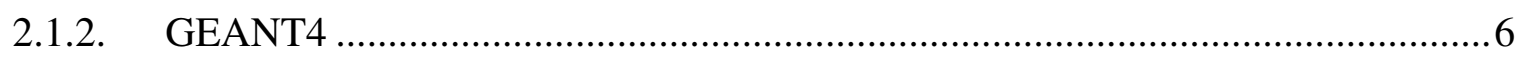

2.1.2.1. Estrutura básica do GEANT4 ….............................................................. 7

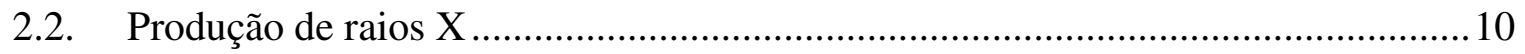

2.2.1. Radiação de freamento ou Bremsstrahlung ....................................................... 10

2.2.2. Radiação característica (fluorescência) ….......................................................... 11

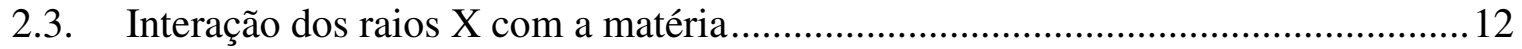

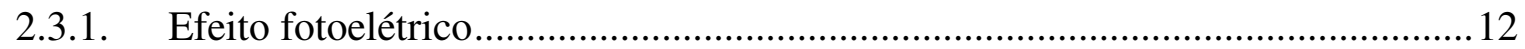

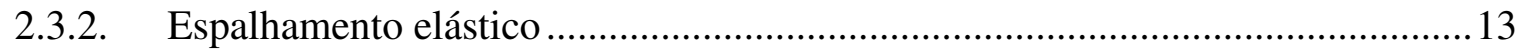

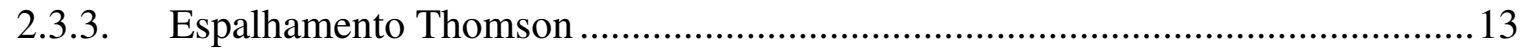

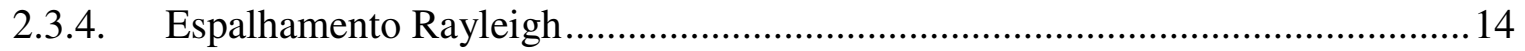

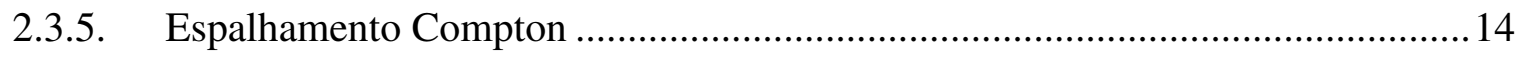

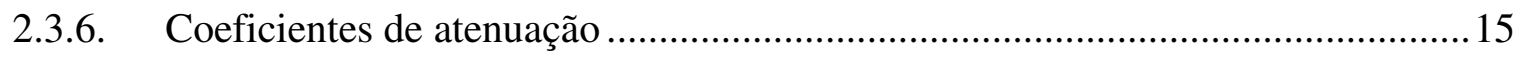

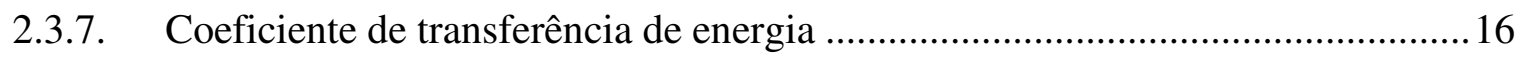




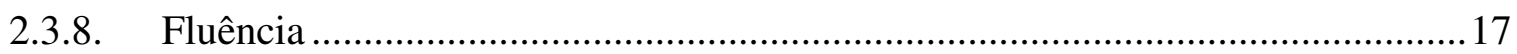

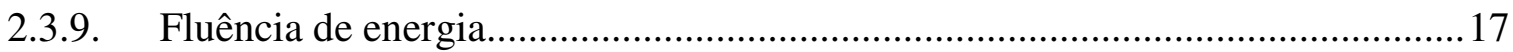

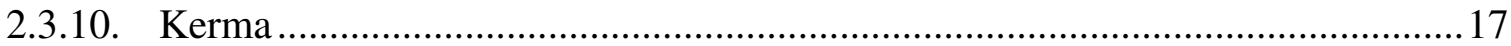

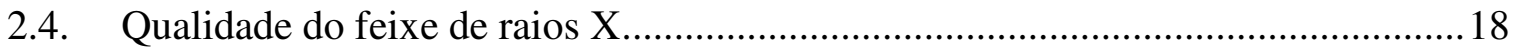

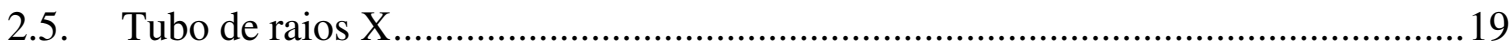

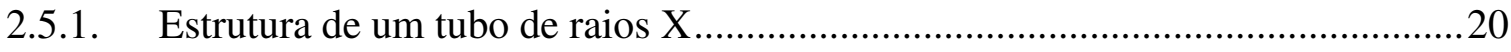

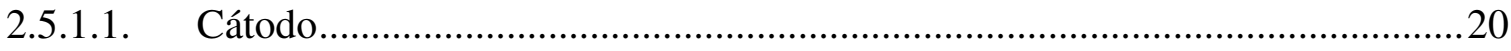

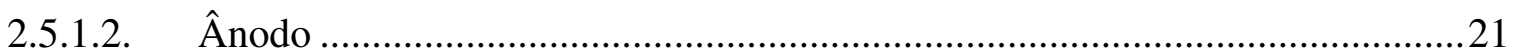

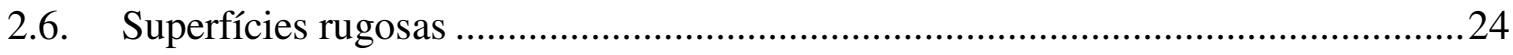

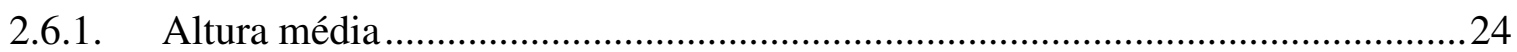

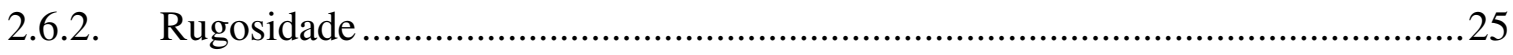

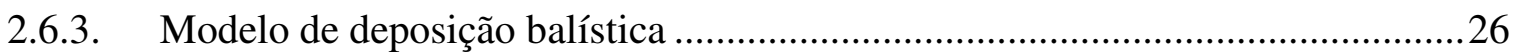

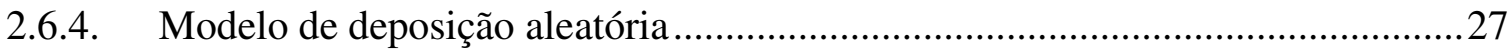

2.6.4.1. Equações estocásticas de crescimento ….......................................................28

2.6.4.2. Modelo de deposição aleatória com relaxação superficial ..............................29

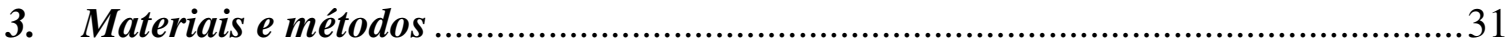

3.1. Estudo da rugosidade do ânodo de tubo de raios X .................................................

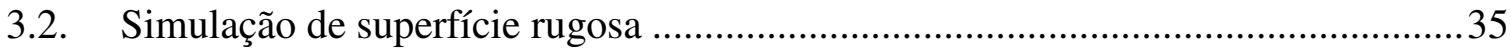

3.2.1. Método proposto por Mattos, Moreira \& Atman ............................................... 35

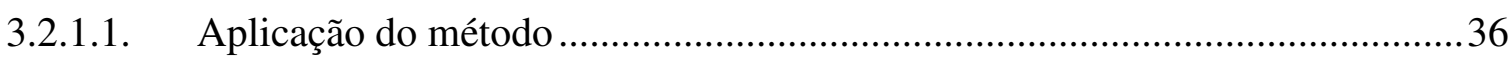

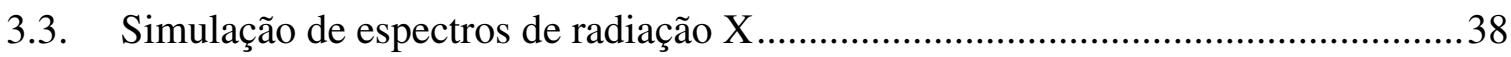

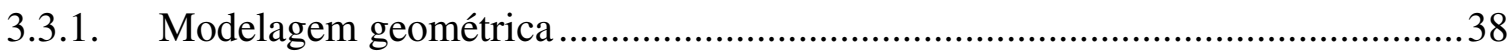

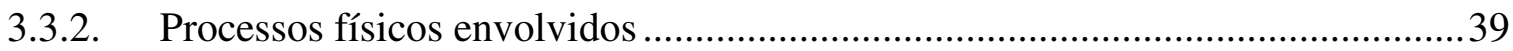

3.3.3. Critério estatístico para a formação do espectro de raios X ................................41

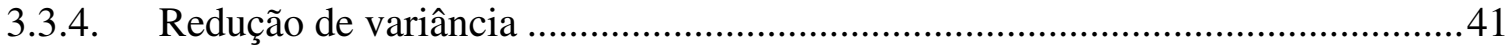

3.4. Espectros de raios $X$ com filtração adicional ........................................................46 
3.4.1. Caracterização dos espectros pela energia média .............................................46

3.4.2. Caracterização de espectros pela camada semi-redutora ...................................47

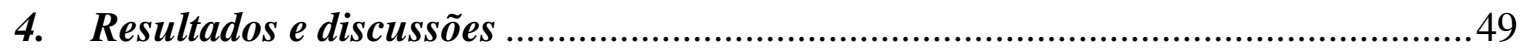

4.1. Simulação de espectros gerados por tubos de raios X com ânodos rugosos ..........49

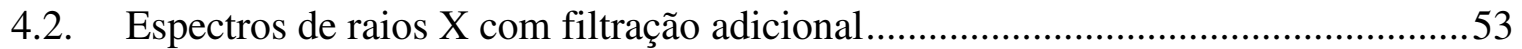

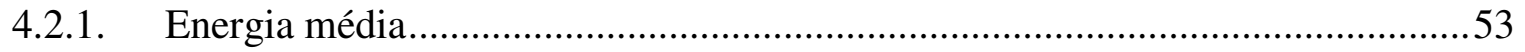

4.2.1.1. Comparação entre espectros simulados e atenuados .......................................59

4.2.1.2. Energia média com adição de filtração de Al ................................................62

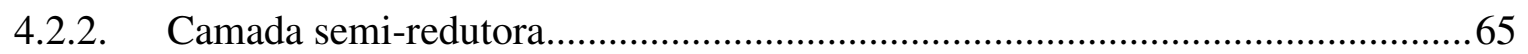

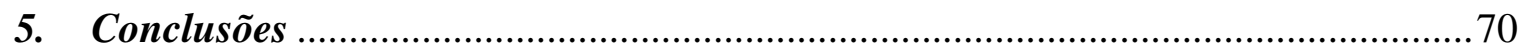

Apêndice 1 - Alguns princípios básicos da teoria de probabilidades ......................... 73

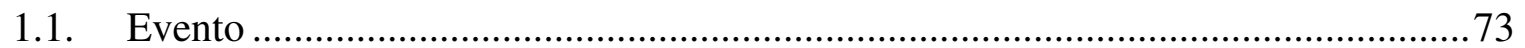

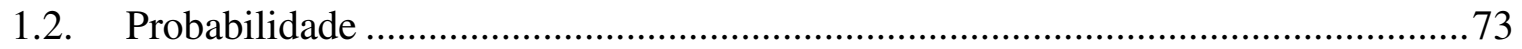

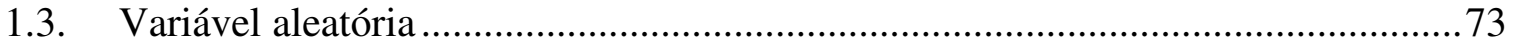

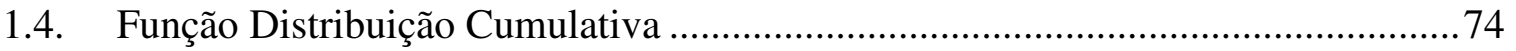

1.5. Função Distribuição de Probabilidade ..................................................................... 74

1.6. Função Densidade de Probabilidade ……............................................................. 74

Apêndice 2 - Códigos utilizados na técnica de redução de variância ..........................75

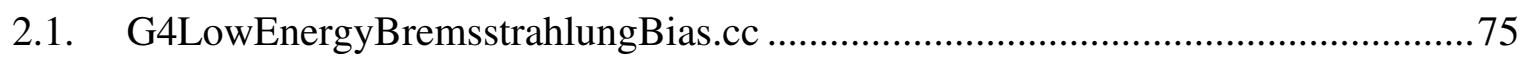

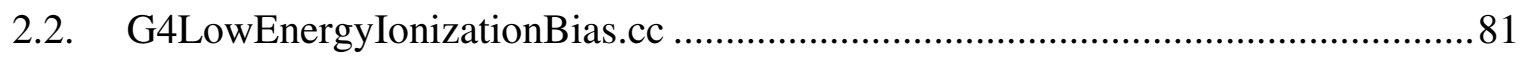

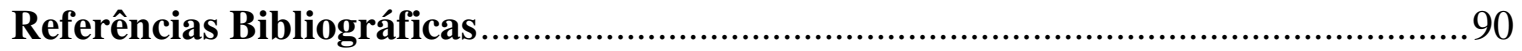




\section{Lista de figuras}

Figura 2.1.2.1-1 - Diagrama de categoria de classes do GEANT4 (Pia, 2003)..................9

Figura 2.2.1-1- Formação da radiação de freamento ou Bremsstrahlung. .......................11

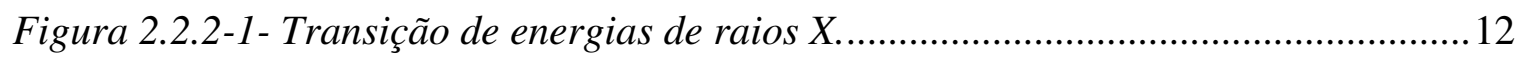

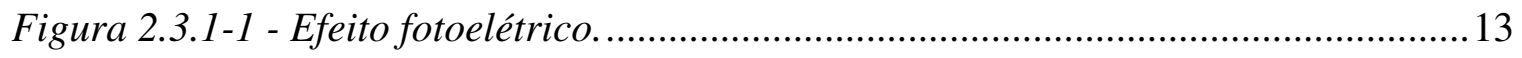

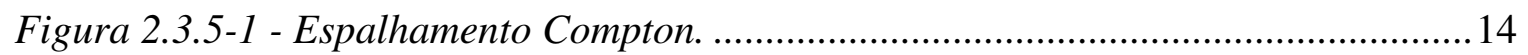

Figura 2.5-1 - Esquema simplificado de um tubo de raios $X$. .......................................... 19

Figura 2.5-2 - Esquema de uma cúpula de raios $X$ utilizado em radiologia diagnóstica.

(Bushberg, Seibert, Leidholdt. Jr., \& Boone, 2002) ........................................................20

Figura 2.5.1.1-1- Cátodo com dois filamentos paralelos e o dispositivo focalizador (Wolbarst, 1993).

Figura 2.5.1.2-1 - Influência do comprimento do filamento do cátodo e do ângulo do ânodo na projeção do ponto focal. (Bushberg, Seibert, Leidholdt. Jr., \& Boone, 2002)..22

Figura 2.5.1.2-2 - Aspecto de um ânodo giratório de um tubo de raios $X$ novo. .23

Figura 2.6.1-1- Distribuição das alturas h em cada sítio i em um determinado tempo t..25

Figura 2.6.3.1-1 - Modelo dedeposição balística. ...........................................................27

Figura 2.6.3.2-1 - Modelo de deposição aleatória. ..........................................................28

Figura 2.6.3.3-1 - Modelo de deposição aleatória com relaxação superficial. .................30

Figura 3.1-1 - Imagem de uma área de um ânodo de um tubo de raios X não bombardeada por elétrons.

Figura 3.1-2 - Imagem de uma área de um ânodo de um tubo de raios $X$ bombardeada por elétrons.

Figura 3.1-3 - Aspecto de um ânodo giratório de um tubo de raios X apresentando rugosidade elevada devido ao bombardeio de elétrons após um longo período.

Figura 3.1-4 - Esquema da trajetória do elétron para a geração do fóton de raios $X$ (vista lateral). .34

Figura 3.2.1.1-1 - Fluxograma para a geração da superfície rugosa...............................36

Figura 3.2.1.1-2 - Perfil da rugosidade $(\omega=0,588 \mu \mathrm{m})$. .37 
Figura 3.2.1.1-3 - Superfície rugosa representada por uma rede L x $n$ (vista superior). 38 Figura 3.3.1-1 - Modelo geométrico do sistema simulado pelo GEANT4.

Figura 3.3.4-1 - Gráfico da relação entre o número de fótons detectados por segundo e a quantidade $N_{f}$ de fótons gerados em uma única interação.

Figura 3.3.4-2 - Espectro de radiação X com tensão aplicada ao tubo de $150 \mathrm{kV}$ com ânodo com rugosidade $\omega=10,0 \mu \mathrm{m}$ simulado com o GEANT4.

Figura 4.1-1 - Espectros de feixes de radiação X aplicado a uma tensão de $40 \mathrm{kV}$ gerados pelo GEANT4 simulando tubos de raios X com ânodos apresentando rugosidade.

Figura 4.1-2 - Espectros de feixes de radiação $X$ aplicado a uma tensão de $80 \mathrm{kV}$ gerados pelo GEANT4 simulando tubos de raios X com ânodos apresentando rugosidade.

Figura 4.1-3 - Espectros de feixes de radiação X aplicado a uma tensão de $150 \mathrm{kV}$ gerados pelo GEANT4 simulando tubos de raios X com ânodos apresentando rugosidade.

Figura 4.2.1-1 - Valores da espessura da filtração de tungstênio conforme as energias médias dos espectros de raios $X$ atenuados contidos na Tabela 4.2.1-1.

Figura 4.2.1-2 - Espectros de feixes de radiação $X$ aplicado a uma tensão de $40 \mathrm{kV}$ atenuados com filtração de tungstênio. .56

Figura 4.2.1-3 - Espectros de feixes de radiação $X$ aplicado a uma tensão de $80 \mathrm{kV}$ atenuados com filtração de tungstênio.

Figura 4.2.1-4 - Espectros de feixes de radiação $X$ aplicado a uma tensão de $150 \mathrm{kV}$ atenuados com filtração de tungstênio.

Figura 4.2.1.1-1 - Espectros de raios X com energia máxima de $40 \mathrm{keV}$ simulado com ânodo com 6,0 $\mu \mathrm{m}$ de rugosidade e atenuado com 1,225 $\mu \mathrm{m}$ de filtração de tungstênio. Ambos com o mesmo valor de energia média.

Figura 4.2.1.1-2 - Espectros de raios X com energia máxima de $80 \mathrm{keV}$ simulado com ânodo com 6,0 $\mu \mathrm{m}$ de rugosidade e atenuado com 2,995 $\mu \mathrm{m}$ de filtração de tungstênio. Ambos com o mesmo valor de energia média.

Figura 4.2.1.1-3 - Espectros de raios X com energia máxima de $150 \mathrm{keV}$ simulado com ânodo com 6,0 $\mu \mathrm{m}$ de rugosidade e atenuado com 4,035 $\mu \mathrm{m}$ de filtração de tungstênio. Ambos com o mesmo valor de energia média. 60 
Figura 4.2.1.1-4 - Valores dos coeficientes de atenuação de massa $\frac{\mu}{\rho}$ em função da energia do fóton para o elemento tungstênio. ...................................................................61 Figura 4.2.1.2-1 - Espectros de feixes de radiação X obtidos com uma tensão de $80 \mathrm{kV} e$ atenuados com filtração de $2,5 \mathrm{~mm}$ de Al. .64 


\section{Lista de tabelas}

Tabela 3.3.4-1 - Tempo estimado da simulação de espectro de raios X, aplicada uma tensão de $150 \mathrm{kV}$, com 10 mil eventos, gerado por tubo de raios $X$ com ânodo rugoso sem a aplicação de técnicas de redução de variância.

Tabela 3.3.4-2 - Valor do desvio padrão estatístico $\sigma_{\text {est }}$ referente às contagens $C_{0}$ e $C_{1}$ e o valor do desvio padrão da diferença média absoluta $\sigma_{<D>}$ referente a $<D>$ dos espectros correspondentes.

Tabela 4.2.1-1 - Valores das energias médias dos espectros de raios $X$ simulados com o GEANT4 para energias máximas de 40, 80 e $150 \mathrm{keV}$ em relação às variações das rugosidades dos ânodos de tubo de raios $X$. .54

Tabela 4.2.1.1-1 - Valores do desvio padrão estatístico $\sigma_{\text {est }}$ referente às contagens $C e$ valores do desvio padrão da diferença média absoluta $\sigma_{<D>}$ referente $a<D>$ dos espectros correspondentes.

Tabela 4.2.1.2-1 - Valores das energias médias do espectro de raios X simulado com o GEANT4 para energia de $80 \mathrm{keV}$ atenuado com filtração de $2,5 \mathrm{~mm} \mathrm{Al}$.

Tabela 4.2.1.2-2 - $\Delta(E)$ referente à diferença da energia média entre espectros de raios $X$ de 80 kV: (a) simulados com ânodo com rugosidade e sem rugosidade; (b) calculados com ânodo com rugosidade média e sem rugosidade (ângulo do ânodo $16^{\circ}, 2,5 \mathrm{~mm} \mathrm{Al}$, distância de $1 \mathrm{~m}$ ).

Tabela 4.2.2-1 - Valores da primeira CSR para espectros de $40 \mathrm{kV}$. .65

Tabela 4.2.2-2 - Valores da primeira CSR para espectros de $80 \mathrm{kV}$. .66

Tabela 4.2.2-3 - Valores da primeira CSR para espectros de $150 \mathrm{kV}$. .66

Tabela 4.2.2-4 - Valores da segunda CSR para espectros de $40 \mathrm{kV}$. .67

Tabela 4.2.2-5 - Valores da segunda CSR para espectros de $80 \mathrm{kV}$.

Tabela 4.2.2-6 - Valores da segunda CSR para espectros de $150 \mathrm{kV}$. .68

Tabela 4.2.2-7 - $\triangle$ CSR referente à diferença da primeira camada semi-redutora entre espectros de raios $X$ de $80 \mathrm{kV}$ : (a) simulados com ânodo com rugosidade e sem rugosidade; (b) atenuados com filtração equivalente em tungstênio e sem filtração; (c) 
calculados com ânodo com rugosidade média e sem rugosidade (ângulo do ânodo $16^{\circ}$,

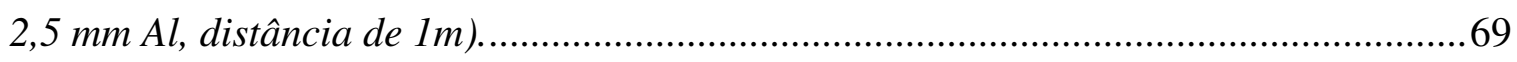





\section{Introdução}

Em diversas áreas da medicina, as radiações ionizantes são amplamente empregadas tanto em aplicações diagnósticas como terapêuticas. Com o avanço tecnológico, diferentes técnicas e instrumentos para medição, calibração e ensaio para dosimetria de radiação e controle de qualidade aplicados nessas áreas foram desenvolvidos. Com isso, novas metodologias para a utilização e avaliação de seus resultados foram criadas. Contudo, para alcançar um nível de confiança adequado nos resultados, deve-se atentar quanto à caracterização de feixes padrões de radiação ionizante em cada tipo de aplicação.

No âmbito da física médica, particularmente na radiologia diagnóstica, a caracterização é realizada em feixes de radiação X. Isto implica em dizer que a avaliação dos parâmetros que influenciam a distribuição espectral do feixe de raios $\mathrm{X}$ está relacionada com a melhora na qualidade dos feixes de radiação X. Essa necessidade leva organismos padronizadores, certificadores e reguladores a estabelecer padrões e métodos que assegurem a qualidade dos procedimentos e equipamentos usados em física médica. Isto resulta na obtenção de informações com qualidade suficiente para que se realize um diagnóstico médico confiável, submetendo o paciente à menor quantidade de radiação possível, dentro do conceito ALARA.

Dentre diversos fatores, o aumento da rugosidade no ânodo do tubo de raios $\mathrm{X}$ em um equipamento para fins radiológicos altera a forma espectral da radiação X (Nowotny \& Meghzifene, 2002). O aumento da rugosidade, ou envelhecimento do tubo de raios X, está relacionado com a carga de trabalho do equipamento e suas condições de operação. Este fato resulta no aumento da filtração inerente do tubo de raios X. Baseado nessas informações, foram realizadas avaliações experimentais nas quais foram inseridos filtros adicionais de tungstênio ao feixe primário de raios $\mathrm{X}$ para simular o efeito da rugosidade em ânodos de tubo de raios X (Bottaro, 2007).

Uma das mais importantes ferramentas para análise da dose do paciente e da qualidade da imagem em radiologia diagnóstica é a simulação computacional do espectro de radiação X (Ay, Shahriari, Sarkar, Adib, \& Zaidi, 2004). Numa abordagem 
computacional, existem basicamente três categorias de métodos para a aquisição de um espectro de raios X: baseados em modelos empíricos (Boone \& Seibert, An accurate method for computer-generating tungsten anode $\mathrm{x}$-ray spectra from 30 to $140 \mathrm{kV}, 1997$ ) (Boone, Fewell, \& Jennings, 1997), semi-empíricos (Birch \& Marshall, 1979) e Método de Monte Carlo (Ng, Kwok, \& Tang, 2000) (Ay, Shahriari, Sarkar, Adib, \& Zaidi, 2004) (Ay, Sarkar, Shahriari, Sardari, \& Zaidi, 2005) (Bonifácio, Murata, \& Moralles, 2005). Nos modelos empíricos e semi-empíricos, apesar do pequeno tempo para a obtenção dos espectros, alguns aspectos físicos envolvidos no sistema não são tratados, além da incapacidade de simulação de modelos geométricos mais complexos. As simulações de Monte Carlo são adotadas como alternativa para resolver as limitações dos outros modelos. No entanto, o tempo para a realização das simulações baseadas no Método de Monte Carlo é bastante longo, principalmente quando são envolvidos modelos geométricos mais elaborados. Portanto, para a aplicação deste modelo necessita-se o uso de computadores com grande capacidade de processamento, armazenamento de dados e memória.

Para a geração do espectro de radiação X baseada no Método de Monte Carlo, existem diversos códigos computacionais que simulam o transporte da radiação e a sua interação com a matéria: EGS4 (Nelson, Hirayama, \& Rogers, 1985), GEANT4 (Agostinelli, et al., 2003), MCNP (X-5 Monte Carlo Team, 2005), PENELOPE (Salvat, Fernández-Varea, \& Sempau, 2006), entre outros. As principais diferenças entre os códigos são a linguagem de programação adotada para a realização das simulações, os recursos de visualização da modelagem geométrica e da interação das partículas com a matéria, a descrição dos processos físicos e das partículas de interesse e a faixa de energia envolvida.

Este trabalho foi realizado com a ferramenta GEANT4, que é um conjunto de códigos implementados na linguagem de programação $\mathrm{C}++$ com recursos de orientação a objetos (Booch, 1994) no âmbito da engenharia de software (Pressman, 2001). Inicialmente, foram realizados estudos do modelo real de um tubo de raios $\mathrm{X}$ e de seus componentes internos. A partir deste modelo real, foi realizada a modelagem geométrica do sistema de modo simplificado, não incluindo elementos que estão relacionados com o aumento da filtração inerente ao tubo de raios X. A superfície rugosa do ânodo foi modelada por um método baseado na equação de Edwards-Wilkinson (Mattos, Moreira, 
\& Atman, 2006). Os processos físicos, para as faixas de energias máximas de 40, 80 e $150 \mathrm{keV}$, empregados nas simulações dos espectros foram anteriormente validados por Bonifácio (Bonifácio D. A., 2007). Com base no modelo geométrico e nos processos físicos envolvidos, foram simulados os espectros de radiação $\mathrm{X}$ gerados por tubo de raios $\mathrm{X}$ com ânodo apresentando superfície rugosa. Com isso, foi realizada uma avaliação do comportamento da distribuição de energias em relação ao aumento da rugosidade.

Complementando as simulações com Monte Carlo, também foi realizado um estudo para avaliar se a adição de filtros de tungstênio na saída do feixe de raios X produz espectro equivalente ao de um tubo de raios $\mathrm{X}$ com ânodo rugoso. Para isto, a partir de um espectro simulado com o GEANT4 gerado por um tubo de raios $\mathrm{X}$ com um ânodo sem a presença de rugosidade, foi realizada a caracterização do feixe pelos parâmetros da energia média e da camada semi-redutora (CSR). Verificou-se que com o aumento da rugosidade, assim como o aumento da filtração equivalente de $\mathrm{W}$, os valores desses parâmetros também aumentaram.

Para a tensão aplicada ao tubo de $80 \mathrm{kV}$, uma filtração inerente de $2,5 \mathrm{~mm}$ de $\mathrm{Al}$ foi introduzida ao feixe primário da radiação $\mathrm{X}$ a fim de comparar variações nos valores de energia média e CSR com os resultados do trabalho de Nowotny e Meghzifene (Nowotny \& Meghzifene, 2002). No trabalho apresentado pela literatura, os espectros foram simulados com o método computacional semi-empírico XCOMP5R e os valores das rugosidades foram determinados com um instrumento para medição de perfil de superfície com precisão de $1 \mu \mathrm{m}$.

Foi verificado que para rugosidades maiores, os valores de variação de energia média obtidos neste trabalho foram semelhantes ao da literatura. Os valores de variação da camada semi-redutora em relação aos resultados obtidos com a simulação com o GEANT4 foram bem divergentes com a literatura, porém, com a filtração de W, os resultados foram equivalentes. Isto demonstra que o método computacional semiempírico utilizado no trabalho de Nowotny e Meghzifene realiza a simulação de forma semelhante à adição de filtração de W e diferente do método de Monte Carlo, que prevê o espalhamento múltiplo de fótons e elétrons. Na simulação que inclui a rugosidade, a modelagem se apresenta mais próxima do sistema real. Portanto, o efeito da rugosidade é diferente do efeito da filtração. 


\section{Conceitos fundamentais}

\subsection{Simulação computacional}

O processo de descrever sistemas complexos do mundo real pode ser trabalhoso ou até impossível em alguns casos. Uma ferramenta muito usada em problemas que exigem a descrição de sistemas complexos é a simulação computacional (McHaney, 1991). Simulação computacional é a utilização de um modelo criado por meio de programação computacional para imitar o comportamento de um processo do mundo real. Nos dias atuais, a simulação computacional constitui uma ferramenta essencial para auxiliar um experimento real em diversos aspectos (Hartmann, 1996), como por exemplo, avaliar e/ou determinar:

- Os potenciais riscos do projeto do experimento;

- O desempenho do experimento;

- O arranjo experimental incluindo a geometria do sistema e os materiais envolvidos;

- A contribuição para o cálculo e validação do experimento físico real;

- Os processos físicos envolvidos;

- A captura e análise dos dados da simulação em diferentes níveis de detalhes e refinamento.

Para que a simulação computacional seja confiável, é necessária a realização da validação da simulação computacional para uma finalidade específica. A validação pode ser feita comparando os resultados da simulação com dados experimentais, teóricos ou outros resultados de simulações confiáveis. 


\subsubsection{Método de Monte Carlo}

O Método de Monte Carlo é um método numérico para a solução de problemas matemáticos por meio de simulação de números aleatórios (Sobol, 1994). O Método de Monte Carlo pode ser usado nas soluções de problemas complexos que não podem ser resolvidos por métodos determinísticos. Essa metodologia passou a ser mais empregada nas mais diversas áreas da ciência a partir do artigo "The Monte Carlo Methods" publicado em 1949 (Metropolis \& Ulam, 1949). Com o aumento da capacidade de memória, processamento e armazenamento de dados dos computadores, o Método de Monte Carlo vem sendo amplamente utilizado.

No Método de Monte Carlo, os eventos de um processo são simulados sequencialmente. Para que um problema possa ser resolvido pelo Método de Monte Carlo é necessário que o sistema físico ou matemático seja descrito por funções densidade de probabilidade $^{l}$. O processo de amostragem estatística dessas funções é baseado na seleção de números aleatórios distribuídos uniformemente no intervalo [0,1]. O resultado obtido é a média de observações sobre muitas simulações. A precisão do resultado dependerá do número de eventos gerados, portanto, para que se tenha uma melhor precisão é necessário um tempo maior de processamento computacional.

No transporte de radiação, o Método de Monte Carlo está presente em toda a história da partícula. A história de uma partícula consiste em sua geração primária, suas trajetórias, com sucessivos eventos, até a sua morte, ou seja, até quando haja a captura ou escape do sistema de interesse, ou quando a partícula deixa de existir ou pára de interagir devido à sua energia ser nula.

\footnotetext{
${ }^{1}$ No Apêndice 1 é apresentado alguns conceitos básicos da teoria de probabilidades
} 


\subsubsection{Redução de variância}

Com a velocidade dos processadores dos computadores atuais, o tempo para a realização de uma simulação baseada no método de Monte Carlo é ainda um fator limitante, principalmente devido ao aumento da complexidade de modelagem para se alcançar uma maior proximidade ao sistema real. Para resolver este problema, são utilizadas as técnicas de redução de variância. Estas técnicas são utilizadas com o objetivo de reduzir o tempo para calcular um resultado em uma simulação (Olsher, 2006). Em uma abordagem computacional, a utilização dessas técnicas aumenta a eficiência $\varepsilon$ do cálculo Monte Carlo (Dresser, 2003). A medida da eficiência é dada por:

$$
\varepsilon=\frac{1}{s^{2} T}
$$

Onde $T$ é o tempo de computação utilizado e $s=\frac{\sigma}{\langle x\rangle \sqrt{N}}$ é o erro relativo de uma quantidade com valor médio $\langle x\rangle$, desvio padrão $\sigma$ e $N$ número de medidas.

Dentre as técnicas de redução de variância podemos citar: pontuação (scoring), amostragem de importância, amostragem estratificada, roleta russa e fracionamento (splitting).

\subsubsection{GEANT4}

A ferramenta computacional GEANT4 (Agostinelli, et al., 2003) é constituída de um conjunto de códigos para simulação da interação de partículas com a matéria em uma extensa faixa de energia (de $250 \mathrm{eV}$ até $1 \mathrm{TeV}$ aproximadamente). O GEANT4 é uma ferramenta multidisciplinar utilizada em experimentos e projetos principalmente nas áreas de física de altas energias, astrofísica e ciências espaciais, física médica e proteção radiológica. Os seus códigos e bibliotecas são disponibilizados livremente no sítio http://geant4.web.cern.ch/geant4/support/download.shtml, desenvolvidos em linguagem de programação $\mathrm{C}++$, com a utilização de tecnologia de Orientação a Objetos (Booch, 
1994) e metodologias de engenharia de software (Pressman, 2001) que facilitam a extensão e o refinamento da ferramenta, sem afetar o código existente utilizado no modo de produção (Cosmo, 2001). No modo de desenvolvimento, escreve-se, em linguagem de programação $\mathrm{C}++$, um código para descrever o sistema a ser simulado. $\mathrm{O}$ código desta aplicação é compilado e executado em um sistema operacional específico (Linux, UNIX ou Windows). Com isso, o usuário pode visualizar o sistema virtual criado, interagir com esse sistema e realizar a análise de dados dos resultados da simulação.

\subsubsection{Estrutura básica do GEANT4}

O núcleo do GEANT4 engloba diversas funcionalidades para a simulação. No entanto, devido à sua arquitetura modular, também é possível a utilização de mecanismos e interfaces externas para a realização de seus recursos (Allison, et al., 2006). As funcionalidades básicas do GEANT4 são:

- Modelagem geométrica - é a construção de todos os objetos pertencentes ao arranjo experimental, tais como objetos atenuadores e detectores, assim como a especificação de seus materiais constituintes. A modelagem geométrica do sistema pode ser realizada no GEANT4 em linguagem de programação $\mathrm{C}++$ utilizando as classes inerentes à ferramenta (Cosmo, 2004) ou também pode ser modelado por meio da linguagem GDML (Geometry Description Markup Language) (Chytracek, McCormick, Pokorski, \& Santin, 2006).

- Processos físicos - são os processos físicos envolvidos nas interações que ocorrem entre as partículas e o sistema. Além dos processos físicos internos ao GEANT4, tais como interações eletromagnéticas, hadrônicas, entre outras (CERN, 2007b), há diversos componentes externos de processos físicos específicos que podem ser incorporados à simulação (Kippen, 2004) (Beringer, et al., 2003) (Khan, Schofield, \& Wright, 2005).

- Interface do usuário - é o modo de exibição da interação entre o usuário e a simulação a ser realizada. No GEANT4, é possível interagir com a simulação executando comandos na linha de comandos (prompt) de uma tela de terminal (via shell) como Tcsh ou Csh. Também há a possibilidade de interagir através de 
interfaces gráficas desenvolvidas por terceiros como o GAG (Nagamatsu, et al., 1998) ou Opacs (Barrand, 1997). E automatizar os processos da simulação escrevendo todos os comandos a serem executados em um arquivo batch de macros.

- Geradores de partículas primárias - são as fontes de emissão de partículas executadas na forma de código utilizando as bibliotecas internas (G4ParticleGun) ou executadas na linha de comandos via GPS (General Particle Source) (Fergunson, 2000). As partículas padrões do GEANT4 possíveis para a simulação são:

- Partículas estáveis tais como elétrons, pósitrons, prótons, nêutrons, raios X e raios gamas;

- Partículas com tempo de vida longos tais como múons e píons carregados;

- Fótons ópticos, para serem utilizados, por exemplo, na luz Cerenkov e luz de cintilação;

- "Geantinos" e "geantinos carregados" que são partículas virtuais que não interagem com nenhum material, mas sofrem com o processo de transporte;

- Núcleos tais como dêuterons, alfas e íons pesados;

- Partículas com tempo de vida curtos tais como mésons vetoriais e delta bárions.

- Visualização - é possível visualizar todos os objetos do arranjo experimental e as trajetórias das partículas em tempo real de execução, através das interfaces para drivers gráficos externos como (Allison, et al., 2007): OpenGL, VRML, OpenInventor, Ray Tracer, WIRED (FreeHep, 2007b), Fukui Render DAWN (Tanaka \& Kawaguti, 1997), entre outros.

- Análise de dados - utilizado para gerar a saída de dados ou resultados da simulação. No GEANT4, a saída de dados padrão é a exibição na tela de terminal. É possível a incorporação de ferramentas para a análise de dados como a interface AIDA (Barrand, Binko, Donszelman, Johnson, \& Pfeiffer, 2001) trabalhando em conjunto com o aplicativo OpenScientist (Barrand, 2004) ou JAS (FreeHep, 2007a), e ROOT (CERN, 2007c).

- Técnicas de redução de variância - há várias técnicas de redução de variância incorporadas no código do GEANT4 (CERN, 2007a): pontuação (scoring); amostragem de importância; roleta russa; viés (bias) de partículas primárias, decaimento radiativo e seção de choque; entre outros. Desde que os processos físicos envolvidos na simulação sejam bem conhecidos, é possível implementar a sua própria técnica de 
redução de variância. A ferramenta GEANT4 fornece diversos mecanismos para essa implementação (CERN, 2007b).

- Processamento paralelo - com a finalidade de minimizar o tempo de simulação, é possível a execução de uma mesma simulação simultaneamente em vários processadores (Cooperman, Casanova, Hayes, \& Witzel, 2002).

Uma visão global abrangendo toda a estrutura de alto nível do GEANT4 (CERN, 2007a) e de suas funcionalidades é exibida no diagrama de categoria de classes (Figura 2.1.2.1-1).

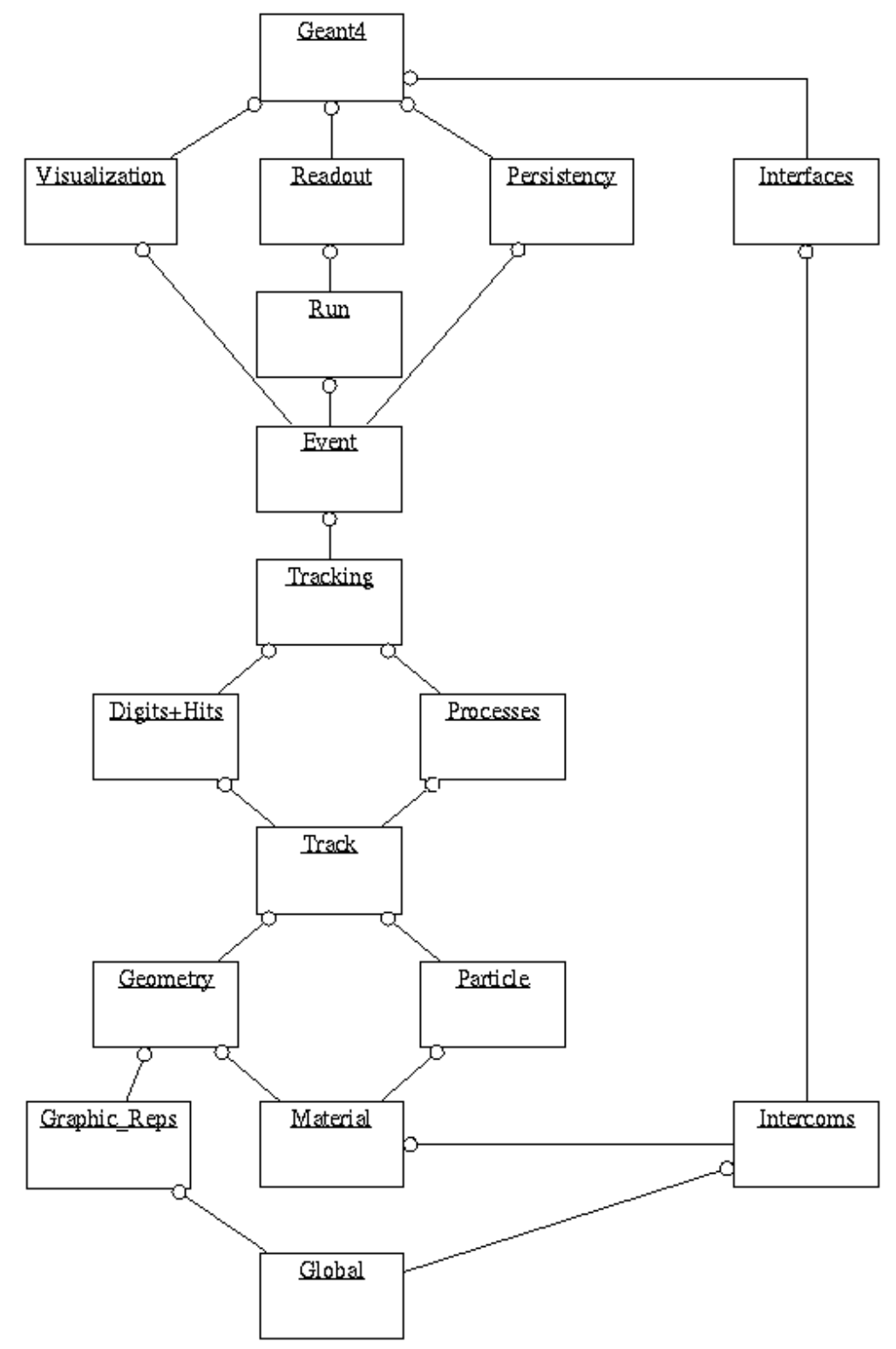

Figura 2.1.2.1-1 - Diagrama de categoria de classes do GEANT4 (Pia, 2003). 


\subsection{Produção de raios $X$}

Os raios $\mathrm{X}$ são radiações eletromagnéticas com comprimento de onda entre $0,01 \mathrm{~nm}$ a $10 \mathrm{~nm}$ aproximadamente. Os raios X possuem um alto poder de penetração na matéria. Quanto maior a energia, conseqüentemente, menor o comprimento de onda e maior o poder de penetração desse tipo de radiação.

Em um tubo de raios $X$, a radiação eletromagnética é produzida quando elétrons em alta velocidade atingem o ânodo do tubo. A eficiência para produção de raios X é aproximadamente proporcional ao número atômico $Z$ do elemento que constitui o alvo e à tensão de aceleração $k V$ dos elétrons (Sprawls, 1995):

\section{Eficiência $\propto k V \times Z$}

Para baixas energias, apenas uma pequena fração da energia depositada no alvo é convertida em raios $\mathrm{X}$, sendo que grande parte dessa energia é absorvida no alvo e convertida em calor. Por exemplo, aplicada uma tensão de aceleração de $120 \mathrm{kV}$ a um alvo de tungstênio $(Z=74)$ a eficiência para produção de raios $X$ é de aproximadamente $1 \%$.

\subsubsection{Radiação de freamento ou Bremsstrahlung}

Ao atingir um alvo, elétrons em altas velocidades podem ser desacelerados devido ao campo Coulombiano dos núcleos, emitindo assim fótons com energia aproximadamente igual à energia cinética perdida pelos elétrons nessa interação. A radiação gerada desta interação é denominada radiação de freamento ou Bremsstrahlung (Figura 2.2.1-1). Ela é responsável pela parte contínua do espectro de energia de raios X. 


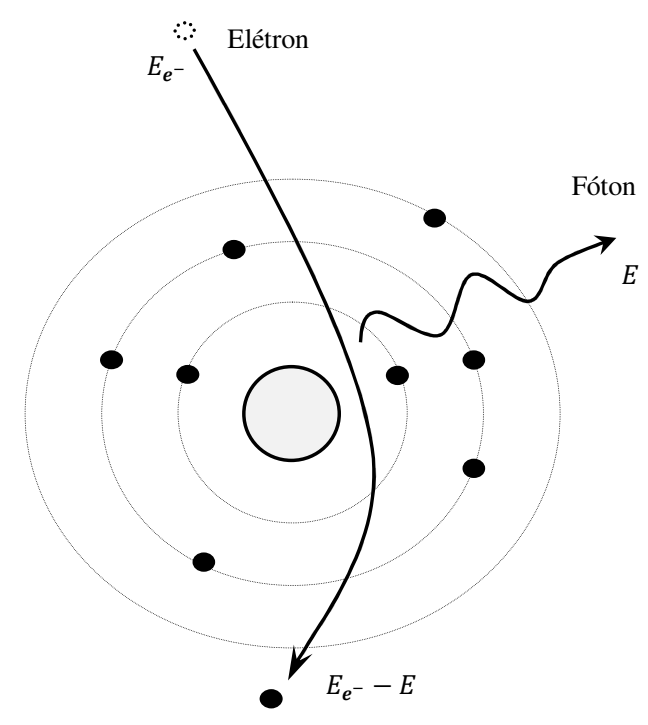

Figura 2.2.1-1- Formação da radiação de freamento ou Bremsstrahlung.

\subsubsection{Radiação característica (fluorescência)}

Elétrons acelerados em altas velocidades podem interagir com elétrons das camadas orbitais (representadas pelas letras $K, L, M$, etc.) de um átomo do alvo. Neste caso, se o elétron incidente possui energia superior à energia de ligação do elétron do alvo, este poderá removê-lo de sua órbita criando uma vacância. Este fato ocorre com maior probabilidade nas camadas orbitais mais internas do átomo. Com isso, a vacância é preenchida por um elétron de um nível maior de energia proveniente de uma camada mais externa. A energia excedente nesta transição é liberada na forma de um fóton de raios $\mathrm{X}$ característico do elemento deste átomo. Este processo é chamado de fluorescência.

As linhas ou picos do espectro de energia de raios $\mathrm{X}$ provenientes da transição dos elétrons da camada $L$ para a camada $K$ são denominados de $K_{\alpha}$. Os $K_{\beta}$ são referentes à transição da camada M para camada K. Assim sucessivamente conforme a Figura 2.2.2-1 (Bushberg, Seibert, Leidholdt. Jr., \& Boone, 2002). 


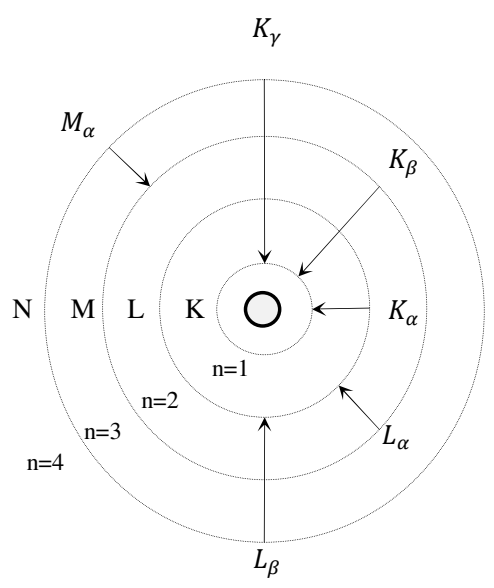

Figura 2.2.2-1- Transição de energias de raios $X$.

\subsection{Interação de raios $X$ com a matéria}

$\mathrm{Na}$ interação entre um fóton e a matéria são emitidos ou criados elétrons ou pósitrons que podem ionizar os átomos do meio. Os principais mecanismos de interação são: espalhamento elástico, efeito fotoelétrico, espalhamento Compton, produção de pares e foto desintegração. Para as energias utilizadas neste trabalho (40, 80 e $150 \mathrm{kV})$, somente o espalhamento elástico, efeito fotoelétrico e espalhamento Compton serão considerados.

\subsubsection{Efeito fotoelétrico}

No efeito fotoelétrico, a energia total do fóton $E=h v$, sendo $h$ a constante de Planck e $v$ frequiência do fóton, é transferida para um elétron orbital, o qual abandona o átomo com uma energia igual à do fóton, menos a energia de ligação $E_{b}$ da camada orbital da qual é ejetado (Figura 2.3.1-1):

$$
\boldsymbol{E}_{e^{-}}=\boldsymbol{h} \boldsymbol{v}-\boldsymbol{E}_{\boldsymbol{b}}
$$

onde $E_{e^{-}}$é a energia cinética do elétron ejetado. O restante da energia aparece na forma de raios $\mathrm{X}$ característicos ou elétrons Auger, durante o preenchimento da vacância na 
camada interna. A probabilidade de ocorrência do efeito fotoelétrico é maior nas camadas orbitais mais internas do átomo. Em materiais com números atômicos elevados, o efeito fotoelétrico é o processo de maior ocorrência em energias abaixo de $150 \mathrm{keV}$.

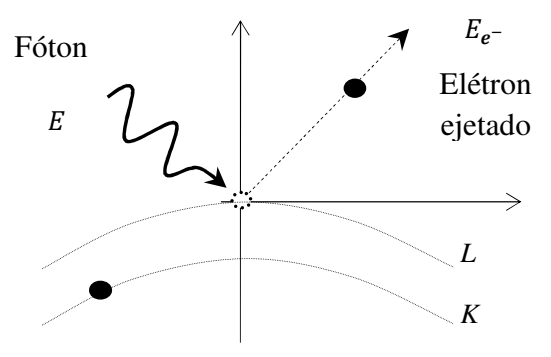

Figura 2.3.1-1 - Efeito fotoelétrico.

\subsubsection{Espalhamento elástico}

Considerando os raios $\mathrm{X}$ como sendo um feixe de ondas eletromagnéticas cujo campo elétrico oscilante age sobre as cargas dos elétrons do alvo, isso faz com que o elétron vibre na mesma freqüência dos fótons incidentes. $\mathrm{O}$ processo de espalhamento dos fótons no qual não há mudança em seu comprimento de onda, portanto sem variação de energia, é denominado espalhamento elástico. Há dois tipos de espalhamento elástico: o espalhamento Thomson e o espalhamento Rayleigh.

\subsubsection{Espalhamento Thomson}

O espalhamento Thomson ocorre quando um elétron do átomo do alvo absorve energia do fóton de baixa energia incidente, oscila e emite radiação em outra direção de mesmo comprimento de onda. A probabilidade de ocorrência do espalhamento Thomson é dependente do número atômico e independente da energia da radiação incidente. 


\subsubsection{Espalhamento Rayleigh}

O espalhamento Rayleigh ocorre quando a radiação encontra com os elétrons do átomo do alvo colocando o átomo num estado de vibração de mesma freqüência da radiação incidente. $\mathrm{O}$ átomo oscila e emite radiação, voltando assim a seu estado não perturbado. A probabilidade de ocorrência do espalhamento Rayleigh é maior em interações com átomos de alto número atômico e baixa energia dos fótons incidentes.

\subsubsection{Espalhamento Compton}

No modelo simplificado do espalhamento Compton, o fóton incidente com energia $E_{i}=h v_{i}$ e momento $p_{i}=\frac{E_{i}}{c}=\frac{h v_{i}}{c}=\frac{h}{\lambda_{i}}$ interage com um elétron livre, sendo $c$ a velocidade da luz e $\lambda_{i}$ o comprimento de onda do fóton incidente. A conseqüência desta interação é a transferência de energia para o elétron livre que é defletido com um ângulo $\phi$ e o fóton é espalhado por um ângulo $\theta$ com uma energia menor (Figura 2.3.5-1).

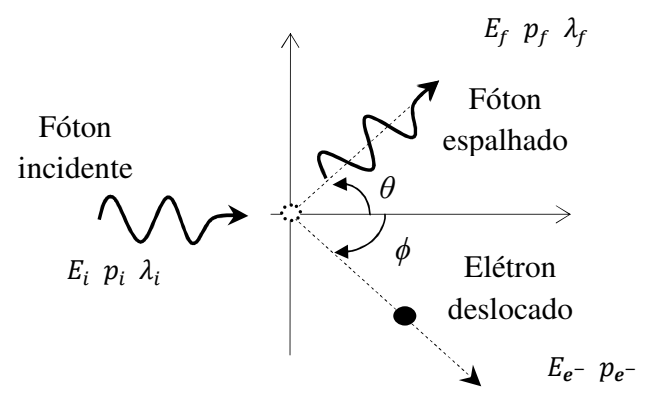

Figura 2.3.5-1 - Espalhamento Compton.

A conservação da energia total relativística impõe que:

$$
E_{i}+m_{0} c^{2}=E_{f}+E_{e^{-}}+m_{0} c^{2}
$$


onde $m_{0}$ é a massa de repouso do elétron. Na equação (2.3.5.1) substituindo as energias dos fótons em função do momento resulta que a energia cinética do elétron deslocado $E_{\boldsymbol{e}^{-}}$ é:

$$
\boldsymbol{E}_{e^{-}}=\left(\boldsymbol{p}_{\boldsymbol{i}}-\boldsymbol{p}_{\boldsymbol{f}}\right) \boldsymbol{c}
$$

A conservação do momento requer que:

$$
\begin{gathered}
p_{i}=p_{f} \cos \theta+p_{e^{-}} \cos \phi \\
p_{f} \operatorname{sen} \theta=p_{e^{-}} \operatorname{sen} \phi
\end{gathered}
$$

Obtém-se a relação em função dos comprimentos de onda, que também é conhecida como equação de Compton:

$$
\lambda_{f}-\lambda_{i}=\frac{h}{m_{0} c}(1-\cos \theta)
$$

\subsubsection{Coeficientes de atenuação}

A intensidade dos raios $\mathrm{X}$, que é proporcional ao número de fótons do feixe, decresce quando o feixe atravessa certos meios. Este fato se chama atenuação, que é devida a absorção e espalhamento do feixe. Para um feixe monoenergético esse decréscimo pode ser descrito pela seguinte expressão exponencial:

$$
I(x)=I_{0} e^{-\mu x}
$$

onde $I$ é a intensidade do feixe após a passagem através de um meio de espessura $x ; I_{0}$ é a intensidade inicial do feixe; $\mu$ é o coeficiente de atenuação linear do meio. Para a faixa de energia abordada neste trabalho, este coeficiente, que depende do meio e da energia da radiação é dado por:

$$
\mu=\tau+\sigma_{r}+\sigma_{c}
$$


onde $\tau$ é o coeficiente de atenuação linear para efeito fotoelétrico, $\sigma_{r}$ o coeficiente de atenuação linear para o espalhamento Rayleigh e $\sigma_{c}$ o coeficiente de atenuação linear para o espalhamento Compton.

A equação (2.3.6.1) também pode ser dada em relação ao coeficiente de atenuação de massa $\frac{\mu}{\rho}$, onde $\rho$ é a densidade, correspondente a equação de Lambert-Beers:

$$
I(x)=I_{0} e^{-\left(\frac{\mu}{\rho}\right) \rho x}
$$

onde o coeficiente de atenuação de massa, analogamente à equação (2.3.6.2) pode ser dado por:

$$
\frac{\mu}{\rho}=\frac{\tau}{\rho}+\frac{\sigma_{r}}{\rho}+\frac{\sigma_{c}}{\rho}
$$

\subsubsection{Coeficiente de transferência de energia}

O coeficiente de transferência de energia $\frac{\mu_{\text {tr }}}{\rho}$ de um material, para partículas não carregadas, é o quociente de $\frac{d R_{t r}}{d R}$ por $\rho d l$, onde $\frac{d R_{t r}}{d R}$ é a fração da energia radiante incidente que é transferida para partículas carregadas em forma de energia cinética, atravessando uma distância $d l$ em um material de densidade $\rho$ :

$$
\frac{\mu_{t r}}{\rho}=\left(\frac{d R_{t r}}{d R}\right)\left(\frac{1}{\rho d l}\right)
$$

A probabilidade total de transferência de energia em massa é dada por:

$$
\frac{\mu_{t r}}{\rho}=\frac{\tau_{t r}}{\rho}+\frac{\sigma_{t r}}{\rho}
$$


onde $\tau_{t r}$ e $\sigma_{t r}$ são os coeficientes de transferência de energia por efeito fotoelétrico e espalhamento Compton, respectivamente. Observa-se que não há transferência de energia por espalhamento Rayleigh.

\subsubsection{Fluência}

Fluência $\Phi$ é a razão entre a quantidade de partículas $d N$ que atravessam a dada seção de área $d A$ :

$$
\Phi=\frac{d N}{d A}
$$

\subsubsection{Fluência de energia}

Fluência de energia $\Psi$ é a quantidade de energia $h v$ que atravessa uma seção unitária de área. Para um feixe monoenergético a fluência de energia é dada por:

$$
\Psi=\Phi . h v=\frac{d N \cdot h v}{d A}
$$

\subsubsection{Kerma}

Kerma K é o acrônimo de "Kinectic Energy Released in Matter" (Energia cinética liberada ao meio). É definido como a soma das energias cinéticas iniciais de todas as partículas carregadas liberadas por partículas ionizantes não-carregadas $d E_{t r}$ em um elemento de volume de massa $d m$ (2.3.10.1). O Kerma é expresso em J/kg no sistema internacional ou Gray.

$$
K=\frac{d E_{t r}}{d m}
$$


Para um feixe monoenergético com fluência $\Phi$ de partículas ou fótons incidentes e energia $h v$ o Kerma é dado por:

$$
\boldsymbol{K}=\boldsymbol{\Phi} \cdot \boldsymbol{h} \boldsymbol{v}\left(\frac{\mu_{t r}}{\rho}\right)_{E_{t r}}=\Psi\left(\frac{\mu_{t r}}{\rho}\right)_{E_{t r}}
$$

Para fótons com um espectro de energia entre $E_{0}$ e $E_{\text {máx }}$, o Kerma é dado por:

$$
K=\int_{E_{0}}^{E_{\text {máx }}} \Psi(E)\left(\frac{\mu_{t r}}{\rho}\right)_{E_{t r}} d E
$$

Para um espectro discreto com $N$ canais de energia, a partir da equação (2.3.10.3), determina-se o Kerma somando as contribuições de cada banda $j$ de energia:

$$
K=\Phi \sum_{j=1}^{N} C_{j} E_{j}\left(\frac{\mu_{t r}}{\rho}\right)_{E_{j}}
$$

onde $C_{j}$ é a freqüência de ocorrência de fótons com energia $E_{j}$.

\subsection{Qualidade do feixe de raios $\mathrm{X}$}

A qualidade do feixe de raios $X$ tem impacto na dose do paciente e na qualidade da imagem radiográfica (Shepard, et al., 2002). Ela descreve a penetrabilidade do feixe de raios X. A quantidade de fótons do feixe, referente à corrente anódica do tubo e ao tempo de exposição, não afeta a qualidade da radiação. Os fatores que influenciam o espectro estão relacionados com a tensão aplicada ao tubo de raios $\mathrm{X}$ e a sua forma de onda, o material e o ângulo do ânodo e a utilização de filtros para a atenuação do feixe.

A qualidade da radiação de um feixe de raios $X$ pode ser caracterizada pelo seu espectro e pelos seguintes parâmetros: energia média do feixe, camada semi-redutora e resolução espectral. No entanto, para a utilização em imagens médicas, é recomendada a 
caracterização por uma combinação desses parâmetros (ICRU, 2005). Este fato é devido à dificuldade de aquisição precisa de medições experimentais para a determinação dos parâmetros.

\subsection{Tubo de raios $\mathrm{X}$}

O tubo de raios $X$ é um componente elétrico responsável pela produção de raios $\mathrm{X}$. Basicamente, o tubo de raios $\mathrm{X}$ utilizado em radiologia diagnóstica consiste de um bulbo de vidro em alto vácuo onde estão inseridos o cátodo (eletrodo negativo) e o ânodo (eletrodo positivo). Quando o ânodo é elevado a um potencial positivo em relação ao cátodo, os elétrons provenientes da nuvem eletrônica formada no cátodo aquecido são acelerados em direção ao ânodo, formando uma corrente anódica. A diferença de potencial aplicada para que ocorra este fato é denominada de tensão de aceleração dos elétrons dada em quilovolt $(\mathrm{kV})$. O bulbo de vidro é geralmente constituído de material borosilicato (pyrex). Nele há uma pequena área de espessura menor, local de saída dos fótons de raios X (Figura 2.5-1).

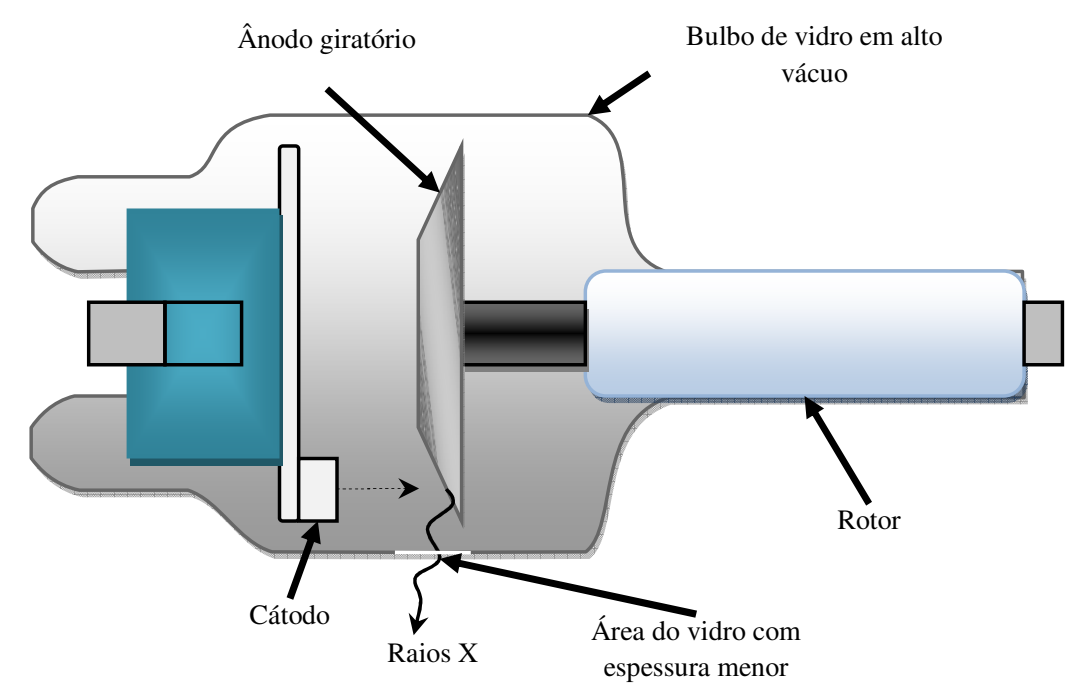

Figura 2.5-1 - Esquema simplificado de um tubo de raios $X$.

O tubo de raios $\mathrm{X}$ está inserido em uma cúpula metálica e mergulhado em óleo isolante. A cúpula utilizada em radiologia diagnóstica é tipicamente constituída de ferro e 
internamente revestida de uma camada de chumbo para a filtração dos raios $\mathrm{X}$ a fim de evitar ou minimizar a radiação de fuga. Na cúpula, há um orifício fechado por um material geralmente constituído de plástico acrílico ou de berílio denominado janela. A janela, local de saída do feixe de raios $\mathrm{X}$ para o exterior da cúpula, está alinhada com a área de espessura menor do bulbo de vidro e do ponto focal. O óleo dentro da cúpula tem a finalidade de dissipação de calor e isolante elétrico. Quando o óleo esquenta excessivamente, a câmara de expansão aumenta de volume e aciona uma chave que desliga o sistema até que ocorra o esfriamento do tubo. A Figura 2.5-2 apresenta o esquema de um tubo de raios $\mathrm{X}$ com seus componentes identificados.

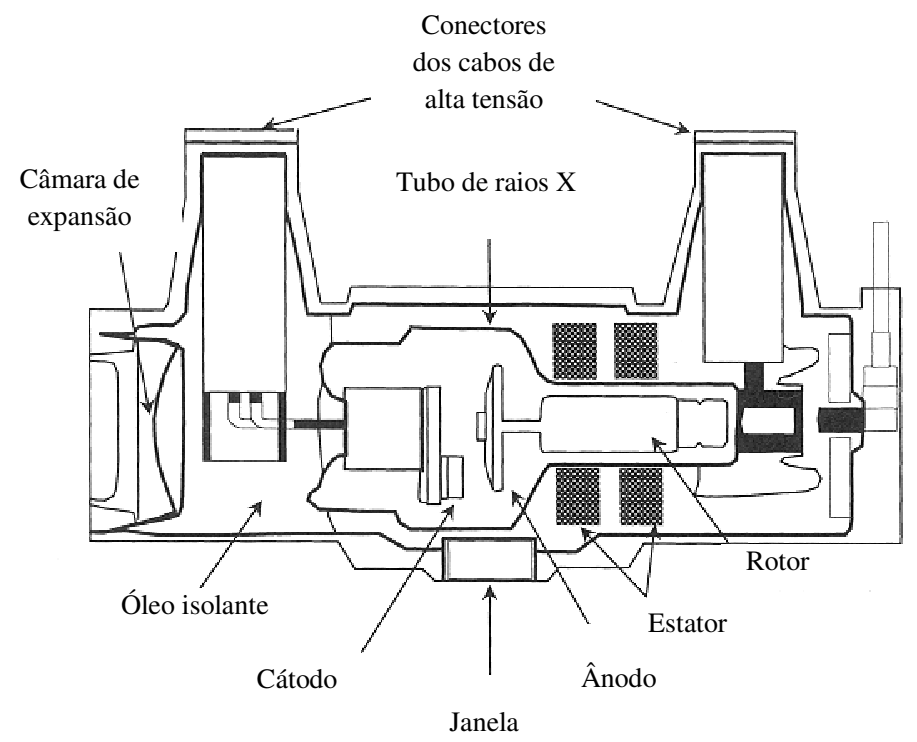

Figura 2.5-2 - Esquema de uma cúpula de raios $X$ utilizado em radiologia diagnóstica. (Bushberg, Seibert, Leidholdt. Jr., \& Boone, 2002)

\subsubsection{Estrutura de um tubo de raios $\mathrm{X}$}

\subsubsection{Cátodo}

A função básica de um cátodo é a produção de elétrons livres. O conjunto do cátodo consiste de um ou dois filamentos e um dispositivo focalizador do feixe de 
elétrons, também conhecido como cilindro de Wilhelm. Um exemplo típico de cátodo de tubo de raios X é mostrado na Figura 2.5.1.1-1.

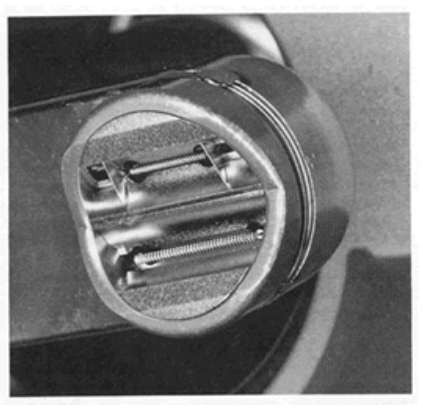

Figura 2.5.1.1-1- Cátodo com dois filamentos paralelos e o dispositivo focalizador (Wolbarst, 1993).

O filamento é um fio em forma helicoidal com diâmetro aproximadamente de $2 \mathrm{~mm}$, geralmente constituído de tungstênio. $\mathrm{O}$ aquecimento direto do filamento devido à passagem de uma baixa corrente provoca emissão de elétrons para fora do fio, gerando uma nuvem eletrônica (carga espacial), que será concentrada no dispositivo focalizador.

O dispositivo focalizador é constituído geralmente de níquel que, devido a sua forma geométrica, produz um campo elétrico que impede que a nuvem eletrônica se disperse. O tamanho do filamento e a forma geométrica do dispositivo focalizador são responsáveis pelo tamanho e pela forma do ponto focal.

\subsubsection{2. Ânodo}

O ânodo é o eletrodo positivo de impacto dos elétrons (alvo). Em radiologia diagnóstica, o material do ânodo é constituído de elementos de números atômicos altos, para maior eficiência na produção de raios X (ver item 2.2); alto ponto de fusão, para evitar efeitos indesejáveis devido às grandes temperaturas, e baixa pressão de vapor, para que poucos átomos constituintes do material do ânodo evaporem em condições normais. O ânodo possui um ângulo de inclinação em relação ao feixe de incidência dos elétrons para maximizar a quantidade de fótons de raios $X$ na direção da janela. A influência da geometria do conjunto cátodo/ânodo é ilustrada na Figura 2.5.1.2-1. 
A

Ânodo com ângulo grande Filamento de comprimento curto

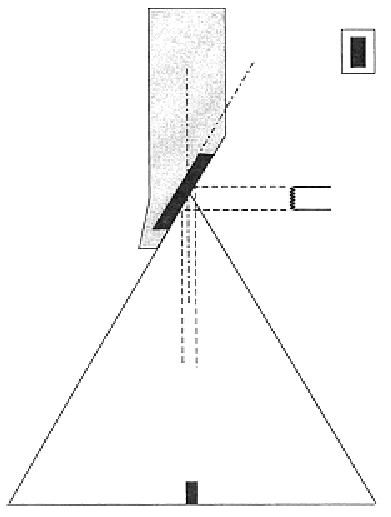

Bom campo de cobertura

Ponto focal efetivo pequen

Poder de resolução ruim
B

Ânodo com ângulo grande Filamento de comprimento longo

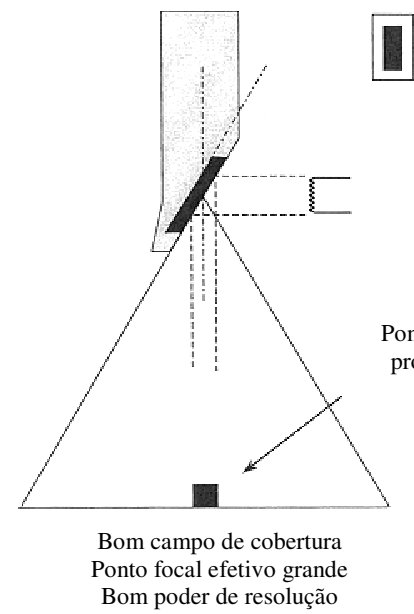

C

Ânodo com ângulo pequeno Filamento de comprimento longo

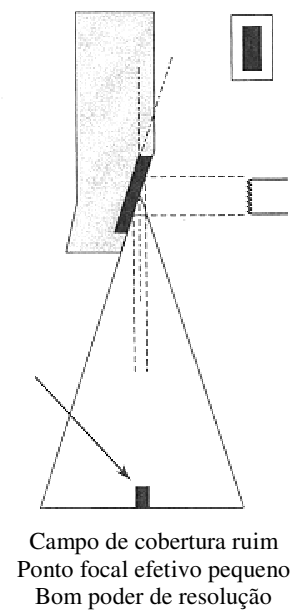

Figura 2.5.1.2-1 - Influência do comprimento do filamento do cátodo e do ângulo do ânodo na projeção do ponto focal. (Bushberg, Seibert, Leidholdt. Jr., \& Boone, 2002)

Há dois tipos de construção de ânodo utilizados em radiologia diagnóstica: o ânodo fixo ou estacionário e o ânodo giratório. No ânodo fixo, o alvo é fixado em um suporte. O suporte do alvo geralmente é constituído de cobre para permitir a rápida condução de calor para fora do tubo de raios X. Devido à superfície do ânodo que recebe o bombardeamento de elétrons, também denominado de foco térmico, ser sempre a mesma durante o uso de um tubo de raios $\mathrm{X}$ de ânodo fixo, é admissível apenas uma pequena potência para uso em radiologia diagnóstica.

O ânodo giratório é um disco composto, em geral, por molibdênio e/ou grafite. A superfície sobre o qual incide o feixe de elétrons é composto de uma liga geralmente de tungstênio e rênio, sendo este último em menor proporção.

O disco do ânodo é conectado a um rotor que é acionado pelo estator do motor de indução localizado externamente ao tubo de raios X. Devido à passagem de corrente elétrica através do estator, são gerados campos magnéticos no interior do tubo, que giram o rotor e o ânodo. Com o ânodo giratório o contato com os elétrons incidentes torna-se mais disperso, minimizando deformações no alvo. Ou seja, o foco térmico é maior, pois o calor é distribuído em forma de anel ou pista e, portanto, tem temperatura menor e maior 
potência admissível. Um ânodo giratório de um tubo de raios $\mathrm{X}$ utilizado em radiologia diagnóstica é apresentado na Figura 2.5.1.2-2.

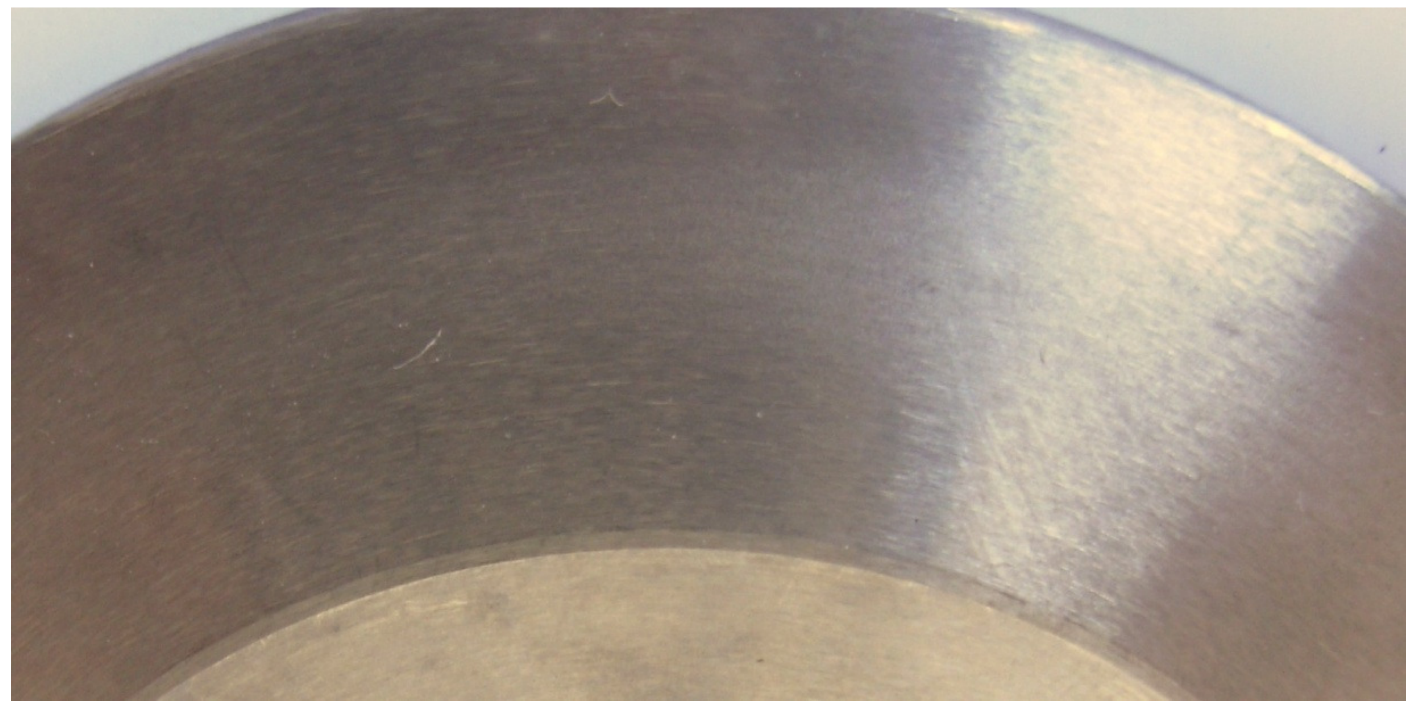

Figura 2.5.1.2-2 - Aspecto de um ânodo giratório de um tubo de raios $X$ novo ${ }^{2}$.

As deformações que podem ocorrer em um ânodo do tubo de raios X:

- Aumento da rugosidade na superfície do ânodo ao longo do tempo de uso - uma das conseqüências do envelhecimento do tubo de raios X (Bottaro, 2007).

- Em casos em que haja problemas no sistema de rotação do ânodo giratório, há a criação de "lágrimas" que é o derretimento do ânodo devido à incidência dos elétrons em uma mesma área em tempos longos. Nessa condição, o tubo deve ser colocado fora de uso.

O envelhecimento do tubo de raios $\mathrm{X}$, de certa maneira, altera a qualidade do feixe de raios $\mathrm{X}$, afetando a dose ao paciente e a imagem radiográfica.

Ao longo do tempo de utilização do tubo de raios $\mathrm{X}$ além das deformações no ânodo, há a evaporação de material metálico proveniente do filamento e do próprio ânodo

\footnotetext{
${ }^{2}$ Na pista do ânodo verifica uma rugosidade um pouco mais acentuada. Isto se deve ao processo de "amaciamento" que é realizada nas fábricas de tubos de raios $X$ antes de sua comercialização (Nagel, 1988).
} 
para as paredes do bulbo de vidro. Com isso, forma-se uma fina camada de material metálico nas paredes do tubo de raios X. Isto resulta no aumento da filtração inerente do tubo de raios X. No entanto, estudos demonstram que esta camada tem espessura inferior a $1 \mu \mathrm{m}$ (Nagel, 1988) ou a 0,01 $\mu \mathrm{m}$ (Stears, Felmlee, \& Gray, 1986) e que isso não influencia significativamente na atenuação dos raios X.

\subsection{Superfícies rugosas}

Numa abordagem computacional, é possível gerar superfícies ou interfaces rugosas a partir de simulações baseadas em equações estocásticas de crescimento. A seguir serão abordados alguns modelos discretos e equações contínuas de crescimento para o estudo de superfícies rugosas, geradas por processos de deposição de partículas idênticas sobre um substrato inicialmente liso (Mattos T. G., 2005).

\subsubsection{Altura média}

Considere uma deposição de partículas idênticas sobre um sistema de dimensão $L$, com sítios indexados por $i=1,2,3, \ldots, L$ colunas. A altura média de uma superfície é dada pela seguinte equação:

$$
\langle h(t)\rangle=\frac{1}{L} \sum_{i=1}^{L} h_{i}(t)
$$

onde $h_{i}(t)$ é altura da coluna $i$ no instante $t$. Se a razão de deposição (número de partículas que chegam em um sítio) for constante, a altura média aumentaria linearmente com o tempo (Barabási \& Stanley, 1995):

$$
\langle\boldsymbol{h}(\boldsymbol{t})\rangle \propto \boldsymbol{t}
$$




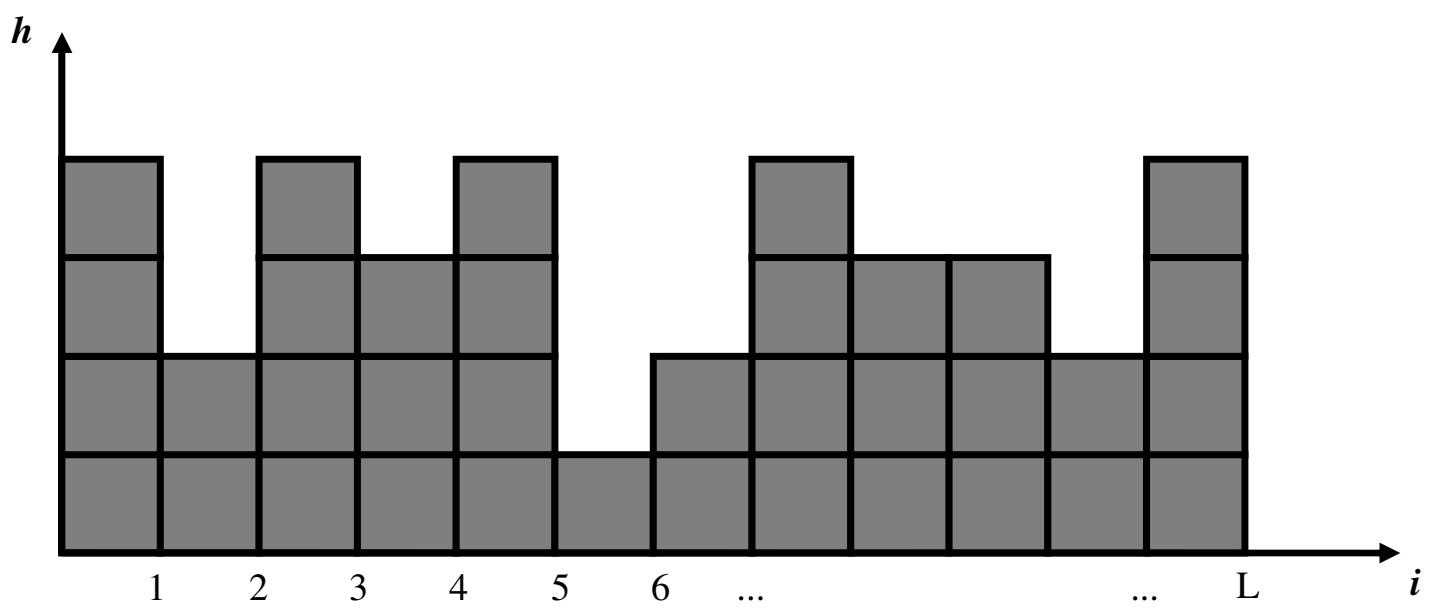

Figura 2.6.1-1- Distribuição das alturas h em cada sítio i em um determinado tempo t.

\subsubsection{Rugosidade}

A rugosidade de uma superfície é caracterizada pelas variações de alturas em relação ao comprimento $L$ do sistema para um determinado tempo de deposição (Barabási \& Stanley, 1995). A rugosidade é o desvio quadrático médio da distribuição das alturas:

$$
\omega(L, t)=\sqrt{\frac{1}{L} \sum_{i=1}^{L}\left[h_{i}(t)-\langle h(t)\rangle\right]^{2}}
$$

O comportamento temporal da rugosidade é dado pela lei de potência:

$$
\omega(L, t) \propto t^{\beta}
$$

onde o expoente $\beta$ é o expoente de crescimento que caracteriza a dinâmica temporal dependente do processo de rugosidade. A rugosidade cresce segundo a lei de potência dependente de $L$ até atingir um valor saturação: 


$$
\omega(L, t \rightarrow \infty) \sim \omega_{s a t}(L) \propto L^{\alpha}
$$

onde $\alpha$ é o expoente de rugosidade, que caracteriza a rugosidade da superfície saturada. $\mathrm{O}$ tempo que o sistema leva para atingir este valor é denominado de tempo de saturação $t_{x}$ :

$$
t_{x} \propto L^{z}
$$

onde $z$ é o expoente dinâmico. Aplicando a relação de escala de Family-Vicsek (Mattos T. G., 2005), fazendo $t=t_{x}$ na equação 2.6.2.2 e substituindo em 2.6.2.3, obtém-se que $t_{x}^{\beta} \sim L^{\alpha}$, que substituindo em 2.6.2.4 resulta na dependência de $\alpha, \beta$ e $z$ :

$$
z=\frac{\alpha}{\beta}
$$

\subsubsection{Modelos de deposição}

Os modelos de deposição são caracterizados por métodos de crescimento de superfícies rugosas geradas por processos de deposição de partículas idênticas sobre um substrato inicialmente liso (Mattos T. G., 2005). A seguir são demonstrados alguns modelos discretos de deposição e as equações estocásticas de crescimento (contínuas) associadas a esses processos de deposição. Esses modelos são as bases para a geração das superfícies rugosas realizada neste trabalho.

\subsubsection{Modelo de deposição balística}

A deposição balística foi introduzida como um modelo de sedimentação em sistemas coloidais (Vold, 1959), e estudos posteriores concentraram-se nas propriedades de agregados porosos gerados por esse modelo (Barabási \& Stanley, 1995). Neste modelo discreto, uma partícula em uma posição aleatória de um sítio de uma rede é solta de uma altura superior à altura máxima da superfície. A partícula cai verticalmente em linha reta 
ou em trajetórias "balísticas" e ao encontrar uma partícula vizinha ela se fixa. As partículas depositadas formam um agregado com uma geometria particular que evolui no tempo. Quantitativamente, este modelo de crescimento, para uma rede bidimensional, é ilustrado na figura a seguir (Figura 2.6.3.1-1):

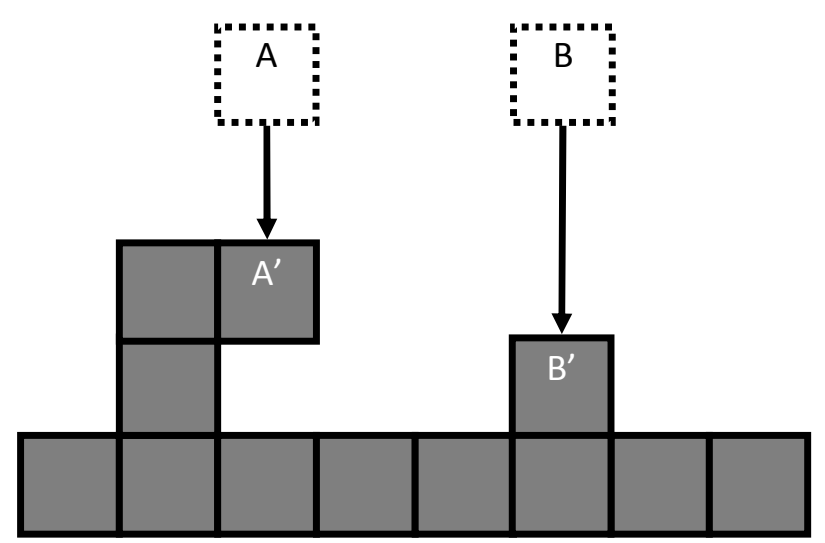

Figura 2.6.3.1-1 - Modelo dedeposição balística.

Para um instante inicial $t=0$ a superfície é plana. Para um sítio $i$ escolhido aleatoriamente em um tempo subseqüente $t=t+1$ obtém-se que:

$$
h_{i}(t+1)=\max \left[h_{i-1}(t), h_{i}(t)+1, h_{i+1}(t)\right]
$$

O modelo de deposição balística em superfícies também pode ser aplicado em sistemas bidimensionais e tridimensionais (Meakin, Ramanlal, Sander, \& Ball, 1986).

\subsubsection{Modelo de deposição aleatória}

O modelo discreto de deposição aleatória é semelhante ao modelo de deposição balística. Neste modelo, uma partícula em uma posição aleatória de um sítio de uma rede é solta de uma altura superior à altura máxima da superfície. A partícula cai verticalmente e ao encontrar o topo da coluna associada ao sítio sorteado ela se fixa. Neste caso, a 
superfície não é correlacionada uma vez que as alturas das colunas crescem independentemente (Figura 2.6.3.2-1).

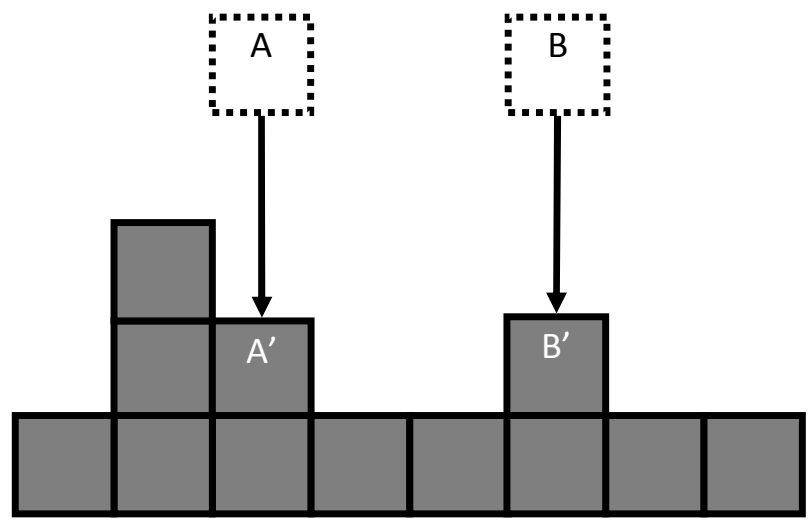

Figura 2.6.3.2-1 - Modelo de deposição aleatória.

Neste modelo o expoente de crescimento é $\beta=\frac{1}{2}$ (Barabási \& Stanley, 1995). Com esse valor, a rugosidade cresce indefinidamente com o tempo, ou seja, não há saturação (Barabási \& Stanley, 1995).

\subsection{Equações estocásticas de crescimento}

Além dos modelos discretos de deposição apresentados, pode-se realizar um tratamento analítico associando equações estocásticas de crescimento aos processos de crescimento. Baseando-se no modelo de deposição aleatória, o crescimento pode ser descrito pela seguinte equação:

$$
\frac{\partial \boldsymbol{h}(\mathbf{x}, t)}{\partial t}=\Phi(\mathbf{x}, t)=F\left(x^{\prime}\right)+\eta(\mathbf{x}, t)
$$

onde $\Phi(\mathrm{x}, t)$ é o número de partículas depositadas na superfície na posição x no instante $t$. Como o fluxo de partículas não é uniforme, devido à aleatoriedade das posições onde são depositadas, $\Phi(\mathrm{x}, t)$ pode ser decomposto em outros termos, onde $F\left(x^{\prime}\right)$ é o número médio de partículas que são depositadas em um sítio $x$ '. A flutuação aleatória no processo de deposição ou ruído $\eta(\mathrm{x}, t)$ tem uma distribuição Gaussiana com média nula: 


$$
\langle\boldsymbol{\eta}(\mathbf{x}, \boldsymbol{t})\rangle=\mathbf{0}
$$

O segundo momento deste ruído é dado por:

$$
\left\langle\boldsymbol{\eta}(\mathbf{x}, \boldsymbol{t}) \boldsymbol{\eta}\left(\mathbf{x}^{\prime}, \boldsymbol{t}^{\prime}\right)\right\rangle=2 D \delta^{d}\left(\mathbf{x}-\mathbf{x}^{\prime}\right) \delta\left(t-t^{\prime}\right)
$$

sendo $d$ a dimensão do substrato e $D$ o coeficiente de difusão (Mattos T. G., 2005).

\subsubsection{Modelo de deposição aleatória com relaxação superficial}

No modelo de deposição aleatória com relaxação superficial, uma partícula em uma posição aleatória de um sítio de uma rede é solta de uma altura superior à altura máxima desta coluna. A partícula cai verticalmente e ao encontrar o topo da coluna associada ao sítio sorteado ela não se fixa, ela "relaxa" e cai sobre o sítio vizinho de menor altura e se fixa. Quando a partícula cai sobre um sítio onde seus vizinhos possuem a mesma altura da coluna onde caiu, ela não "relaxa" e se fixa no sítio onde caiu (Figura 2.6.3.3-1). 


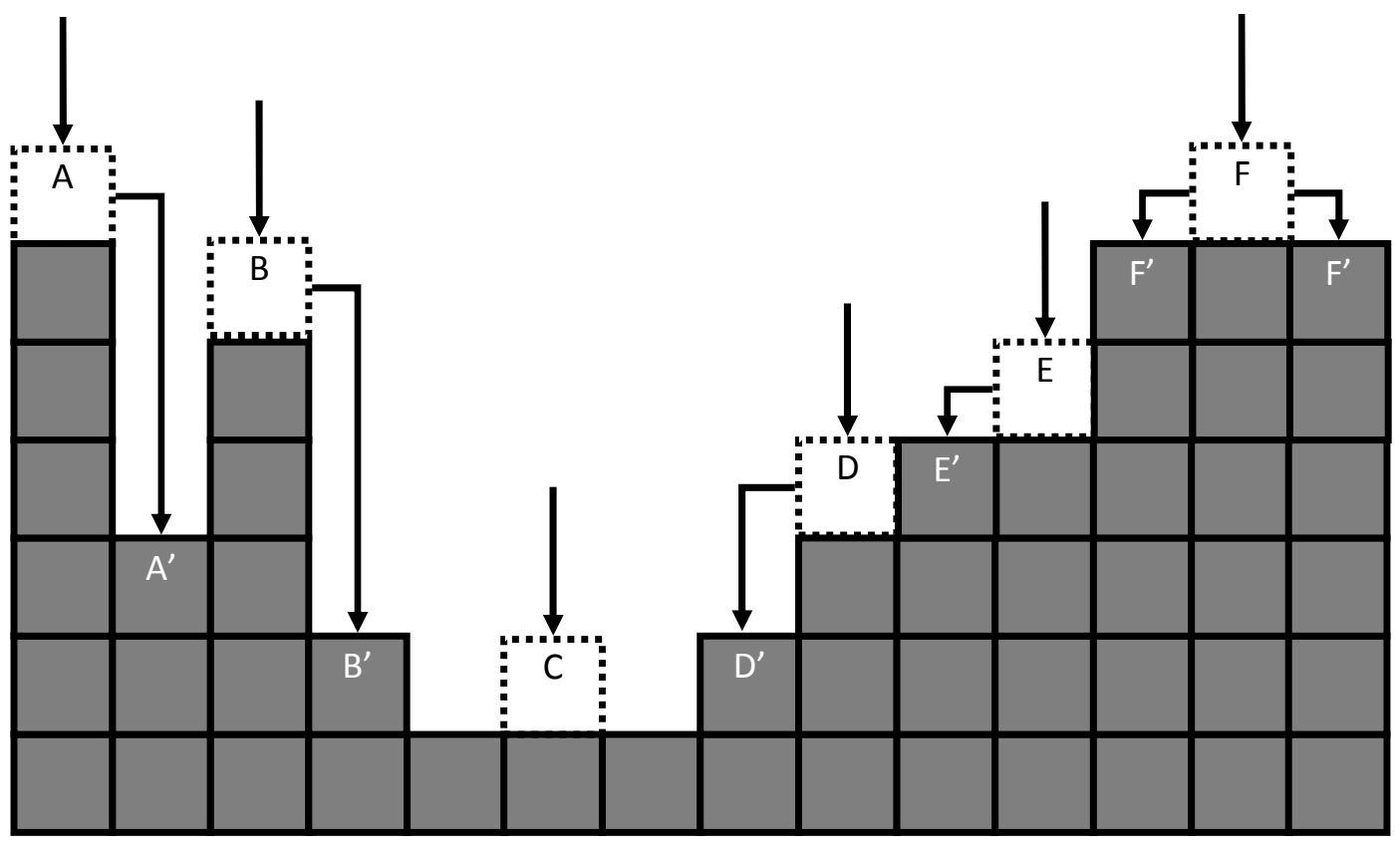

Figura 2.6.3.3-1 - Modelo de deposição aleatória com relaxação superficial.

O fluxo de partículas neste modelo é maior para posições de mínimo local ou, analiticamente, onde a segunda derivada é positiva. Portanto é razoável afirmar que a taxa de crescimento é proporcional ao laplaciano:

$$
\frac{\partial h(\mathbf{x}, t)}{\partial t}=\Phi(\mathbf{x}, t)=v \nabla^{2} h(\mathbf{x}, t)+\eta(\mathbf{x}, t)
$$

onde $v$ é o coeficiente linear. Esta equação é conhecida como equação EdwardsWilkinson (Edwards \& Wilkinson, 1982). Os resultados obtidos para os expoentes neste modelo são: $\alpha=\frac{2-d}{2}, \beta=\frac{2-d}{4}$ e $z=2$. 


\section{Materiais e métodos}

Para a realização deste trabalho, foram utilizados computadores com processador de dois núcleos de 64-bits Intel® ${ }^{\circledR}$ Core $^{\mathrm{TM}} 2$ Duo T5500 1,6GHz; processador de 32-bits Intel ${ }^{\circledR}$ Pentium ${ }^{\circledR} 43,20 \mathrm{GHz}$ e processador de 32-bits AMD ${ }^{\circledR}$ Athlon ${ }^{\mathrm{TM}}$ XP 2000+ $1,67 \mathrm{GHz}$.

\subsection{Estudo da rugosidade do ânodo de tubo de raios $\mathrm{X}$}

Alguns aspectos da modelagem da rugosidade do ânodo, assim como os valores das rugosidades escolhidos para a realização das simulações dos espectros de radiação X e as formas das rugas, foram baseados em estudos que resultaram nas imagens da Figura 3.1-1 e da Figura 3.1-2.

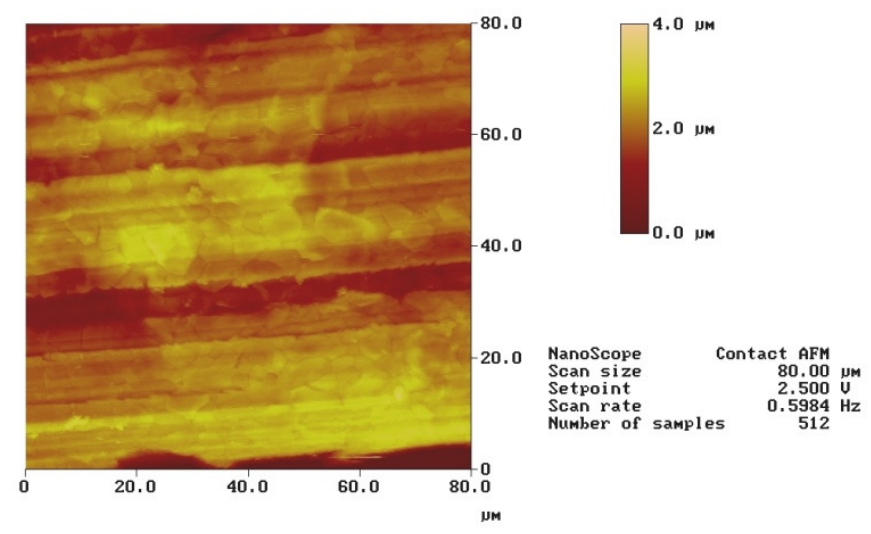

05201130.002

Figura 3.1-1 - Imagem de uma área de um ânodo de um tubo de raios $X$ não bombardeada por elétrons. ${ }^{3}$

\footnotetext{
${ }^{3}$ Imagem obtida por Daniel A. B. Bonifácio durante o curso de Microscopia de Força Atômica e Tunelamento oferecido na Pós-Graduação do IFUSP pela Profa . Maria Cecília Salvadori (equipamento FAPESP proc. no. 95/5651-0). A rugosidade média apresenta valor de 145,28 nm.
} 


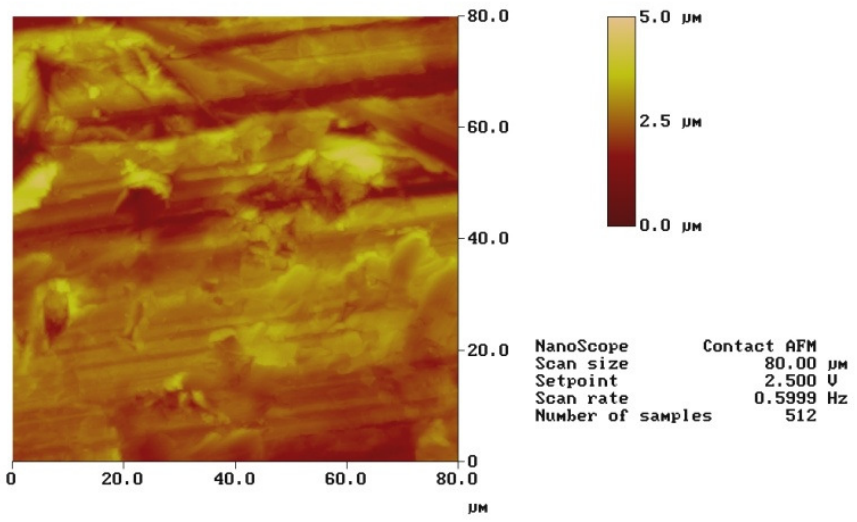

05121506.002

Figura 3.1-2 - Imagem de uma área de um ânodo de um tubo de raios X bombardeada por elétrons. ${ }^{4}$

Nas duas figuras anteriores verifica-se que a área não bombardeada pelos elétrons (Figura 3.1-1) possui uma variação do valor da rugosidade entre 0,0 e 4,0 $\mu \mathrm{m}$ e que na área bombardeada (Figura 3.1-2) o valor da rugosidade varia entre 0,0 e 5,0 $\mu \mathrm{m}$. As imagens obtidas foram de um tubo de raios $\mathrm{X}$ sem uso. Contudo, o bombardeamento de elétrons no ânodo, neste caso, se deve ao processo de "amaciamento" do tubo realizado pelo fabricante antes de ser comercializado (Nagel, 1988). Nessas condições foram escolhidos os seguintes valores de rugosidade para as simulações no GEANT4: 0,5; 1,0; 2,0; 3,0;4,0; 5,0 e 6,0 $\mu \mathrm{m}$ e sem rugosidade. Não foi possível realizar simulações com rugosidade com valores entre $0,0 \mu \mathrm{m}<\omega<0,5 \mu \mathrm{m}$ devido ao longo tempo computacional de simulação demandado para a aquisição de espectros.

\footnotetext{
${ }^{4}$ Imagem obtida por Daniel A. B. Bonifácio durante o curso de Microscopia de Força Atômica e

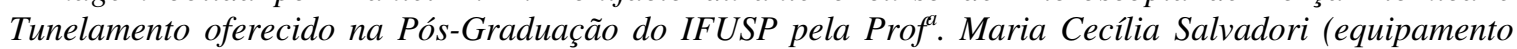
FAPESP proc. no. 95/5651-0). A rugosidade média apresenta valor de 280,60 nm.
} 


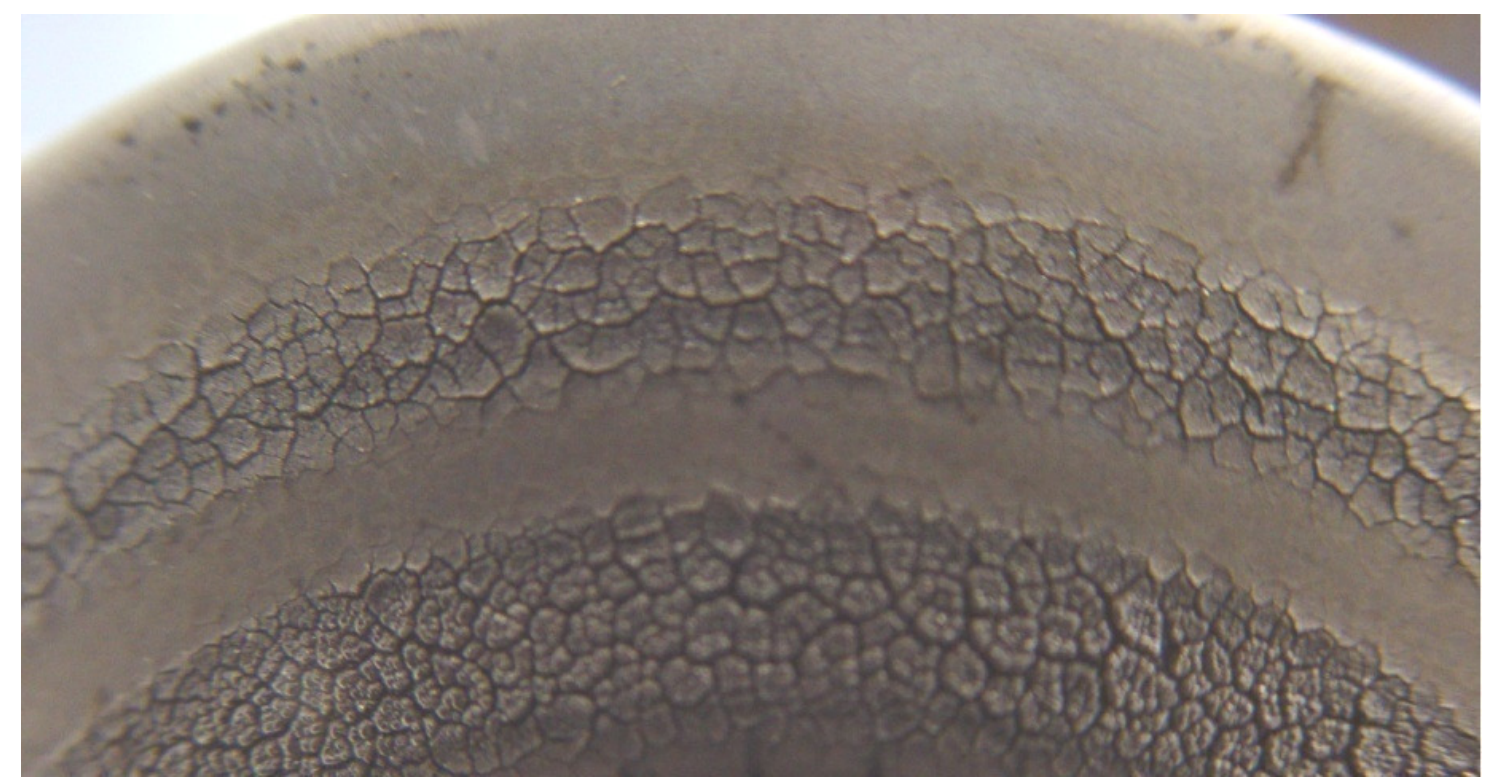

Figura 3.1-3 - Aspecto de um ânodo giratório de um tubo de raios X apresentando rugosidade elevada devido ao bombardeio de elétrons após um longo período 5 .

A Figura 3.1-3 apresenta um ânodo com carga de trabalho bastante elevada. Notase grandes sulcos formado pelo choque com os elétrons. Este fato sugere que na modelagem geométrica do sistema, o ânodo possua essas formações de vales.

Para a modelagem da geometria dos objetos, a ferramenta GEANT4 dispõe de diversos sólidos geométricos, desde as mais usuais (cubo, esfera, cilindro, etc.) até geometrias mais complexas (tubo com perfil hiperbólico, trapezóide torcido, etc.). Este último, no entanto, requer uma grande quantidade de memória e processamento computacional. Neste trabalho, para a criação da superfície rugosa foi necessário grande quantidade de volumes geométricos. Portanto, para a escolha da forma geométrica considerou-se o tempo de processamento e a quantidade de memória disponível para a simulação nos computadores utilizados (seção 3).

Numa primeira averiguação, a superfície rugosa virtual foi implementada com a adição de volumes com formatos de paralelepípedos ou cúbicos (rugas). No entanto, esta implementação não gerou um resultado satisfatório, pois o espectro de radiação $X$ resultante dessa modelagem apresentou um espectro que diferia muito pouco ao de um simulado com ânodo sem rugosidade. Também foram realizadas avaliações com formas elípticas, sendo que estas foram inviáveis devido ao grande tempo computacional e

\footnotetext{
${ }^{5}$ Nota-se a rugosidade nas pistas relativas ao foco fino e ao foco grosso.
} 
quantidade de memória dispensados. Isto provavelmente se deve ao fato que formas arredondadas no GEANT4 são aproximados por pequenos voxels quadrados, aumentando assim a quantidade de volumes no sistema. Por fim, entre as formas geométricas disponíveis no GEANT4, escolheu-se então a forma piramidal, que representou uma aproximação melhor para a rugosidade real (Figura 3.1-4).
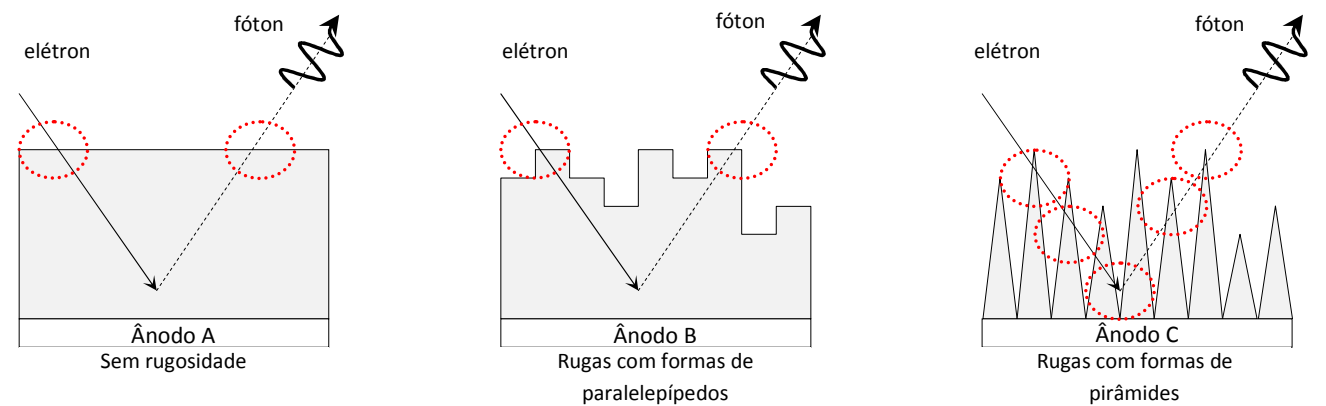

Figura 3.1-4 - Esquema da trajetória do elétron para a geração do fóton de raios X (vista lateral).

Realizando um estudo das trajetórias das partículas verificou-se que a formação de vales influencia nas formas dos espectros. $\mathrm{Na}$ simulação com o ânodo contendo rugosidade em forma de pirâmides, averiguou-se que a partícula sofre mais interações dentro das rugas, ou seja, durante a história da partícula ocorreram mais eventos nessas regiões. A Figura 3.1-4 mostra que no ânodo C, a partícula encontra mais pontos de interfaces entre o ânodo e o vácuo. Com as mesmas condições para o ânodo A e B, a intensidade do fóton gerado em $\mathrm{C}$ é diferente de ambos. Portanto, neste trabalho, o modelo geométrico da superfície rugosa foi composto de pequenos volumes de pirâmides, cada um representando uma ruga.

\footnotetext{
${ }^{6}$ O círculo pontilhado representa a interface entre o material anódico e o vácuo. A reta contínua representa uma possível trajetória do elétron. A reta tracejada representa uma possível trajetória do fóton gerado.
} 


\subsection{Simulação de superfície rugosa}

\subsubsection{Método proposto por Mattos, Moreira \& Atman}

Neste trabalho foi simulada uma superfície rugosa por um método baseado na equação de Edwards-Wilkinson (Mattos, Moreira, \& Atman, 2006). Considerando uma rede unidimensional de comprimento $L$ com condições periódicas de fronteira e inicialmente lisa, todos os sítios dessa rede são visitados simultaneamente, de maneira que o sítio $i$ receberá uma partícula no instante $t$ com probabilidade $p_{i}(t)$, dada por:

$$
p_{i}(t)=\rho e^{\kappa \Gamma_{i}(t)}
$$

onde $\rho$ e $\kappa$ são parâmetros de controle, fixos durante a dinâmica sendo que $0<\rho<1$ e $\kappa>0$. A função temporal $\Gamma_{i}(t)$ é um kernel que depende das alturas do sítio $i$ e de seus vizinhos. A forma funcional deste kernel será dada pela discretização do laplaciano $\nabla^{2} h(\mathrm{x}, t)$ da equação de Edwards-Wilkinson:

$$
\nabla^{2} h_{i}(t)=\nabla\left(\nabla h_{i}(t)\right) \rightarrow \Gamma_{i}(t)=h_{i+1}(t)-2 h_{i}(t)+h_{i-1}(t)
$$

com a condição:

$$
p_{i}(t) \geq 1 \Rightarrow p_{i}(t)=1 \Rightarrow h_{i}(t+1)=h_{i}(t)+1
$$

Assim, existe um valor $\Gamma_{\text {máx }}(\rho, \kappa)$ tal que:

$$
\Gamma_{m a ́ x}(\rho, \kappa)=\operatorname{int}\left(-\frac{1}{\kappa} \ln \rho\right)
$$

onde int(x) é a parte inteira de x. Com a condição:

$$
\Gamma_{\text {máx }}(\rho, \kappa) \geq 1
$$


E um valor $\Gamma_{\min }(\rho, \kappa)$ :

$$
\begin{gathered}
\Gamma_{\text {min }}(\rho, \kappa)=\operatorname{int}\left[-\frac{1}{\kappa}(\ln \rho+10 \ln 10)\right] \\
\Rightarrow \Gamma_{\text {min }}(\rho, \kappa)=\Gamma_{\text {máx }}(\rho, \kappa)-\operatorname{int}\left(\frac{10}{\kappa} \ln 10\right)
\end{gathered}
$$

sendo que:

$$
\kappa \leq \ln \left(\frac{1}{\rho}\right)
$$

\subsubsection{Aplicação do método}

O método foi utilizado na geração da rugosidade na modelagem geométrica para a simulação de espectros de raios X. Foi utilizado um algoritmo de crescimento adaptado do proposto por Mattos (Mattos T. G., 2005) para um tempo $t>0$ até que a rugosidade descrita pela equação (2.6.2.1) atingisse o valor da rugosidade $\omega$ desejada, de acordo com o fluxograma da Figura 3.2.1.1-1:

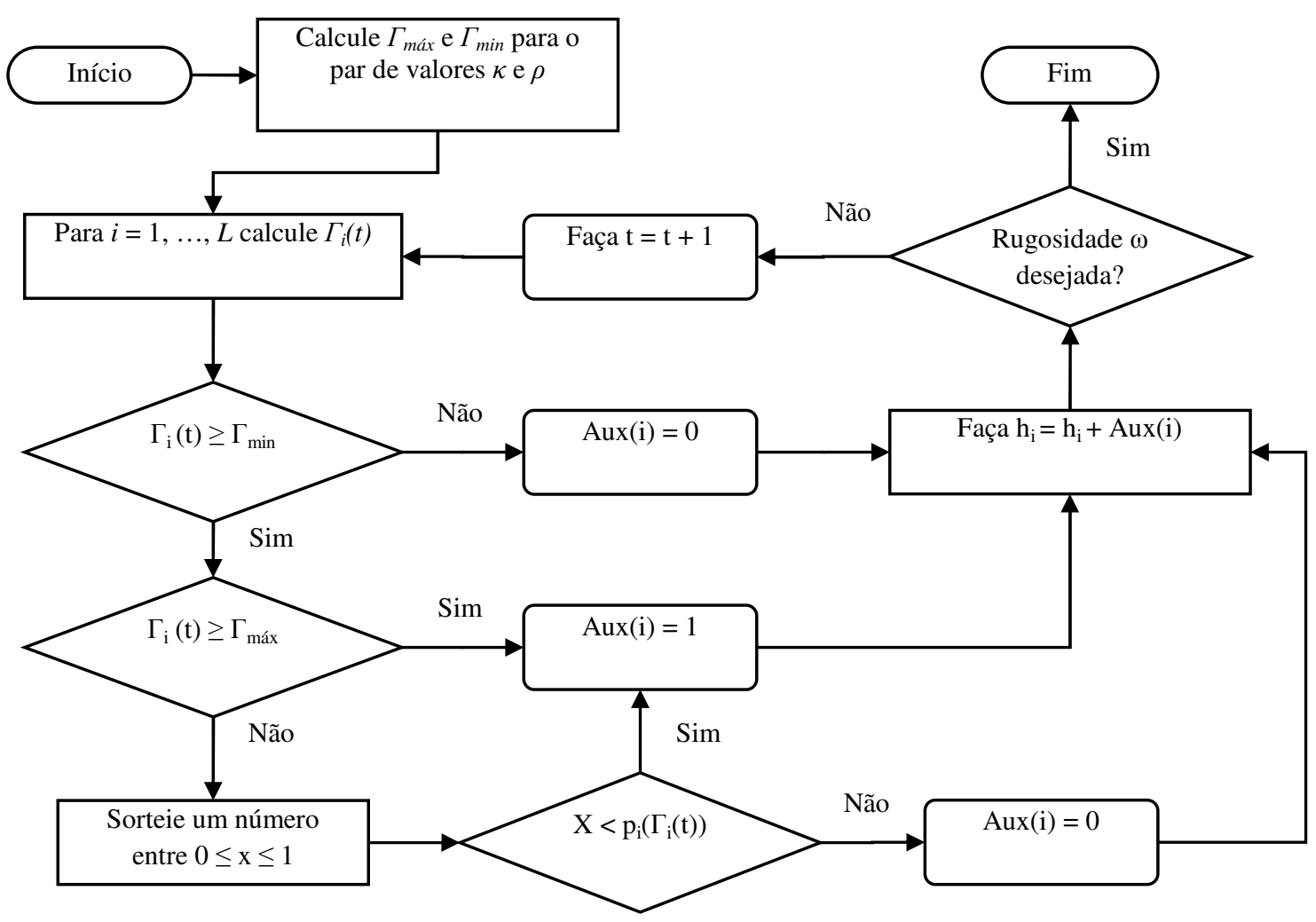

Figura 3.2.1.1-1 - Fluxograma para a geração da superfície rugosa. 
A evolução das interfaces foi simulada utilizando os seguintes valores para os coeficientes: $\kappa=0,1$ e $\rho=0,5$ resultando no gráfico da Figura 3.2.1.1-2.

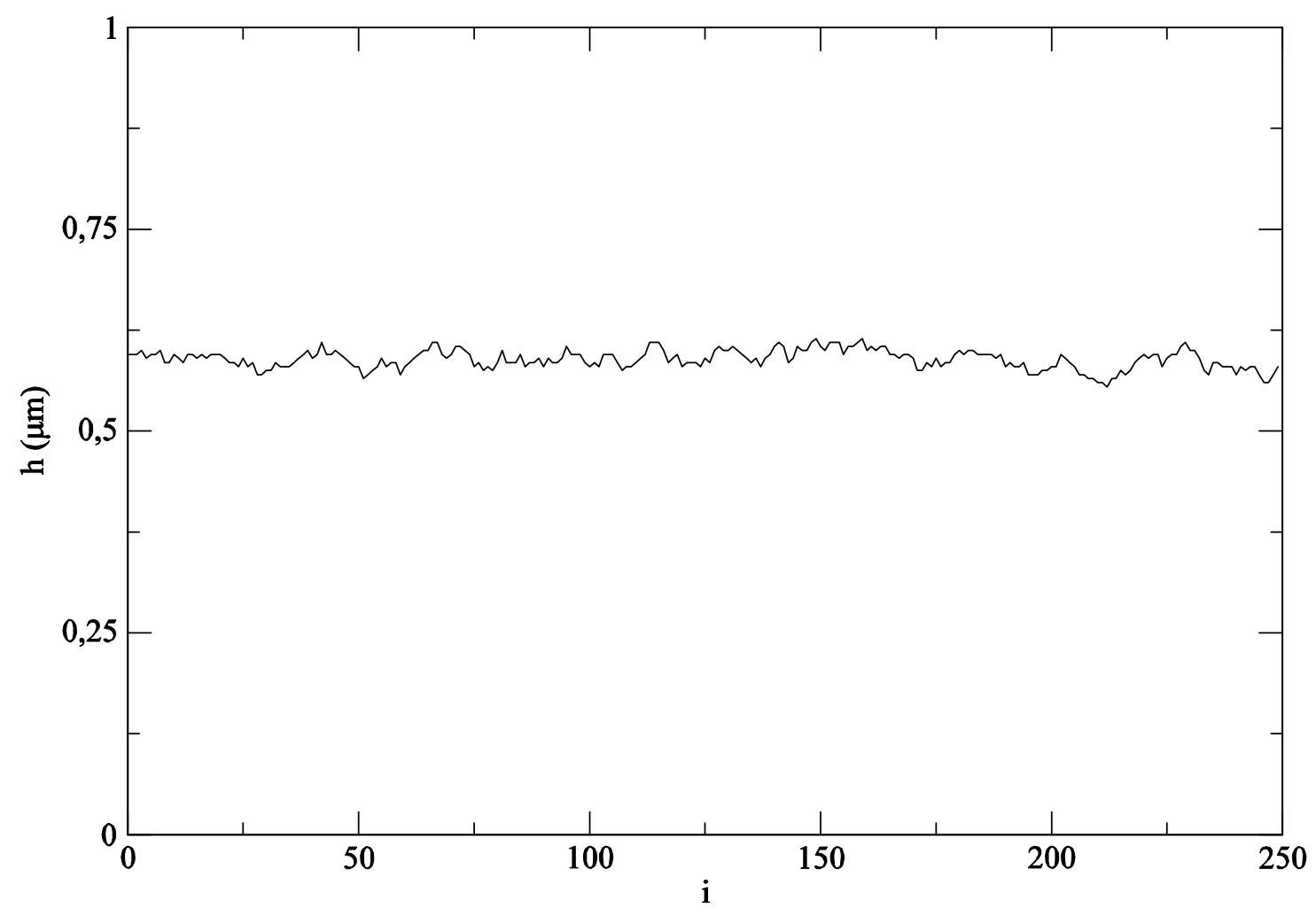

Figura 3.2.1.1-2 - Perfil da rugosidade $(\omega=0,588 \mu m)$.

O método de crescimento proposto por Mattos considera o sistema de uma rede unidimensional com comprimento $L$. Neste trabalho, a superfície rugosa foi simulada repetindo o método de crescimento $n$ vezes, ou seja, para cada posição $(i, j)$ de uma rede $L \times n$ foi disposta uma ruga com forma piramidal (Figura 3.2.1.1-3). Neste caso, os valores das posições variaram de $i=0,1,2, \ldots, L=250$ e $j=0,1,2, \ldots, n=250$. Para uma superfície com rugosidade $\omega$, foi fixado o valor de $\frac{\omega}{10}$ para cada lado da base quadrada de cada pirâmide da superfície. Portanto, o comprimento e a largura máxima da rede $L \times n$ foram de $25 \omega$. 


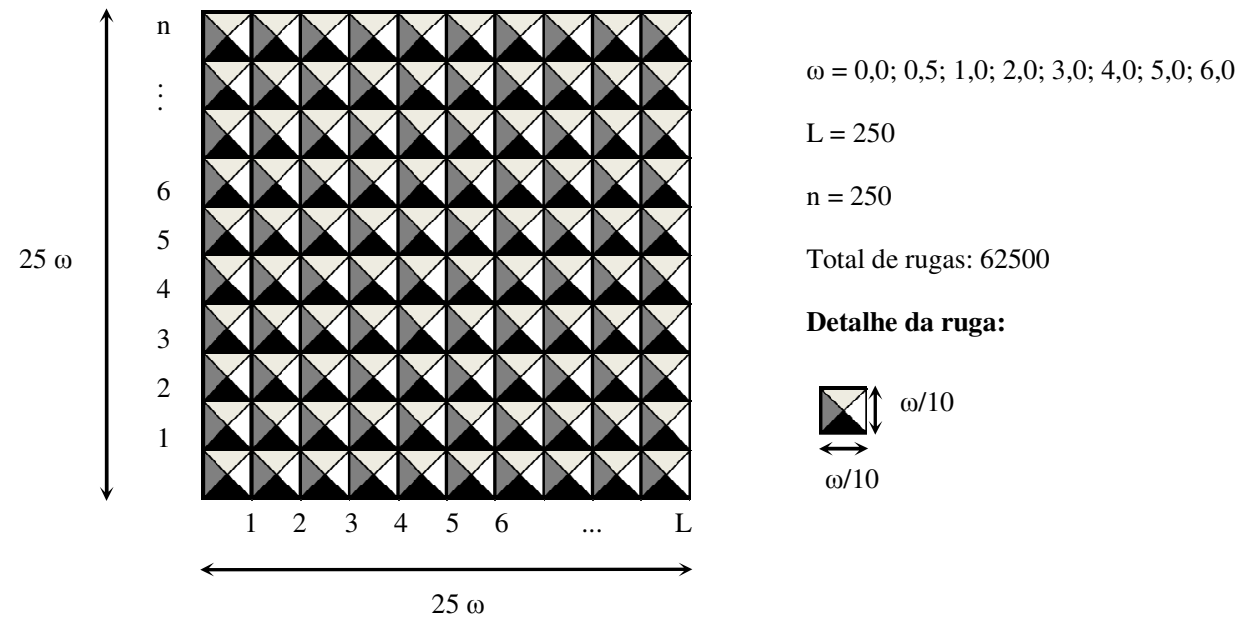

Figura 3.2.1.1-3 - Superfície rugosa representada por uma rede L $x$ n (vista superior).

\subsection{Simulação de espectros de radiação $X$}

Foi realizada a simulação de espectros de raios $X$ com a ferramenta computacional GEANT4 versão 9.0. A modelagem geométrica incluindo a superfície rugosa foi gerada no código da aplicação do GEANT4. Para a análise de dados foi utilizado a interface AIDA versão 3.2.1 (Barrand, Binko, Donszelman, Johnson, \& Pfeiffer, 2001) juntamente com o OpenScientist versão v16r0 (Barrand, 2004) (ver item 2.1.2.1).

\subsubsection{Modelagem geométrica}

$\mathrm{O}$ modelo geométrico criado para a simulação de espectros de radiação $\mathrm{X}$ foi baseado num tubo de raios $\mathrm{X}$ simplificado. Neste modelo, o tubo de raios $\mathrm{X}$ foi resumido somente em cátodo e o ânodo. $\mathrm{O}$ vidro do tubo, o óleo isolante e a janela da cúpula do tubo de raios $X$, que são as filtrações inerentes ao tubo, neste trabalho não foram considerados. Para a geração das partículas primárias foi utilizada a ferramenta GPS (General Particle Source) incluída no pacote de ferramentas do GEANT4. O ânodo foi 
modelado com um ângulo fixo de $16^{\circ}$ e de material constituído de $95 \%$ de tungstênio e $5 \%$ de rênio. A superfície rugosa, modelada conforme visto na seção 3.2.1.1, foi introduzida sobre o ânodo liso (com espessura variável, dependendo do valor da rugosidade, com no mínimo $1 \mathrm{~mm}$ ) na face de incidência do feixe de elétrons emitido pelo cátodo (Figura 3.3.1-1). O objeto sensível à detecção de fótons foi disposto a uma distância de 1,0 m do ponto focal com raio de abertura do feixe definido por um ângulo sólido de $32^{\circ}$, que é o maior ângulo possível onde os fótons não sofrem influência do efeito heel (Johns \& Cunningham, 1983).

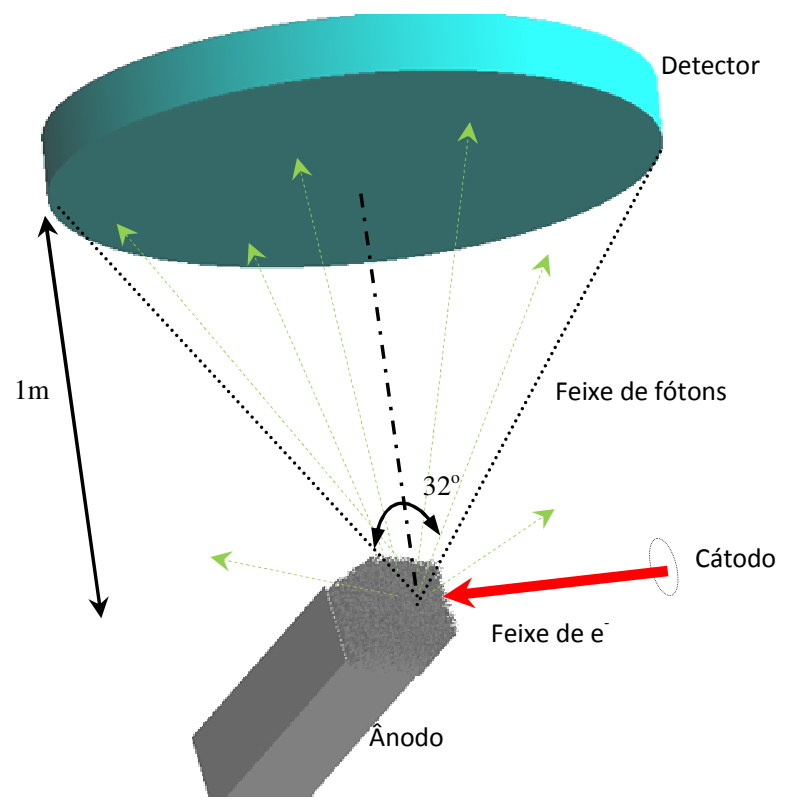

Figura 3.3.1-1 - Modelo geométrico do sistema simulado pelo GEANT4.

\subsubsection{Processos físicos envolvidos}

No GEANT4, é possível selecionar todos os processos físicos que serão envolvidos na simulação. Além de seus processos internos, também é possível incluir outros processos desenvolvidos por terceiros. Esta ferramenta computacional disponibiliza três modelos básicos para interações eletromagnéticas para baixas energias: standard, low energy e Penelope (CERN, 2007b). O modelo utilizado nas simulações foi o low energy 
(Chauvie, et al., 2004), devido à faixa de energia utilizada para gerar os espectros de radiação $X$.

Os processos que fazem parte do modelo low energy são: efeito fotoelétrico, espalhamento Compton, espalhamento Rayleigh, produção de pares, bremsstrahlung e ionização (Chauvie, et al., 2004). Neste modelo, para os processos primários de ionização e efeito fotoelétrico, a ocorrência da relaxação atômica por meio de fluorescência ou de efeito Auger foi implementada (Guatelli, Mantero, Mascialino, Nieminen, Pia, \& Saliceti, 2004).

No processo de bremsstrahlung, a distribuição angular dos fótons emitidos pode ser amostrada de acordo com um desses três modelos (Rodrigues, et al., 2004): Tsai modificado, 2BS ou 2BN (Peralta, Rodrigues, Trindade, \& Pia, 2005). Para interações eletromagnéticas baseadas no low energy, o modelo $2 B N$ é o mais adequado conforme trabalho de S. Chauvie (Chauvie, et al., 2006). Portanto, este modelo foi utilizado neste trabalho devido à faixa de energia empregada para as simulações dos espectros de raios $\mathrm{X}$.

\section{Base de dados:}

As bases de dados utilizadas para a determinação das seções de choque foram extraídas das seguintes bibliotecas de dados: EPDL97 (Evaluated Photons Data Library) (Cullen, Hubbell, \& Kissel, 1997); EEDL (Evaluated Electrons Data Library) (Perkins, Cullen, \& Seltzer, 1991); e EADL (Evaluated Atomic Data Library) (Perkins, Cullen, Chen, Hubbell, Rathkopf, \& Scofield, 1991). Também foram considerados os efeitos de stopping power nuclear e correções devido a estrutura molecular dos materiais (Amako, et al., 2004).

\section{Corte para produção de partículas secundárias:}

Tanto no processo de bremsstrahlung quanto no processo de ionização, o limite de energia para produção de partículas secundárias foi definido como $4 \mathrm{keV}$ para o ânodo. Os limites para produção de partículas secundárias para demais processos foram definidos 
em termos de distância, sendo $50 \mathrm{~nm}$ para elétrons e $200 \mathrm{~nm}$ para fótons. Os critérios para a utilização desses valores foram: a faixa de energia, valores das alturas das rugas e tempo de processamento computacional para a realização das simulações.

\subsubsection{Critério estatístico para a formação do espectro de raios X}

Neste trabalho, para se obter os espectros com a qualidade estatística desejada foi estipulado um critério no qual a incerteza percentual do tipo A $u_{A}(\%)$ da intensidade do canal correspondente a $90 \%$ da energia máxima do espectro fosse de, no máximo, $u_{A}(\%)=2 \%$ para espectros de energia de $40 \mathrm{keV}, u_{A}(\%)=2,5 \%$ para espectros de energia de $80 \mathrm{keV}$ e $u_{A}(\%)=3,0 \%$ para espectros de energia de $150 \mathrm{keV}$. A largura de energia de cada canal do espectro foi estipulada em $0,5 \mathrm{keV}$.

\subsubsection{Redução de variância}

Devido à grande quantidade de volumes para a geração da superfície rugosa, o tempo estimado para a realização da simulação dos espectros sem a utilização de técnicas de redução de variância é bastante longo (Tabela 3.3.4-1). 
Tabela 3.3.4-1 - Tempo estimado da simulação de espectro de raios X, aplicada uma tensão de $150 \mathrm{kV}$, com 10 mil eventos, gerado por tubo de raios $X$ com ânodo rugoso sem a aplicação de técnicas de redução de variância ${ }^{7}$.

\begin{tabular}{cc}
\hline \hline Rugosidade $(\mu \mathrm{m})$ & Tempo $(\mathrm{s})$ \\
\hline 0,0 & 7,82 \\
0,5 & 565,24 \\
1,0 & 278,67 \\
2,0 & 116,92 \\
3,0 & 84,63 \\
4,0 & 67,43 \\
5,0 & 58,98 \\
6,0 & 50,15 \\
\hline
\end{tabular}

Na Tabela 3.3.4-1 estão descritos os tempos de simulação para um feixe de 10 mil elétrons para um espectro de radiação X sob uma tensão de aceleração de 150 kV. Sendo que a eficiência para produção de raios $\mathrm{X}$ é de aproximadamente $1 \%$, somente cerca de 100 fótons são gerados e destes, muitos não serão detectados. Para uma boa estatística na aquisição de um espectro seria, no mínimo, necessária a simulação com 100 milhões de eventos. Com isso, por exemplo, o tempo de simulação de um espectro de raios X para a rugosidade de $0,5 \mu \mathrm{m}$ seria de aproximadamente 3925 dias, o que torna a simulação nessas condições inviável para a infra-estrutura computacional utilizada. Portanto, para satisfazer o critério estatístico para a obtenção dos espectros (seção 3.3.3) para tempos mais curtos de simulação foi necessária a utilização de uma técnica de redução de variância.

Neste trabalho, a técnica de redução de variância empregada foi baseada no fracionamento (splitting) de bremsstrahlung (Tinslay, Faddegon, Perl, \& Asai, 2007). Esta técnica consiste na geração de $N_{f}$ fótons secundários na interação com um elétron. Para a realização desta técnica, foram substituídos os arquivos do GEANT4 G4LowEnergyBremsstrahlung.cc e G4LowEnergyIonisation.cc pelos arquivos G4LowEnergyBremsstrahlungBias.cc e G4LowEnergyIonisationBias.cc respectivamente (no Apêndice 2 são exibidos os códigos desses dois arquivos).

\footnotetext{
${ }^{7}$ O tempo da simulação foi obtido a partir de um computador com processador de dois núcleos de 64-bits Intel® Core ${ }^{\mathrm{TM}} 2$ Duo T5500 1,6GHz
} 
Para valores de $N_{f}$ entre 1 e 400, foram realizadas medições do tempo computacional de simulação em segundos e da quantidade dos fótons detectadas pelo volume sensível (Figura 3.3.4-1).

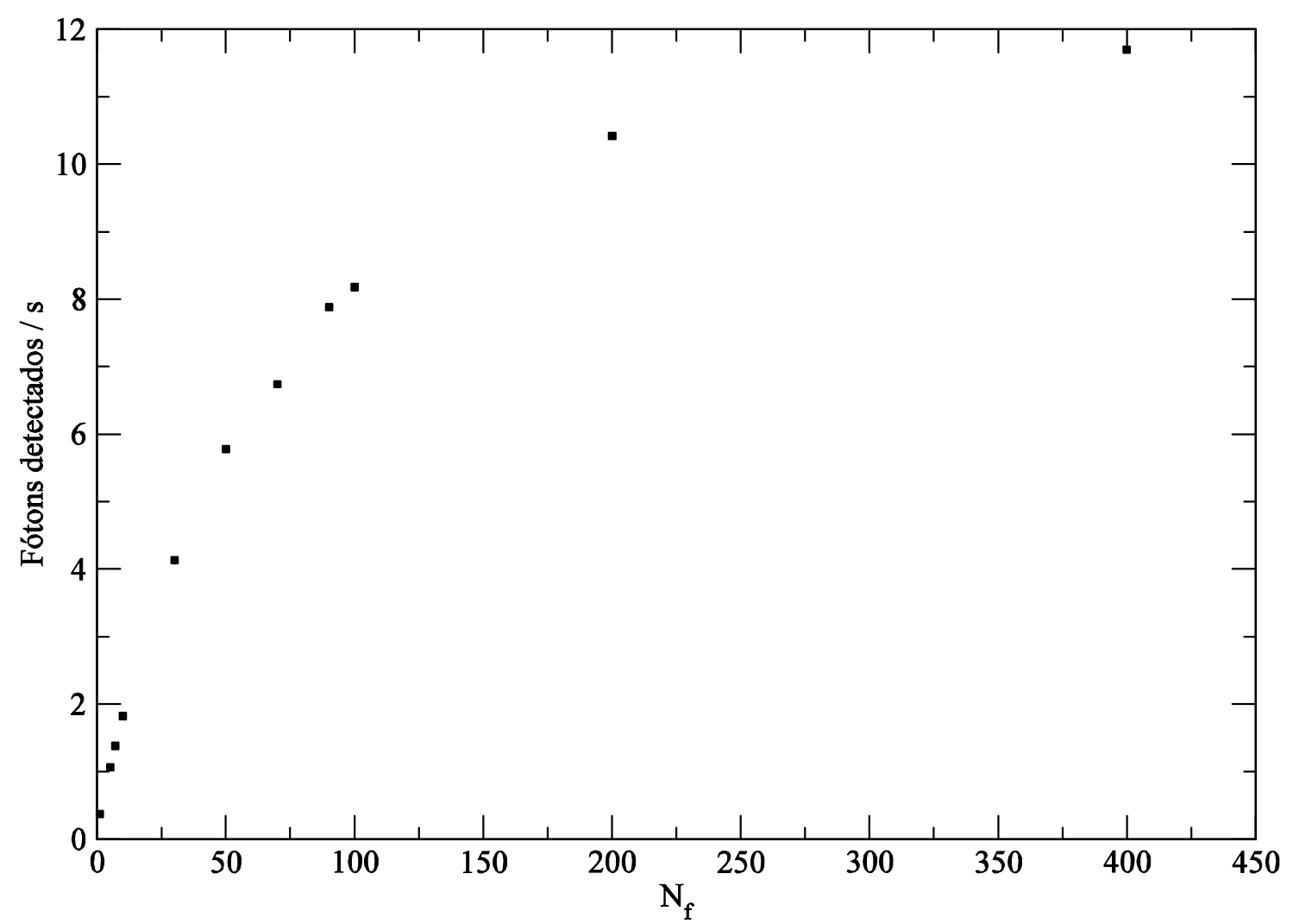

Figura 3.3.4-1 - Gráfico da relação entre o número de fótons detectados por segundo e a quantidade $N_{f}$ de fótons gerados em uma única interação ${ }^{8}$.

Para o valor de $N_{f} \rightarrow \infty$ verifica-se a tendência de saturação em relação à razão de fótons detectados por segundo. Neste trabalho, foi escolhido o valor de $N_{f}=100$, correspondente a 8,18 fótons detectados por segundo para a realização das simulações dos espectros de raios X (nos códigos do Apêndice 2, a variável nBiasedevents corresponde à quantidade $N_{f}$ de fótons gerados em uma única interação).

\footnotetext{
${ }^{8}$ Gerado a partir das simulações de espectros de radiação X com tensão aplicada ao tubo de $70 \mathrm{kV}$ com ânodo com superfície rugosa $\omega=10,0 \mu \mathrm{m}$.
} 
Para verificar a consistência do método utilizado, foi realizada uma comparação entre um espectro simulado com redução de variância para $N_{f}=100$ e um espectro sem o uso de técnicas de redução de variância (Figura 3.3.4-2).

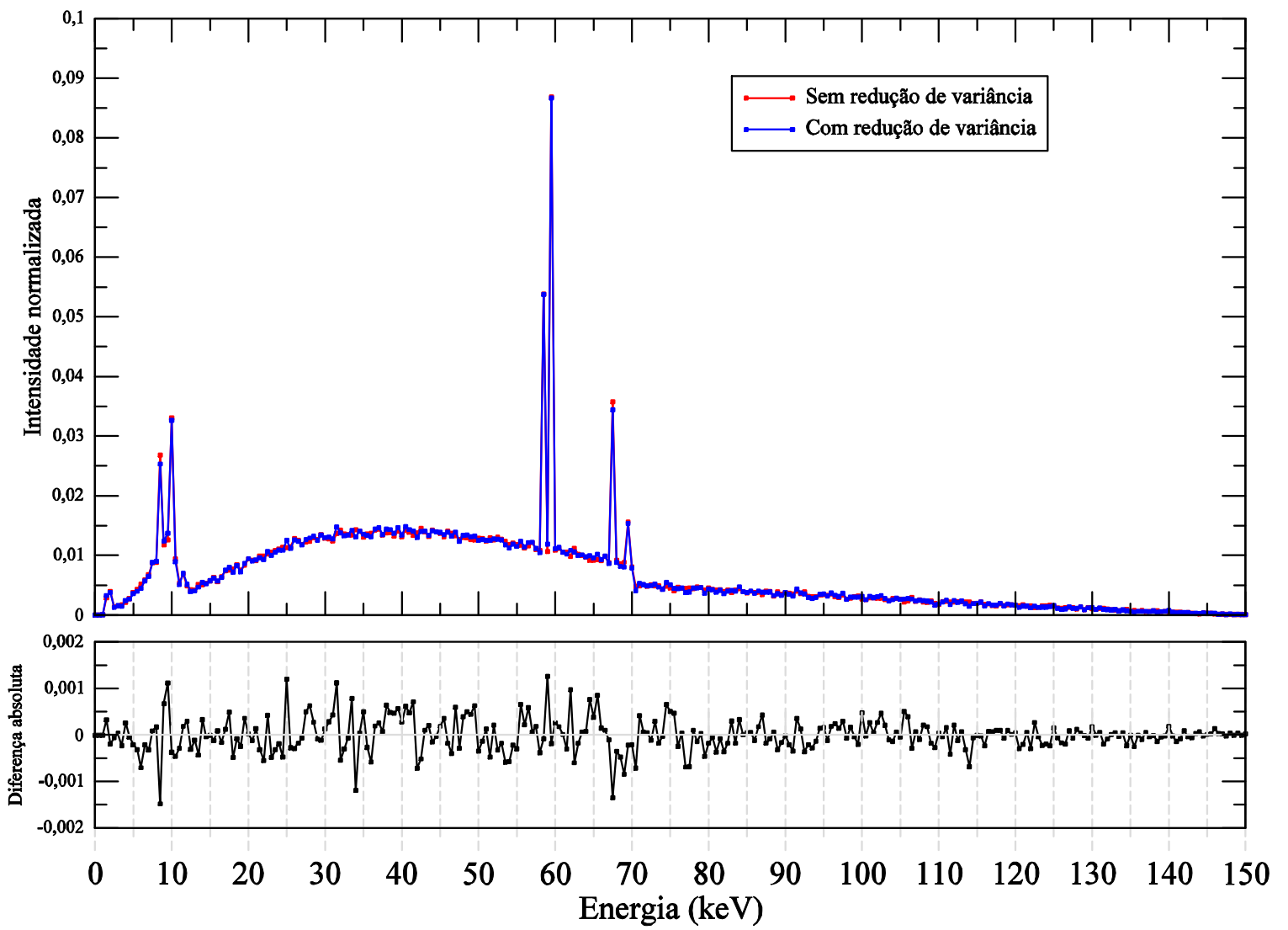

Figura 3.3.4-2 - Espectro de radiação X com tensão aplicada ao tubo de $150 \mathrm{kV}$ com ânodo com rugosidade $\omega=10,0$ um simulado com o GEANT4.

Na Figura 3.3.4-2, o número total de contagens $C_{0}$ obtido do espectro sem a aplicação de redução de variância foi de $C_{0}=123410$ e $C_{1}=76163$ foi o número total de contagens $C_{1}$ referente ao espectro com a aplicação de redução de variância. Com os valores de $C_{0}$ e $C_{1}$ foi calculado o desvio padrão estatístico (ver Tabela 3.3.4-2) dado pela equação (3.3.4.1):

\footnotetext{
${ }^{9}$ A diferença absoluta representa o espectro gerado com redução de variância subtraído do espectro simulado sem redução de variância. O espectro foi simulado com rugosidade $\omega=10,0 \mu \mathrm{m}$ devido ao tempo elevado de simulação para rugosidades menores sem a utilização de redução de variância.
} 


$$
\sigma_{e s t}=\frac{\sqrt{\sigma_{C_{0}}^{2}+\sigma_{C_{1}}^{2}}}{C_{0}+C_{1}}
$$

sendo que:

$$
\sigma_{C_{0}}=\sqrt{C_{0}}, \sigma_{C_{1}}=\sqrt{C_{1}}
$$

Para o espectro da Figura 3.3.4-2, foi calculado o desvio padrão da diferença absoluta média dada pela seguinte equação (3.3.4.3):

$$
\sigma_{\langle D\rangle}=\sqrt{\frac{\sum_{i=1}^{N}\left(D_{i}-\langle D\rangle\right)^{2}}{N-1}}
$$

onde $D_{i}$ é a diferença absoluta entre as intensidades sem redução de variância e com redução de variância, do canal $i$ do espectro que contém $N$ canais. A diferença absoluta média $\langle D\rangle$ é dada pela equação (3.3.4.4):

$$
\langle D\rangle=\frac{1}{N} \sum_{i=1}^{N} D_{i}
$$

O desvio padrão estatístico $\sigma_{e s t}$ estabelece a flutuação estatística relacionada com o número de contagens $C_{0}$ e $C_{1}$ e o desvio padrão da diferença absoluta média $\sigma_{\langle D\rangle}$ determina a dispersão da diferença absoluta em torno de zero (Tabela 3.3.4-2).

Tabela 3.3.4-2 - Valor do desvio padrão estatístico $\sigma_{e s t}$ referente às contagens $C_{0} e C_{1}$ e o valor do desvio padrão da diferença média absoluta $\sigma_{<D>}$ referente $a<D>$ dos espectros correspondentes.

\begin{tabular}{c|ccc|cc}
\hline \hline $\begin{array}{c}\text { Espectros } \\
\text { correspondentes }\end{array}$ & $\boldsymbol{C}_{\mathbf{0}}\left(\times 10^{5}\right)$ & $\boldsymbol{C}_{\mathbf{1}}\left(\times 10^{4}\right)$ & $\langle\mathrm{D}\rangle$ & $\boldsymbol{\sigma}_{\text {est }}\left(\times 10^{-3}\right)$ & $\boldsymbol{\sigma}_{\langle D\rangle}\left(\times 10^{-3}\right)$ \\
\hline Figura 3.3.4-2 & 1,2 & 7,6 & 0 & 2,2 & 0,4 \\
\hline \hline
\end{tabular}


Cabe ressaltar que o valor de $\langle D\rangle$ é nulo porque se refere à diferença de dois espectros normalizados. Na Tabela 3.3.4-2, verifica-se que $\sigma_{\langle D\rangle}<\sigma_{\text {est }}$, ou seja, a dispersão da diferença absoluta do espectro da Figura 3.3.4-2 está relacionada com a flutuação estatística dos dados. Isto demonstra que, por critérios estatísticos, estes espectros são equivalentes. Também foi verificado que, no espectro simulado com redução de variância, para cada valor de energia de fóton detectado, não houve repetições desses valores. Isto demonstrou que a técnica de redução de variância aplicada não inferiu de forma tendenciosa no resultado final.

\subsection{Espectros de raios $\mathrm{X}$ com filtração}

Além de simulação de espectros de raios $\mathrm{X}$ de tubos com anodos rugosos, por cálculos analíticos foram gerados espectros a partir da radiação $\mathrm{X}$, com filtração adicional de tungstênio ao feixe primário de radiação $X$, provenientes de tubos com ânodos sem rugosidades. Esses espectros foram caracterizados pelos parâmetros da energia média e da camada semi-redutora.

\subsubsection{Caracterização dos espectros pela energia média}

Foram calculadas as energias médias dos espectros de raios $\mathrm{X}$, com $N$ canais, simulados com o tubo de raios $\mathrm{X}$ com ânodos rugosos (3.4.1.1) e as suas respectivas incertezas (3.4.1.2):

$$
\begin{gathered}
\langle E\rangle=\frac{\sum_{i=1}^{N}\left(E_{i} \cdot C_{i}\right)}{\sum_{i=1}^{N} C_{i}} \\
\sigma_{\langle E\rangle}=\frac{\sqrt{\sum_{i=1}^{N}\left(E_{i}-\langle E\rangle\right)^{2} C_{i}}}{\sum_{i=1}^{N} C_{i}}
\end{gathered}
$$

onde $C_{i}$ e $E_{i}$ são o número de eventos e a energia do canal $i$ respectivamente. 
Para cada valor de rugosidade, foi calculada numericamente a espessura de tungstênio necessária para produzir o mesmo valor de energia média. Os espectros de raios X filtrados foram gerados numericamente a partir da equação (2.3.6.3) onde os valores dos coeficientes de atenuação de massa $\frac{\mu}{\rho}$ para cada intensidade $I_{0}$ e a densidade do tungstênio $\rho=19,30 \frac{\mathrm{g}}{\mathrm{cm}^{3}}$ foram obtidos da tabela de coeficientes de atenuação de massa do NIST (National Institute of Standards and Technology) (Hubbell \& Seltzer, 2004).

\subsubsection{Caracterização de espectros pela camada semi-redutora}

A espessura de um absorvedor que reduz à metade o valor inicial da intensidade de radiação incidente é chamada de camada semi-redutora (CSR). De acordo com a norma IEC 61267 (IEC, 2005), a primeira CSR é a espessura do material absorvedor necessária para reduzir a taxa de kerma no ar à metade do valor sem este absorvedor. A segunda CSR é definida como a quantidade de material adicional para reduzir a taxa de kerma no ar para um quarto deste valor. De acordo com a equação (2.3.10.4) a primeira CSR pode ser determinada pela seguinte equação:

$$
\frac{K_{a r}^{\text {atenuado }}}{K_{\text {ar }}^{\text {inicial }}}=\frac{\sum_{j=1}^{N} C_{j} E_{j} e^{-\mu_{i} x_{C S R}}\left(\frac{\mu_{e n}}{\rho}\right)_{E_{j}, a r}}{\sum_{j=1}^{N} C_{j} E_{j}\left(\frac{\mu_{e n}}{\rho}\right)_{E_{j}, a r}}=\frac{1}{2}
$$

Na equação acima, verifica-se que os coeficientes de transferência de energia $\left(\frac{\mu_{t r}}{\rho}\right)$ foram substituídos pelos coeficientes de absorção de energia $\left(\frac{\mu_{e n}}{\rho}\right)$. Isto foi realizado devido ao fato que, para faixa de energia utilizada e o ar ser predominante composto de partículas com Z pequeno (Hubbell \& Seltzer, 2004), a energia transferida ao meio é praticamente toda absorvida.

Para a faixa de energia utilizada foi estabelecida a incerteza de $3 \%$ para as seções de choque, sendo que $2 \%$ correspondem à fotoionização e $1 \%$ referente a outros 
processos (Cullen, Hubbell, \& Kissel, 1997). Com isso, a incerteza da CSR foi estimada de acordo com a equação (3.4.2.2) (Bonifácio D. A., 2007):

$$
\sigma_{x_{C S R}}=\frac{3}{100}\left(\frac{\ln (2)}{\mu_{\langle E\rangle}}\right)_{A l}
$$

onde $\mu_{\langle E\rangle}$ é o coeficiente de atenuação linear referente ao valor de energia média do espectro para o elemento alumínio. 


\section{Resultados e discussões}

Neste capítulo serão apresentados os resultados das simulações realizadas com o GEANT4 e a avaliação dos cálculos da energia média e da camada semi-redutora para espectros simulados sem a aplicação do modelo de rugosidade e com filtração de W. Os espectros dispostos a seguir foram normalizados pelas suas respectivas áreas totais. Os valores das incertezas correspondentes às intensidades de cada energia no espectro foram omitidos por serem inferiores ao tamanho do ponto.

\subsection{Simulação de espectros gerados por tubos de raios X com ânodos rugosos}

As figuras 4.1-1 a 4.1-3 apresentam os espectros de radiação para tubos de raios $\mathrm{X}$ com tensões de 40, 80 e $150 \mathrm{kV}$. Para cada espectro gerado com diferentes valores de tensões, foram utilizados ânodos com rugosidades de 0,$5 ; 1,0 ; 2,0 ; 3,0 ; 4,0 ; 5,0$ e $6,0 \mu \mathrm{m}$ e sem rugosidade. As demais características dos tubos de raios $\mathrm{X}$ simulados estão descritas na seção 3.3.1. Nas figuras em questão, a diferença absoluta representa o espectro produzido por um ânodo rugoso subtraído de um espectro gerado por um ânodo sem rugosidade. A simulação foi realizada sem a contribuição de qualquer filtração inerente ou adicional. Os picos presentes nas energias abaixo de $2,5 \mathrm{keV}$ não têm significado físico, porém sua origem é atribuída aos cortes de energia que são necessários nos cálculos com método de Monte Carlo. 

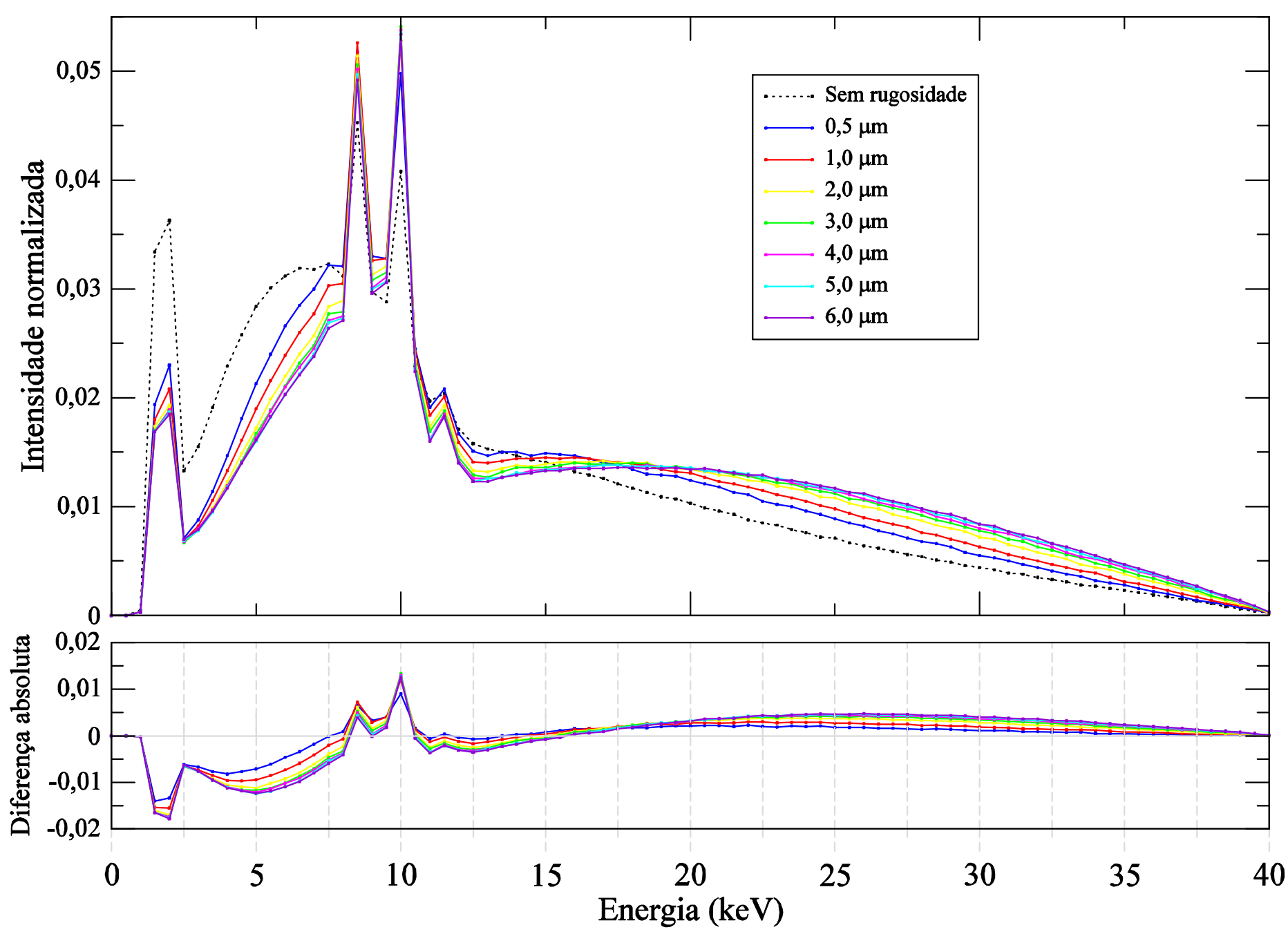

Figura 4.1-1 - Espectros de feixes de radiação X aplicado a uma tensão de 40 kV gerados pelo GEANT4 simulando tubos de raios X com ânodos apresentando rugosidade. 

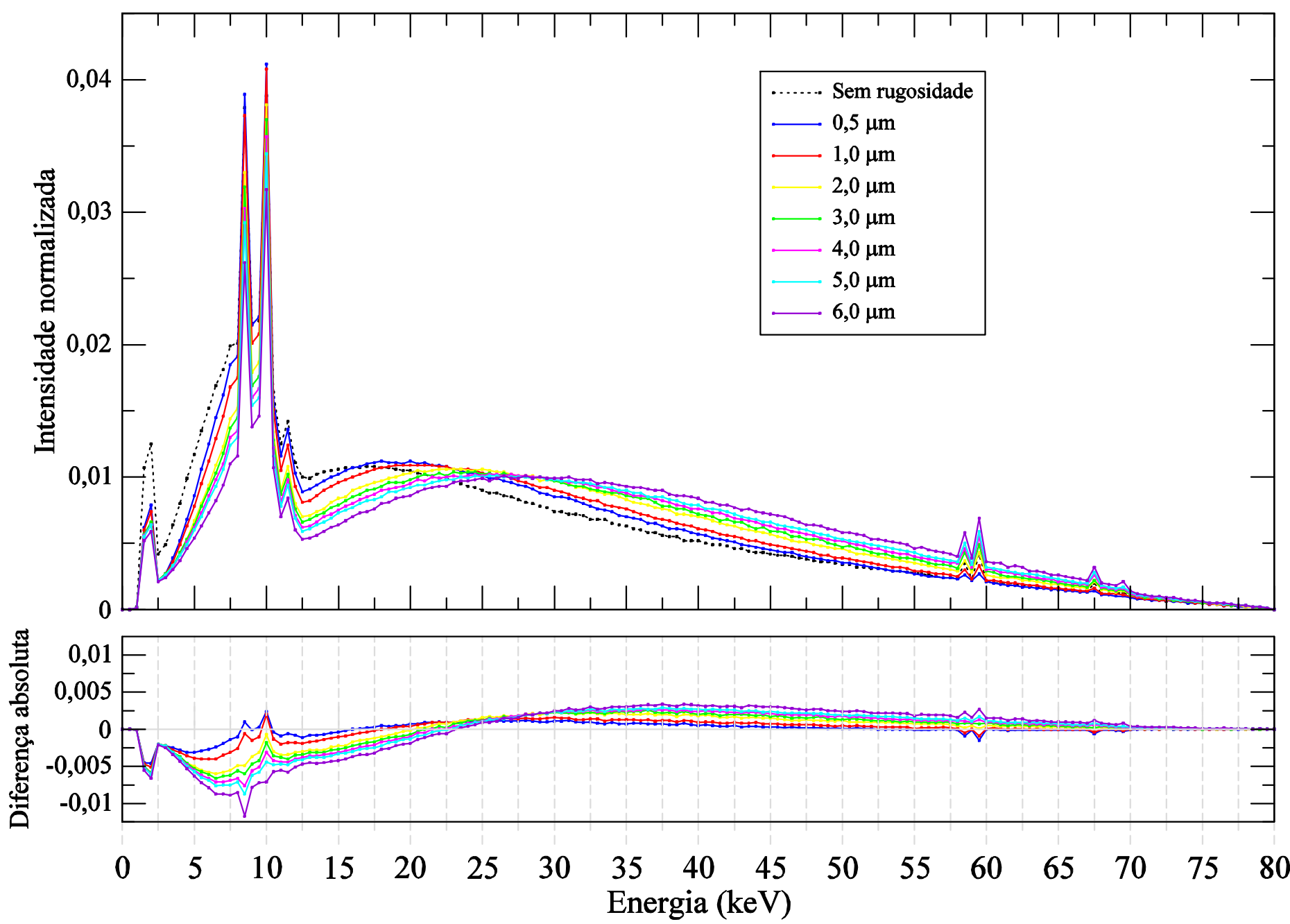

Figura 4.1-2 - Espectros de feixes de radiação X aplicado a uma tensão de 80 kV gerados pelo GEANT4 simulando tubos de raios X com ânodos apresentando rugosidade. 

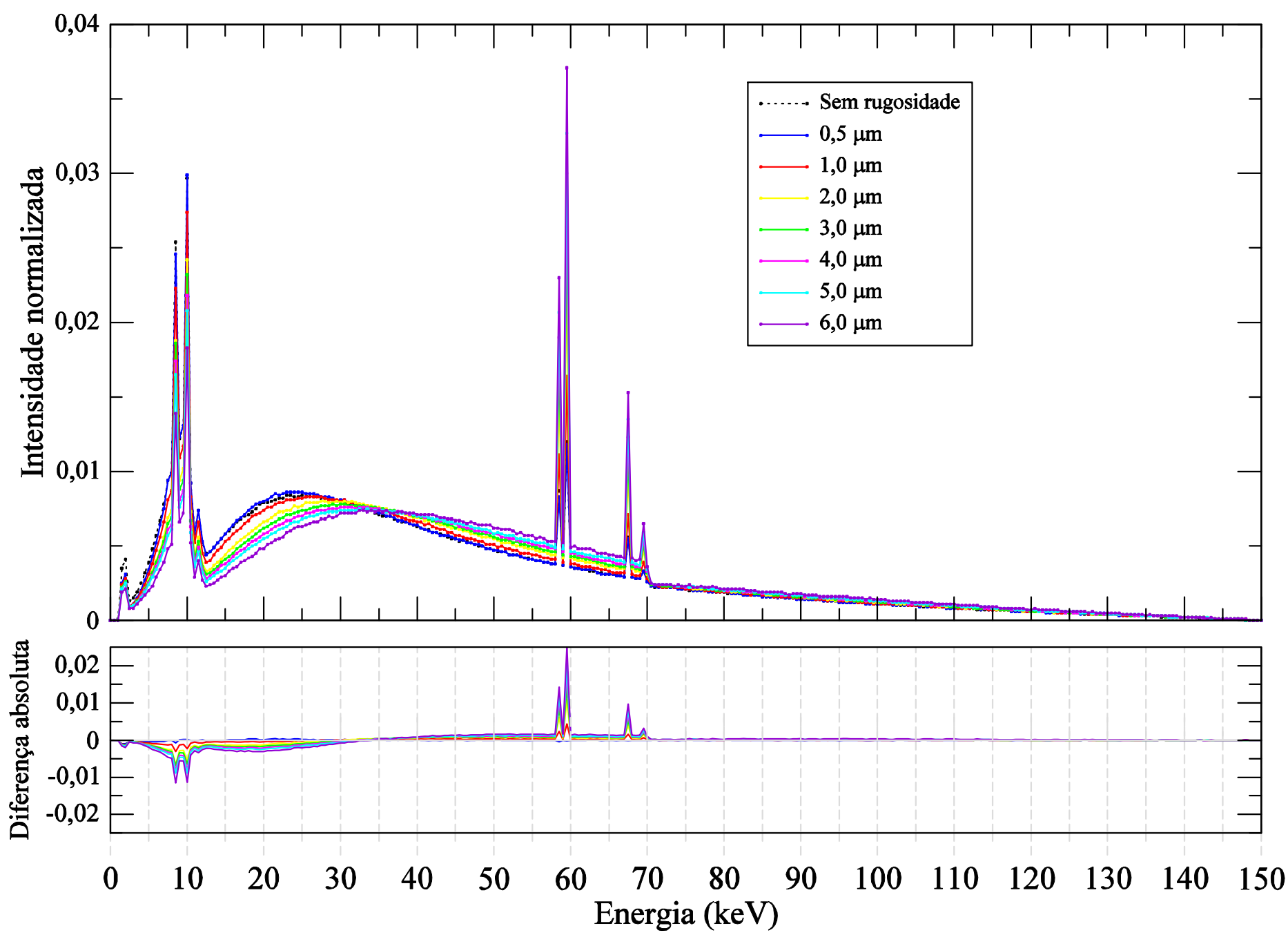

Figura 4.1-3 - Espectros de feixes de radiação X aplicado a uma tensão de $150 \mathrm{kV}$ gerados pelo GEANT4 simulando tubos de raios X com ânodos apresentando rugosidade. 
$\mathrm{O}$ efeito da rugosidade no ânodo do tubo de raios $\mathrm{X}$ foi evidenciado nos resultados das simulações dos espectros pelo GEANT4 com o "endurecimento" do espectro. No espectro de $40 \mathrm{kV}$ verifica-se que, na parte correspondente ao bremsstrahlung, para as energias mais altas do espectro, as intensidades aumentam quando a rugosidade aumenta. Para as energias mais baixas do espectro, o resultado é inverso: as intensidades diminuem para rugosidades mais altas. Isso ocorre porque os fótons de mais baixa energia sofrem maior atenuação do que os de mais alta energia. Este fato fica mais evidente nos espectros do tubo com tensão de $150 \mathrm{kV}$ : tanto nas partes contínuas dos espectros a partir de aproximadamente $32,5 \mathrm{keV}$ quanto nos picos característicos o aumento da rugosidade provoca o aumento nas intensidades das energias de seus correspondentes canais, enquanto para valores inferiores o resultado é o oposto. Esse efeito na distribuição espectral também foi verificado nos espectros normalizados gerados por Nowotny e Meighzifene (Nowotny \& Meghzifene, 2002).

\subsection{Espectros de raios $\mathrm{X}$ com filtração adicional}

A seguir, apresentam-se os cálculos dos seguintes parâmetros espectrais que descrevem a qualidade da radiação dos raios X: a caracterização da saída de radiação do tubo de raios X pela energia média e camada semi-redutora.

\subsubsection{Energia média}

A partir dos espectros simulados com o GEANT4 foram calculados os valores de suas respectivas energias médias (Tabela 4.2.1-1). 
Tabela 4.2.1-1 - Valores das energias médias dos espectros de raios X simulados com o GEANT4 para energias máximas de 40, 80 e $150 \mathrm{keV}$ em relação às variações das rugosidades dos ânodos de tubo de raios $X$.

\begin{tabular}{cccc}
\hline \hline & $\begin{array}{c}\text { Espectro de raios X de } \\
\mathbf{E}_{\mathbf{m a ́ x}}=\mathbf{4 0} \mathbf{~ k e V}\end{array}$ & $\begin{array}{c}\text { Espectro de raios X de } \\
\mathbf{E}_{\text {máx }}=\mathbf{8 0} \mathbf{~ k e V}\end{array}$ & $\begin{array}{c}\text { Espectro de raios X de } \\
\mathbf{E}_{\mathbf{m a ́ x}}=\mathbf{1 5 0} \mathbf{k e V}\end{array}$ \\
\hline Rugosidade $(\mu \mathrm{m})$ & Energia média $\langle E\rangle$ & Energia média $\langle E\rangle$ & Energia média $\langle E\rangle$ \\
& $(\mathrm{keV})$ & $(\mathrm{keV})$ & $(\mathrm{keV})$ \\
\hline 0,0 & $12,338(4)$ & $23,826(9)$ & $40,839(14)$ \\
0,5 & $13,775(6)$ & $24,722(9)$ & $40,969(15)$ \\
1,0 & $14,348(4)$ & $25,715(6)$ & $42,520(15)$ \\
2,0 & $14,936(6)$ & $27,523(12)$ & $44,528(15)$ \\
3,0 & $15,247(7)$ & $28,205(12)$ & $45,362(10)$ \\
4,0 & $15,422(8)$ & $28,985(8)$ & $46,351(11)$ \\
5,0 & $15,558(6)$ & $29,570(9)$ & $47,174(11)$ \\
6,0 & $15,647(6)$ & $30,952(12)$ & $49,002(15)$ \\
\hline \hline
\end{tabular}

Conforme o aumento da tensão aplicada ao tubo de raios $\mathrm{X}$ e com o crescimento da rugosidade o valor da energia média de seu correspondente espectro também aumenta.

Os cálculos dos valores das espessuras correspondentes à filtração de $\mathrm{W}$ foram efetuados a partir do espectro, com sua respectiva tensão de aceleração aplicada ao tubo e energia média de acordo com a Tabela 4.2.1-1, simulado sem a utilização do modelo de rugosidade (Figura 4.2.1-1). 


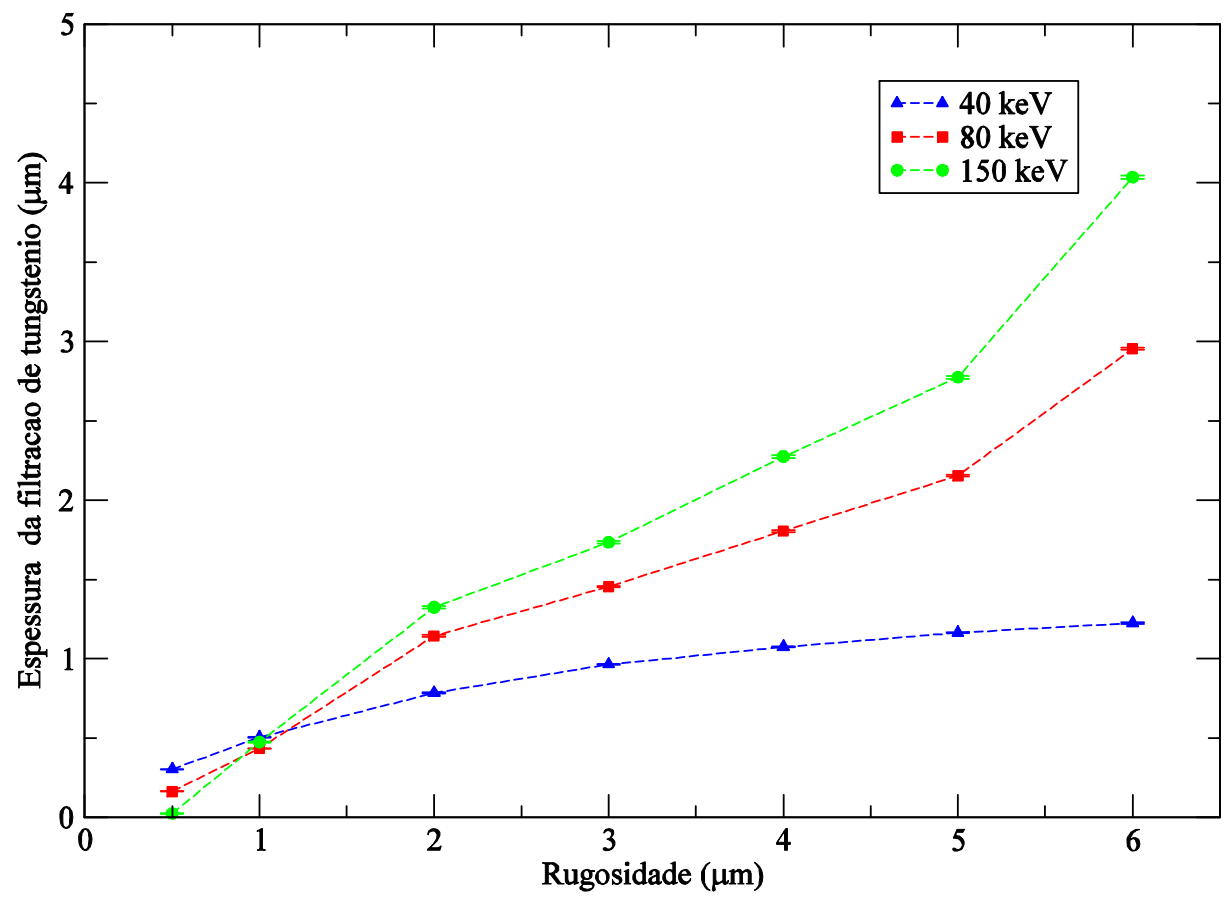

Figura 4.2.1-1 - Valores da espessura da filtração de W conforme as energias médias dos espectros de raios $X$ atenuados contidos na Tabela 4.2.1-1.

Pela Figura 4.2.1-1 é possível verificar o aumento da espessura da filtração de W com o aumento da rugosidade. A partir dos valores das espessuras calculadas da filtração de W, foram gerados os espectros da Figura 4.2.1-2 a Figura 4.2.1-4. Cabe ressaltar que as espessuras de filtração calculadas têm valores muito superiores àquelas devidas à deposição de tungstênio na janela do tubo (Stears, Felmlee, \& Gray, 1986) (Nagel, 1988). 

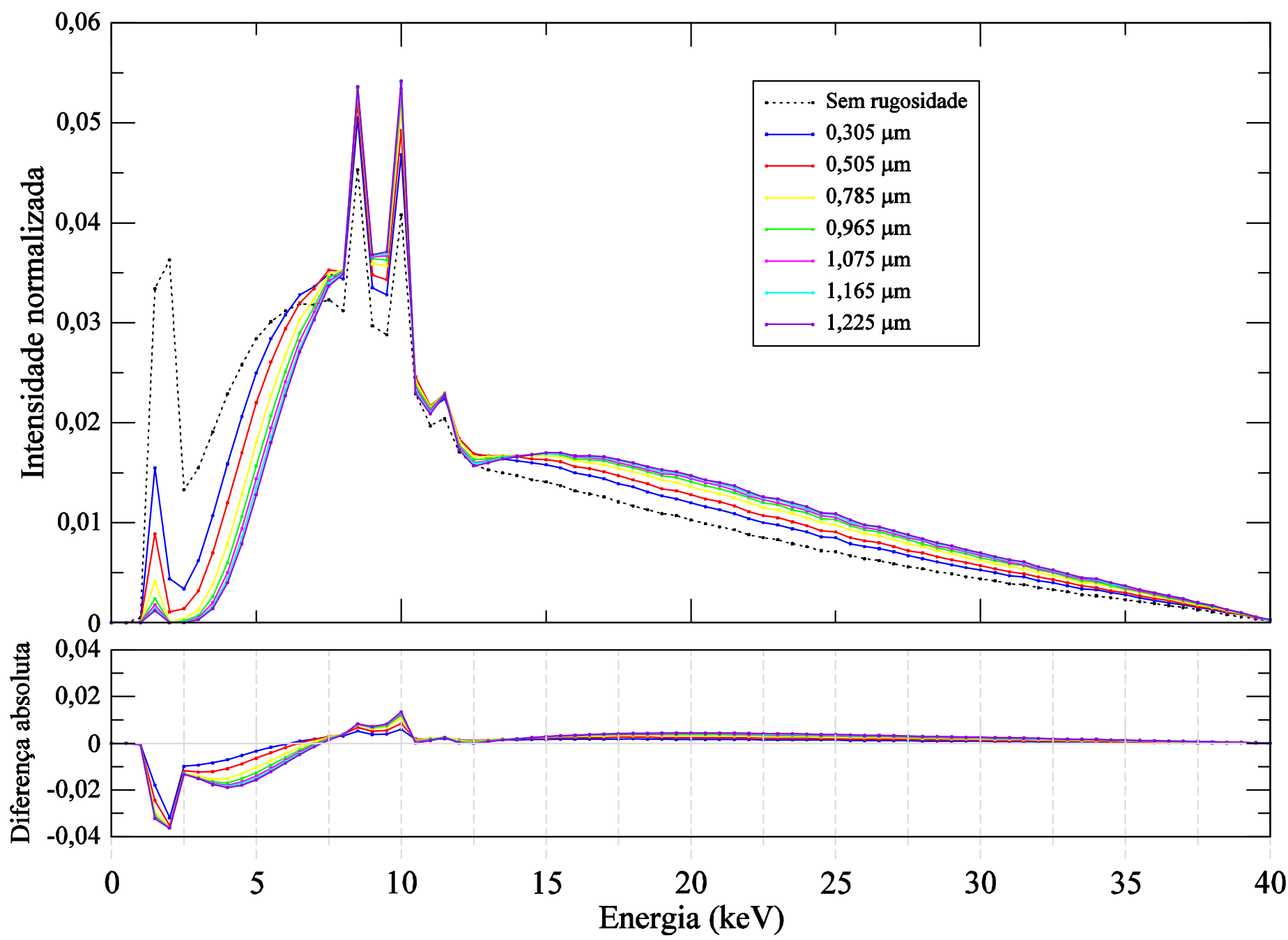

Figura 4.2.1-2 - Espectros de feixes de radiação X aplicado a uma tensão de $40 \mathrm{kV}$ atenuados com filtração de W. 

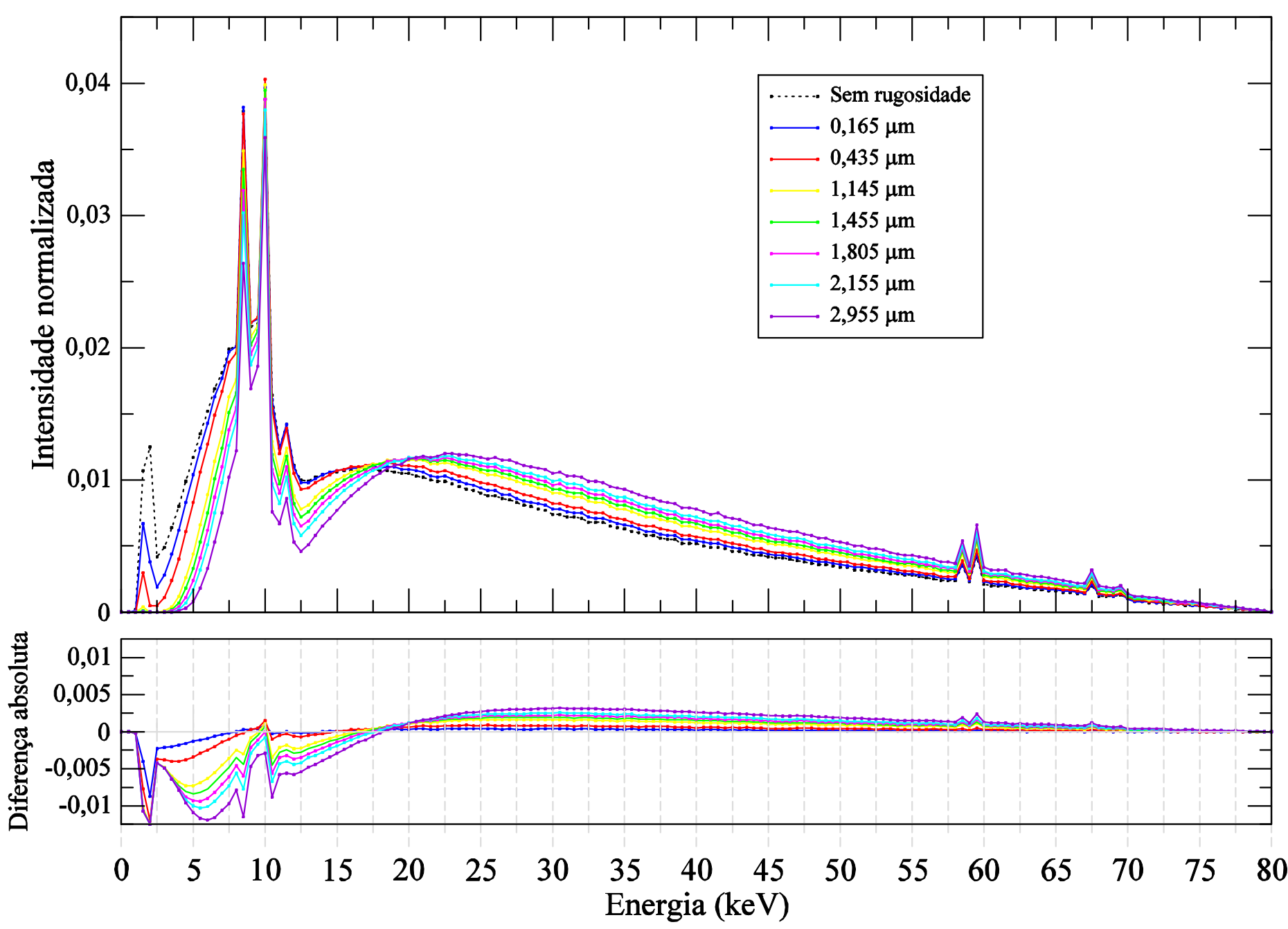

Figura 4.2.1-3 - Espectros de feixes de radiação X aplicado a uma tensão de $80 \mathrm{kV}$ atenuados com filtração de $W$. 

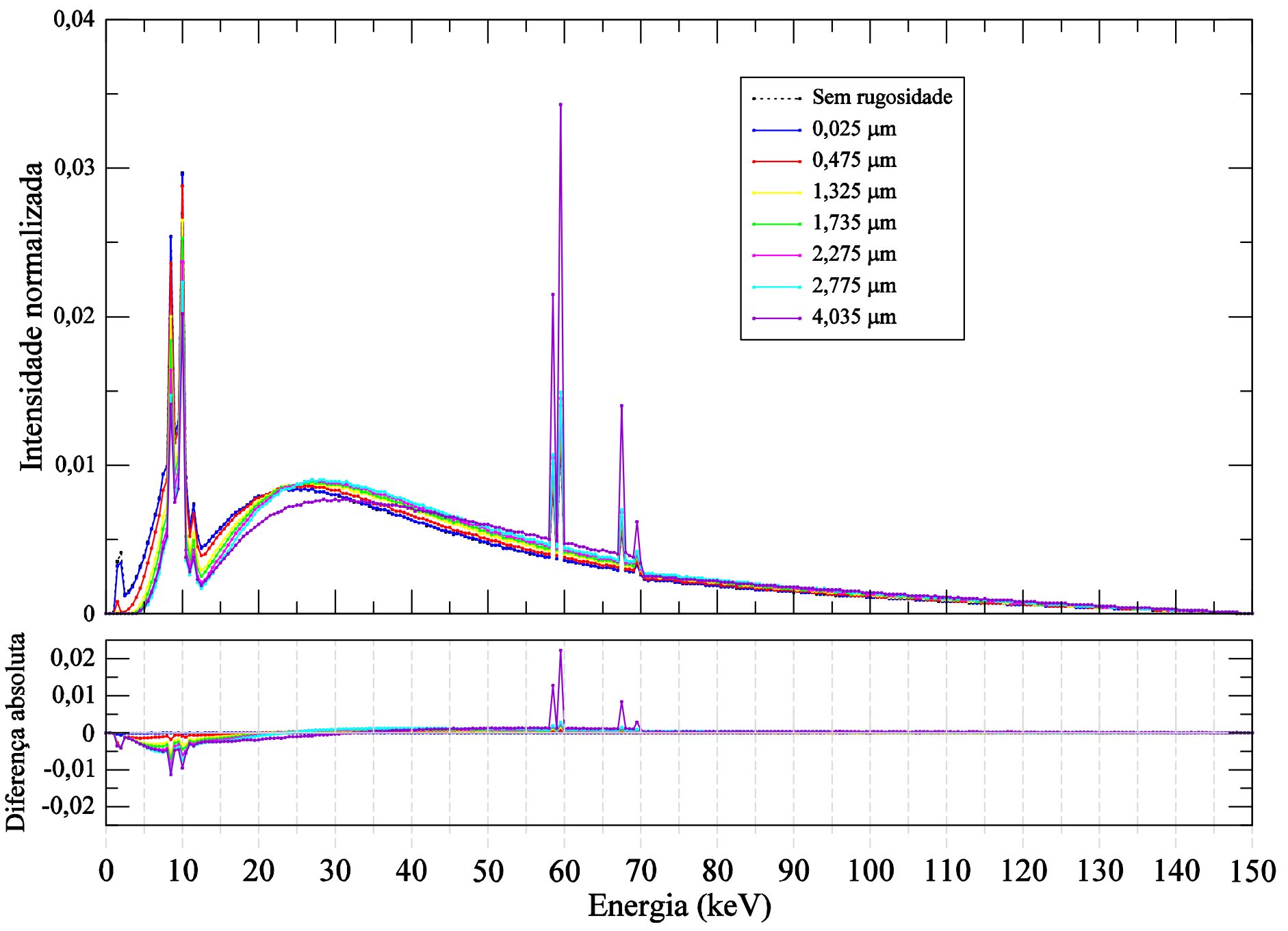

Figura 4.2.1-4 - Espectros de feixes de radiação X aplicado a uma tensão de $150 \mathrm{kV}$ atenuados com filtração de W. 
Qualitativamente, pode-se perceber nas energias mais baixas do espectro uma diferença entre os espectros com rugosidade e com filtração adicional. No entanto, para um melhor detalhamento, foi realizado uma comparação entre o espectro com rugosidade e o filtrado para um determinado valor de rugosidade.

\subsubsection{Comparação entre espectros com rugosidade e filtrados}

Foram realizadas comparações entre o espectro gerado por meio de simulação e o espectro simulado sem rugosidade anódica atenuado com filtração de W, ambos os espectros com o mesmo valor de energia média. As figuras 4.2.1.1-1 a 4.2.1.1-3 apresentam os espectros simulados com rugosidade de $6,0 \mu \mathrm{m}$ e os correspondentes espectros com filtração. Nestas comparações foram utilizadas, para os espectros simulados, este valor de rugosidade devido à situação ser mais extrema para o caso do envelhecimento do tubo de raios X utilizado nestas avaliações. A diferença absoluta abaixo do gráfico corresponde ao valor da intensidade da energia do espectro atenuado subtraído do espectro simulado com o GEANT4.

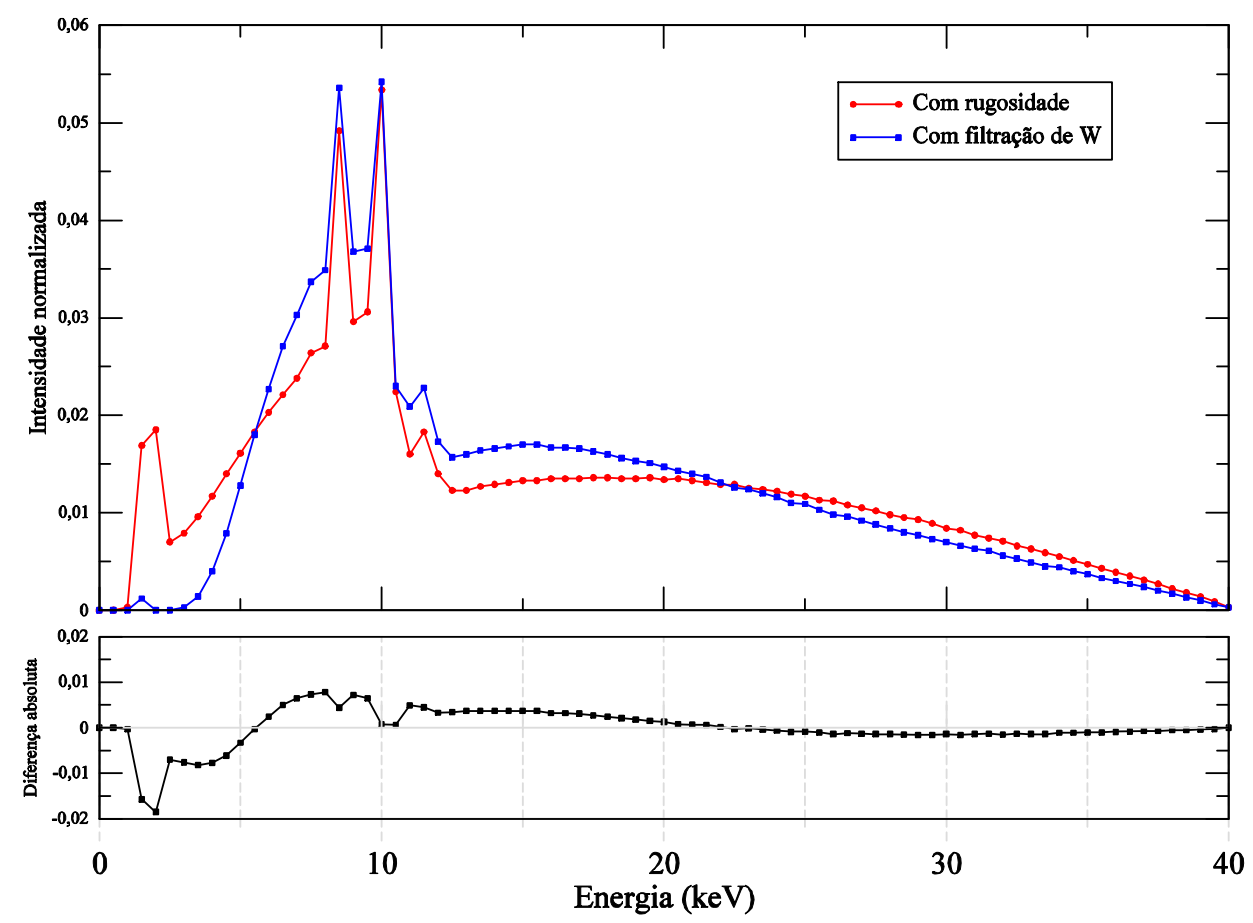

Figura 4.2.1.1-1 - Espectros de raios X com energia máxima de $40 \mathrm{keV}$ simulado com ânodo com 6,0 $\mu \mathrm{m}$ de rugosidade e atenuado com 1,225 $\mu \mathrm{m}$ de filtração de W. Ambos com o mesmo valor de energia média. 


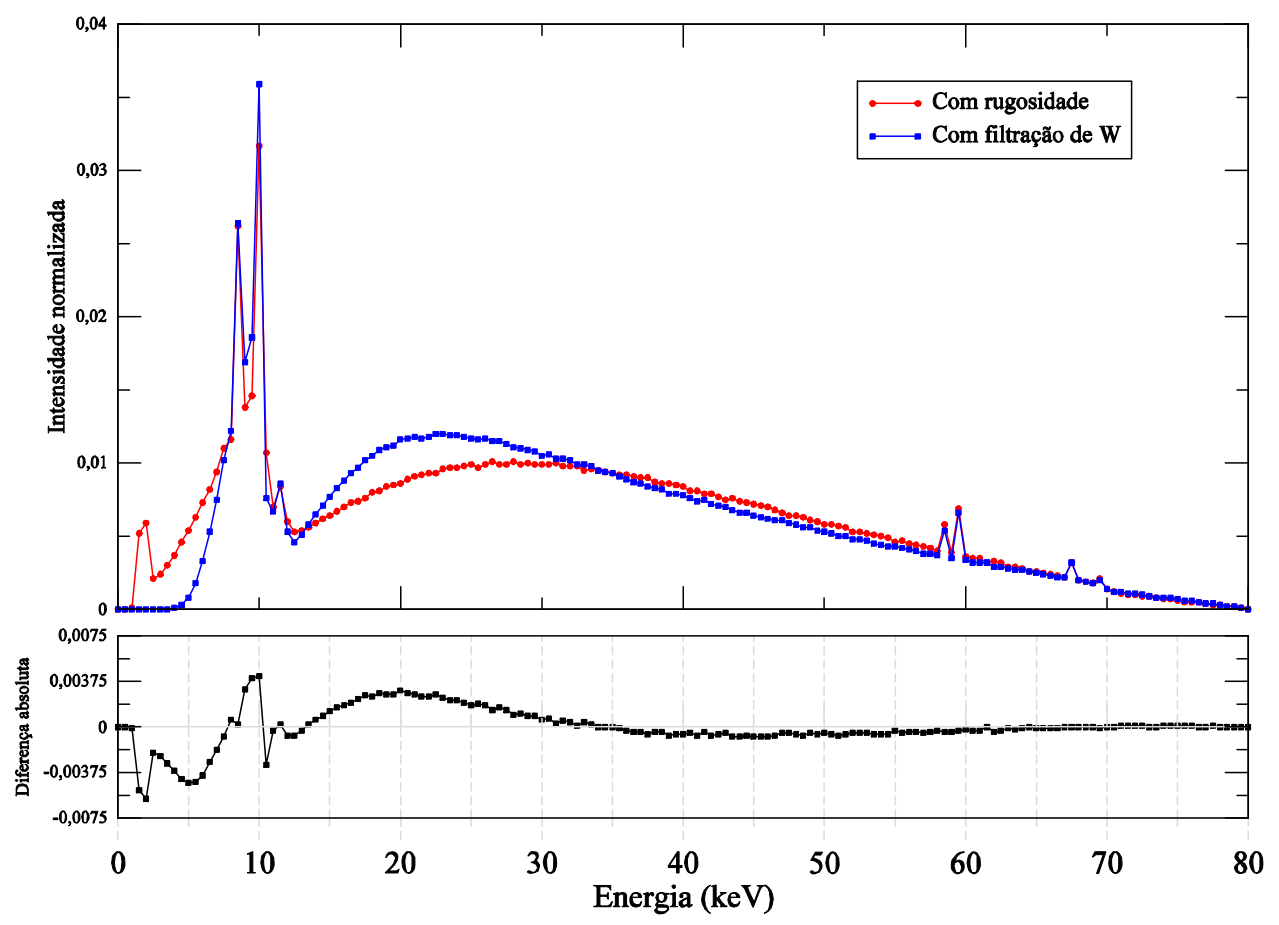

Figura 4.2.1.1-2 - Espectros de raios X com energia máxima de $80 \mathrm{keV}$ simulado com ânodo com 6,0 $\mu \mathrm{m}$ de rugosidade e atenuado com $2,995 \mu \mathrm{m}$ de filtração de $W$. Ambos com o mesmo valor de energia média.

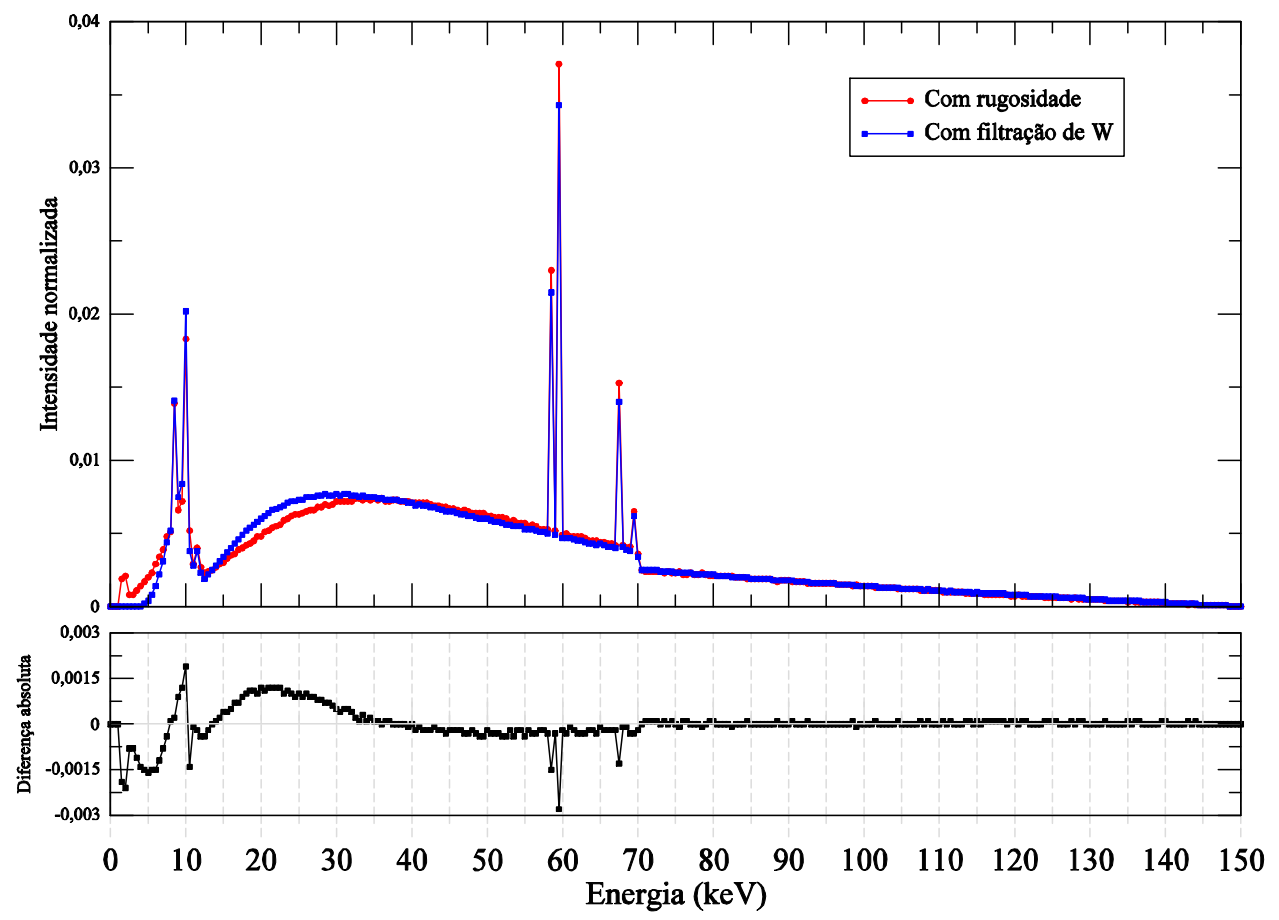

Figura 4.2.1.1-3 - Espectros de raios X com energia máxima de $150 \mathrm{keV}$ simulado com ânodo com 6,0 $\mu m$ de rugosidade e atenuado com 4,035 $\mu \mathrm{m}$ de filtração de W. Ambos com o mesmo valor de energia média. 
Verifica-se que nos espectros simulados com o GEANT4, com o aumento da rugosidade as formas das distribuições espectrais se alteram pouco, diminuindo a parte correspondente às energias mais baixas do bremsstrahlung e aumentando os picos característicos do espectro. Nos espectros com filtração de W verifica-se que a forma espectral é alterada de maneira distinta: para as energias mais baixas dos espectros a atenuação é quase total, obedecendo os valores dos coeficientes de atenuação de massa $\frac{\mu}{\rho}$ que são maiores para as energias mais baixas do espectro (Figura 4.2.1.1-4).

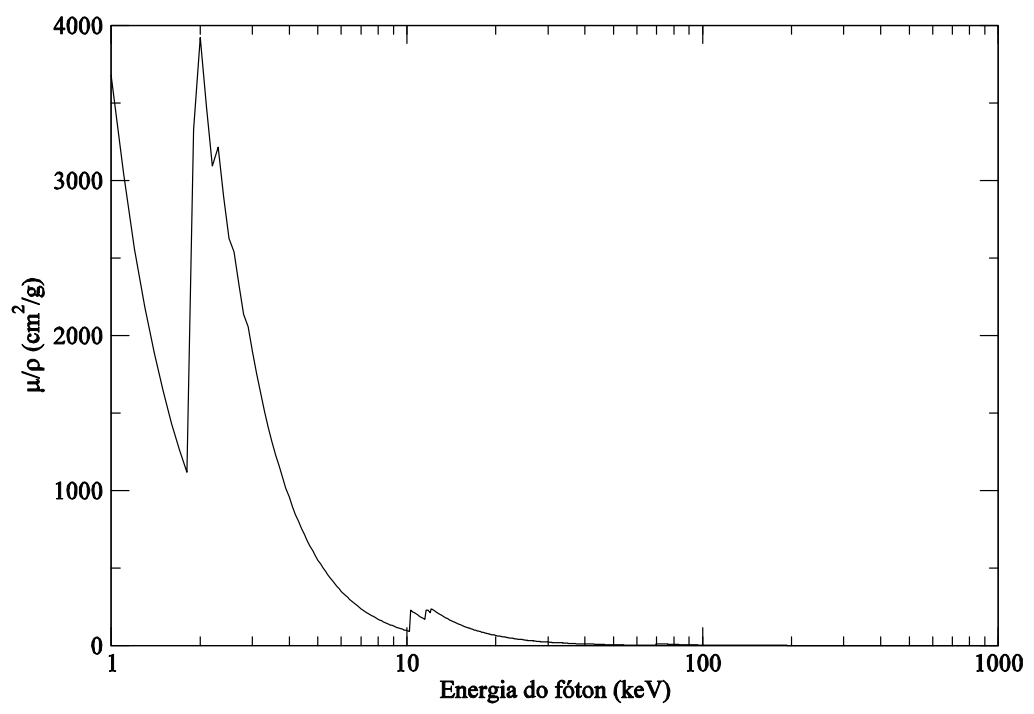

Figura 4.2.1.1-4 - Valores dos coeficientes de atenuação de massa $\frac{\mu}{\rho}$ em função da energia do fóton para o elemento tungstênio.

Conforme Tabela 4.2.1.1-1, foi realizada uma análise estatística dos espectros das figuras 4.2.1.1-1 a 4.2.1.1-3, na qual foi calculado o desvio padrão da diferença média absoluta e o desvio padrão estatístico das mesmas. As contagens dos dados dos espectros $C=C_{0}=C_{1}$ são referentes às contagens do espectro com rugosidade e do espectro atenuado com filtração equivalente em tungstênio. 
Tabela 4.2.1.1-1 - Valores do desvio padrão estatístico $\sigma_{\text {est }}$ referente às contagens $C$ e valores do desvio padrão da diferença média absoluta $\sigma_{<D>}$ referente a $<D>$ dos espectros correspondentes.

\begin{tabular}{c|cc|cc}
\hline $\begin{array}{c}\text { Espectros } \\
\text { correspondentes }\end{array}$ & $\boldsymbol{C}\left(\mathrm{x} 10^{6}\right)$ & $\langle\boldsymbol{D}\rangle$ & $\boldsymbol{\sigma}_{\text {est }}\left(\mathrm{x} 10^{-4}\right)$ & $\boldsymbol{\sigma}_{\langle\boldsymbol{D}\rangle}\left(\mathrm{x} 10^{-4}\right)$ \\
\hline Figura 4.2.1.1-1 & 2,1 & 0 & 4,9 & 42,0 \\
Figura 4.2.1.1-2 & 2,1 & 0 & 4,9 & 16,0 \\
Figura 4.2.1.1-3 & 3,6 & 0 & 3,7 & 5,0 \\
\hline \hline
\end{tabular}

Cabe ressaltar que os valores de $\langle D\rangle$ são nulos porque se referem à diferença de dois espectros normalizados. Pela Tabela 4.2.1.1-1 verifica-se que $\sigma_{\langle D\rangle}>\sigma_{\text {est }}$, ou seja, a dispersão apresentada nos espectros não correspondem a flutuações estatísticas. Isto demonstra que os espectros simulados com ânodo com rugosidade de 6,0 $\mu \mathrm{m}$ não são equivalentes aos espectros atenuados com filtração de W. A dispersão é maior nos espectros correspondentes às tensões mais baixas $(40 \mathrm{kV})$ e é menor para os espectros com tensões mais altas $(150 \mathrm{kV})$.

\subsubsection{Energia média com adição de filtração de $\mathrm{Al}$}

O espectro com energia máxima de $80 \mathrm{keV}$ foi atenuado com filtração de $2,5 \mathrm{~mm}$ de Al e calculou-se a energia média (Tabela 4.2.1.2-1). Com esses valores de energia média foram calculadas as variações de energia média $(\Delta\langle\mathrm{E}\rangle)$ (4.2.1.2.1) e comparadas com os resultados obtidos por Nowotny e Meighzifene (Nowotny \& Meghzifene, 2002) (Tabela 4.2.1.2-2).

$$
\Delta\langle E\rangle=\langle E\rangle_{\text {com rugosidade }}-\langle E\rangle_{\text {sem rugosidade }}
$$


Tabela 4.2.1.2-1 - Valores das energias médias do espectro de raios X simulado com o GEANT4 para energia de $80 \mathrm{keV}$ atenuado com filtração de $2,5 \mathrm{~mm} \mathrm{Al}$.

\begin{tabular}{cc}
\hline \hline & $\begin{array}{c}\text { Espectro de raios X de } \\
\mathbf{E}_{\text {máx }}=\mathbf{8 0} \mathbf{~ k e V}\end{array}$ \\
\hline Rugosidade $(\mu \mathrm{m})$ & Energia média $\langle E\rangle(\mathrm{keV})$ \\
\hline 0,0 & $42,844(14)$ \\
0,5 & $41,972(14)$ \\
1,0 & $42,254(9)$ \\
2,0 & $42,867(16)$ \\
3,0 & $43,236(16)$ \\
4,0 & $43,592(10)$ \\
5,0 & $43,891(11)$ \\
6,0 & $44,428(14)$ \\
\hline
\end{tabular}

Tabela 4.2.1.2-2 - $\Delta(E)$ referente à diferença da energia média entre espectros de raios X de $80 \mathrm{kV}:$ (a) simulados com ânodo com rugosidade e sem rugosidade; (b) calculados com ânodo com rugosidade média e sem rugosidade (ângulo do ânodo $16^{\circ}, 2,5 \mathrm{~mm}$ Al, distância de $1 \mathrm{~m}$ ).

\begin{tabular}{cc|cc}
\hline \hline \multicolumn{2}{c|}{ (a) Simulado com GEANT4 } & \multicolumn{2}{c}{ (b) Nowotny e Meighzifene } \\
\hline $\begin{array}{c}\text { Rugosidade } \\
(\mu \mathrm{m})\end{array}$ & $\begin{array}{c}\Delta(\mathrm{E}\rangle \\
(\mathrm{keV})\end{array}$ & $\begin{array}{c}\text { Rugosidade } \\
\text { média }(\mu \mathrm{m})\end{array}$ & $\begin{array}{c}\Delta\langle\mathrm{E}\rangle(\mathrm{keV}) \\
\left(\text { valores }_{\text {aproximados }}{ }^{10}\right)\end{array}$ \\
\hline 0,5 & $-0,87(2)$ & --- & --- \\
1,0 & $-0,58(2)$ & 1,32 & 0,1 \\
2,0 & $0,02(2)$ & 2,05 & 0,3 \\
3,0 & $0,39(2)$ & --- & --- \\
4,0 & $0,75(2)$ & 3,81 & 0,7 \\
5,0 & $1,05(2)$ & 5,22 & 1,0 \\
6,0 & $1,58(2)$ & --- & --- \\
\hline \hline
\end{tabular}

Observa-se que os valores para a $\Delta\langle\mathrm{E}\rangle$ referente às rugosidades de 4,0 e 5,0 $\mu \mathrm{m}$ são próximas aos valores obtidos por Nowotny e Meighzifene. No trabalho de Nowotny e Meighzifene (Nowotny \& Meghzifene, 2002), os resultados de $\Delta\langle E\rangle$ para rugosidades

\footnotetext{
${ }^{10}$ Valores aproximados obtidos da figura 8 (a) do trabalho publicado por Nowotny e Meighzifene (Nowotny \& Meghzifene, 2002)
} 
menores apresentaram grandes flutuações, provavelmente devido a isso, esses resultados diferiram com os obtidos nesta avaliação.

A Figura 4.2.1.2-1 apresenta a comparação entre o espectro de raios X de ânodos com rugosidade de 5,0 $\mu \mathrm{m}$ e sem rugosidade com a adição de filtração inerente equivalente a $2,5 \mathrm{~mm}$ de $\mathrm{Al}$.

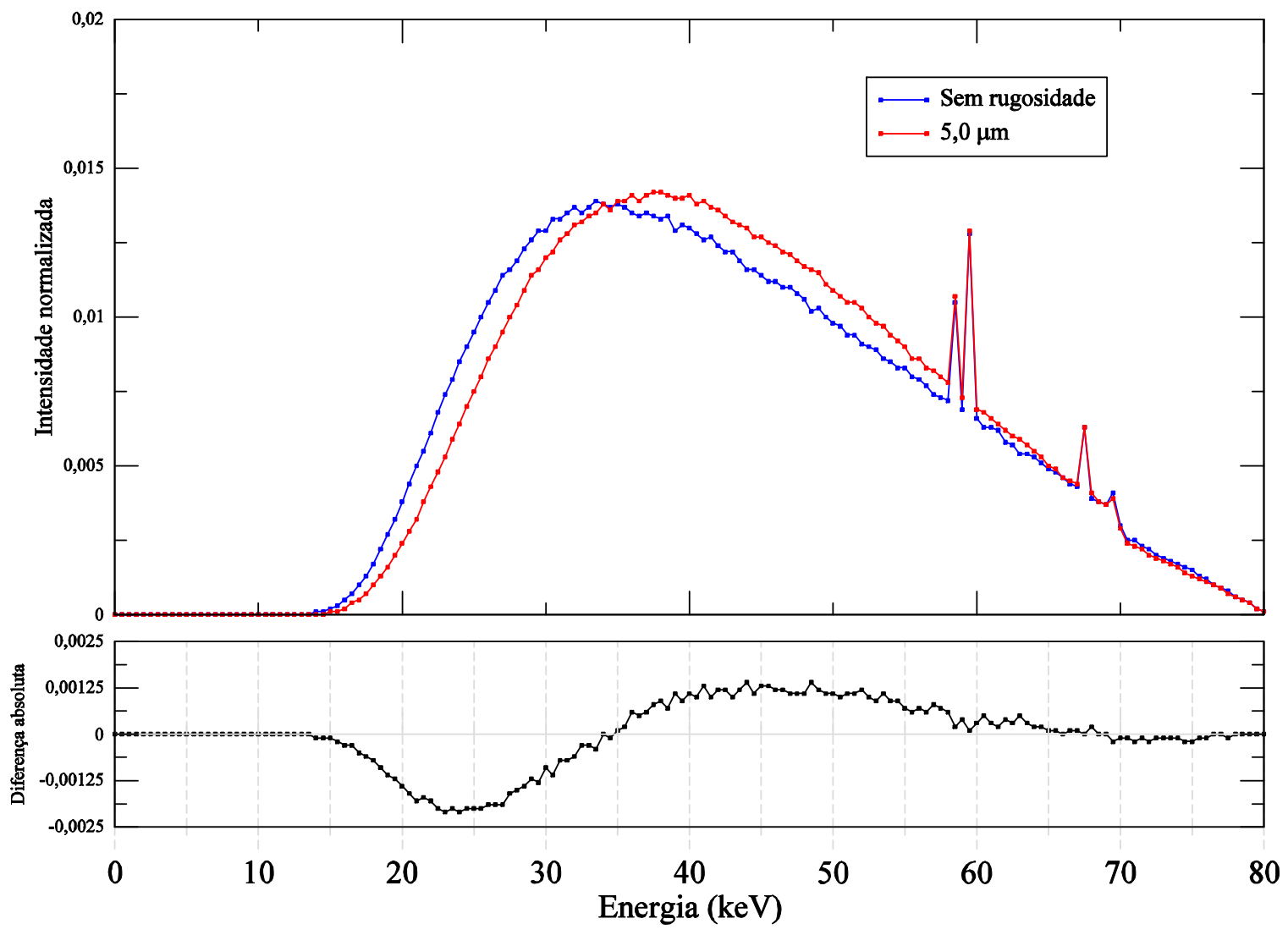

Figura 4.2.1.2-1 - Espectros de feixes de radiação X obtidos com uma tensão de $80 \mathrm{kV}$ e atenuados com filtração inerente de $2,5 \mathrm{~mm} \mathrm{de} \mathrm{Al}$.

A Figura 4.2.1.2-1 demonstra o "endurecimento" do espectro com o aumento da rugosidade. Nos estudos realizados por Nowotny e Meighzifene (Nowotny \& Meghzifene, 2002) este fato também é demonstrado. 


\subsubsection{Camada semi-redutora}

Foram realizados os cálculos da primeira (Tabela 4.2.2-1 a Tabela 4.2.2-3) e segunda (Tabela 4.2.2-4 a Tabela 4.2.2-6) camada semi-redutora para os espectros simulados com o GEANT4 (Figura 4.1-1 a Figura 4.1-3) e para os espectros com filtração de W (Figura 4.2.1-2 a Figura 4.2.1-4). Para os cálculos das camadas semi-redutoras os feixes de radiação $X$ foram atenuados com filtração de $2,5 \mathrm{~mm}$ de $\mathrm{Al}$ para efeito de comparação com os estudos realizados por Nowotny e Meighzifene (Nowotny \& Meghzifene, 2002).

Tabela 4.2.2-1 - Valores da primeira CSR para espectros de $40 \mathrm{kV}$.

\begin{tabular}{cc|cc}
\hline \hline \multicolumn{2}{c|}{ Com rugosidade } & \multicolumn{2}{c}{ Com filtração de W } \\
\hline Rugosidade $(\mu \mathrm{m})$ & $1^{\mathrm{a}}$. CSR $(\mathrm{mm}$ de Al) & Filtração $(\mu \mathrm{m})$ & $1^{\mathrm{a}}$. CSR $(\mathrm{mm}$ de Al) \\
\hline 0,0 & $1,353(66)$ & --- & -- \\
0,5 & $1,370(66)$ & $0,305(1)$ & $1,364(66)$ \\
1,0 & $1,402(67)$ & $0,505(2)$ & $1,371(66)$ \\
2,0 & $1,444(68)$ & $0,785(3)$ & $1,383(67)$ \\
3,0 & $1,470(69)$ & $0,965(3)$ & $1,388(67)$ \\
4,0 & $1,488(69)$ & $1,075(3)$ & $1,393(67)$ \\
5,0 & $1,499(70)$ & $1,165(3)$ & $1,396(67)$ \\
6,0 & $1,510(70)$ & $1,225(4)$ & $1,398(67)$ \\
\hline \hline
\end{tabular}


Tabela 4.2.2-2 - Valores da primeira CSR para espectros de $80 \mathrm{kV}$.

\begin{tabular}{cc|cc}
\hline \hline \multicolumn{2}{c|}{ Com rugosidade } & \multicolumn{2}{c}{ Com filtração de W } \\
\hline Rugosidade $(\mu \mathrm{m})$ & $1^{\mathrm{a}}$. CSR $(\mathrm{mm} \mathrm{de} \mathrm{Al})$ & Filtração $(\mu \mathrm{m})$ & $1^{\mathrm{a}}$. CSR $(\mathrm{mm} \mathrm{de} \mathrm{Al})$ \\
\hline 0,0 & $2,62(18)$ & --- & --- \\
0,5 & $2,56(18)$ & $0,165(2)$ & $2,63(19)$ \\
1,0 & $2,64(18)$ & $0,435(2)$ & $2,66(19)$ \\
2,0 & $2,79(19)$ & $1,145(5)$ & $2,72(19)$ \\
3,0 & $2,88(19)$ & $1,455(5)$ & $2,75(19)$ \\
4,0 & $2,96(19)$ & $1,805(5)$ & $2,78(19)$ \\
5,0 & $3,03(19)$ & $2,155(6)$ & $2,81(19)$ \\
6,0 & $3,17(20)$ & $2,955(7)$ & $2,88(19)$ \\
\hline \hline
\end{tabular}

Tabela 4.2.2-3 - Valores da primeira CSR para espectros de $150 \mathrm{kV}$.

\begin{tabular}{cc|cc}
\hline \hline \multicolumn{2}{c|}{ Com rugosidade } & \multicolumn{2}{c}{ Com filtração de W } \\
\hline Rugosidade $(\mu \mathrm{m})$ & $1^{\mathrm{a}}$. CSR $(\mathrm{mm}$ de Al) & Filtração $(\mu \mathrm{m})$ & $1^{\mathrm{a}}$. CSR $(\mathrm{mm}$ de Al) \\
\hline 0,0 & $4,38(31)$ & --- & -- \\
0,5 & $4,34(31)$ & $0,025(3)$ & $4,39(31)$ \\
1,0 & $4,53(31)$ & $0,475(5)$ & $4,44(31)$ \\
2,0 & $4,79(31)$ & $1,325(7)$ & $4,55(32)$ \\
3,0 & $4,94(32)$ & $1,735(8)$ & $4,61(32)$ \\
4,0 & $5,10(32)$ & $2,275(9)$ & $4,67(32)$ \\
5,0 & $5,24(32)$ & $2,775(9)$ & $4,74(32)$ \\
6,0 & $5,50(32)$ & $4,035(11)$ & $4,89(32)$ \\
\hline \hline
\end{tabular}

Pode-se verificar que aumenta a diferença da primeira CSR entre os espectros simulados com o GEANT4 e os espectros atenuados com filtração de W de acordo com o crescimento da rugosidade. Como o espectro de referência utilizado para a realização da atenuação é o espectro simulado sem rugosidade, para rugosidade menos elevadas a primeira CSR dos espectros com rugosidade e com filtração são equivalentes.

A camada semi-redutora pode ser um bom parâmetro para especificar a qualidade dos feixes de raios $\mathrm{X}$, no entanto, uma mesma CSR pode ser obtida para feixes que não 
possuam as mesmas características espectrais. Devido a este fato, foi realizada a avaliação da segunda CSR para uma melhor especificação da qualidade do feixe de raios X.

Tabela 4.2.2-4 - Valores da segunda CSR para espectros de $40 \mathrm{kV}$.

\begin{tabular}{cc|cc}
\hline \hline \multicolumn{2}{c|}{ Com rugosidade } & \multicolumn{2}{c}{ Com filtração de W } \\
\hline Rugosidade $(\mu \mathrm{m})$ & $2^{\mathrm{a}}$. CSR $(\mathrm{mm}$ de Al) & Filtração $(\mu \mathrm{m})$ & $2^{\mathrm{a}}$. CSR $(\mathrm{mm}$ de Al) \\
\hline 0,0 & $1,692(73)$ & --- & -- \\
0,5 & $1,698(73)$ & $0,305(1)$ & $1,702(73)$ \\
1,0 & $1,732(74)$ & $0,505(2)$ & $1,709(74)$ \\
2,0 & $1,779(75)$ & $0,785(3)$ & $1,721(74)$ \\
3,0 & $1,808(76)$ & $0,965(3)$ & $1,725(74)$ \\
4,0 & $1,829(76)$ & $1,075(3)$ & $1,731(74)$ \\
5,0 & $1,841(76)$ & $1,165(3)$ & $1,733(74)$ \\
6,0 & $1,855(77)$ & $1,225(4)$ & $1,735(74)$ \\
\hline \hline
\end{tabular}

Tabela 4.2.2-5 - Valores da segunda CSR para espectros de $80 \mathrm{kV}$.

\begin{tabular}{cc|cc}
\hline \hline \multicolumn{2}{c|}{ Com rugosidade } & \multicolumn{2}{c}{ Com filtração de W } \\
\hline Rugosidade $(\mu \mathrm{m})$ & $2^{\mathrm{a}}$. CSR $(\mathrm{mm}$ de Al) & Filtração $(\mu \mathrm{m})$ & $2^{\mathrm{a}}$. CSR $(\mathrm{mm} \mathrm{de} \mathrm{Al})$ \\
\hline 0,0 & $3,99(21)$ & --- & -- \\
0,5 & $3,82(21)$ & $0,165(2)$ & $4,01(21)$ \\
1,0 & $3,91(21)$ & $0,435(2)$ & $4,04(21)$ \\
2,0 & $4,10(21)$ & $1,145(5)$ & $4,10(21)$ \\
3,0 & $4,21(21)$ & $1,455(5)$ & $4,13(22)$ \\
4,0 & $4,32(21)$ & $1,805(5)$ & $4,17(22)$ \\
5,0 & $4,41(22)$ & $2,155(6)$ & $4,20(22)$ \\
6,0 & $4,58(22)$ & $2,955(7)$ & $4,27(22)$ \\
\hline \hline
\end{tabular}


Tabela 4.2.2-6 - Valores da segunda CSR para espectros de $150 \mathrm{kV}$.

\begin{tabular}{cc|cc}
\hline \hline \multicolumn{2}{c|}{ Com rugosidade } & \multicolumn{2}{c}{ Com filtração de W } \\
\hline Rugosidade $(\mu \mathrm{m})$ & $2^{\mathrm{a}}$. CSR $(\mathrm{mm} \mathrm{de} \mathrm{Al)}$ & Filtração $(\mu \mathrm{m})$ & $2^{\mathrm{a}}$. CSR $(\mathrm{mm}$ de Al) \\
\hline 0,0 & $7,37(35)$ & --- & --- \\
0,5 & $7,33(35)$ & $0,025(3)$ & $7,38(35)$ \\
1,0 & $7,50(35)$ & $0,475(5)$ & $7,42(35)$ \\
2,0 & $7,72(35)$ & $1,325(7)$ & $7,53(35)$ \\
3,0 & $7,85(35)$ & $1,735(8)$ & $7,59(36)$ \\
4,0 & $8,00(35)$ & $2,275(9)$ & $7,63(36)$ \\
5,0 & $8,12(35)$ & $2,775(9)$ & $7,70(36)$ \\
6,0 & $8,34(35)$ & $4,035(11)$ & $7,83(36)$ \\
\hline \hline
\end{tabular}

$\mathrm{Na}$ análise da segunda CSR pode-se perceber um comportamento semelhante ao ocorrido na avaliação da primeira CSR.

Para espectros de raios $\mathrm{X}$ com tensão aplicada de $80 \mathrm{kV}$ simulados com rugosidade e com filtração equivalente em tungstênio foram calculadas as suas respectivas variações da camada semi-redutora $(\Delta \mathrm{CSR})$ (4.2.2.1) e comparadas com os resultados obtidos por Nowotny e Meighzifene (Nowotny \& Meghzifene, 2002) (Tabela 4.2.2-7).

$$
\Delta C S R=C S R_{\text {com rugosidade }}-C_{S} R_{\text {sem rugosidade }}
$$


Tabela 4.2.2-7 -4CSR referente à diferença da primeira camada semi-redutora entre espectros de raios $X$ de $80 \mathrm{kV}$ : (a) simulados com ânodo com rugosidade e sem rugosidade; (b) atenuados com filtração equivalente de W e sem filtração; (c) calculados com ânodo com rugosidade média e sem rugosidade (ângulo do ânodo $16^{\circ}, 2,5 \mathrm{~mm} \mathrm{Al}$, distância de $1 \mathrm{~m}$ ).

\begin{tabular}{cc|cc|cc}
\hline \hline \multicolumn{2}{c|}{ (a) Com rugosidade } & \multicolumn{2}{c|}{ (b) Com filtração de W } & \multicolumn{2}{c}{ (c) Nowotny e Meighzifene } \\
\hline $\begin{array}{c}\text { Rugosidade } \\
(\mu \mathrm{m})\end{array}$ & $\begin{array}{c}\Delta \mathrm{CSR} \\
(\mathrm{mm} \mathrm{de} \mathrm{Al})\end{array}$ & $\begin{array}{c}\text { Filtração } \\
(\mu \mathrm{m})\end{array}$ & $\begin{array}{c}\Delta \mathrm{CSR} \\
(\mathrm{mm} \text { de Al })\end{array}$ & $\begin{array}{c}\text { Rugosidade } \\
\text { média }(\mu \mathrm{m})\end{array}$ & $\begin{array}{c}\Delta \mathrm{CSR}(\mathrm{mm} \text { de Al) } \\
(\text { valores aproximados) }\end{array}$ \\
\hline 0,5 & $-0,060(65)$ & $0,025(3)$ & $0,015(69)$ & --- & --- \\
1,0 & $0,017(66)$ & $0,475(5)$ & $0,039(69)$ & 1,32 & 0,031 \\
2,0 & $0,171(68)$ & $1,325(7)$ & $0,102(69)$ & 2,05 & 0,069 \\
3,0 & $0,259(69)$ & $1,735(8)$ & $0,130(70)$ & --- & --- \\
4,0 & $0,341(70)$ & $2,275(9)$ & $0,160(70)$ & 3,81 & 0,128 \\
5,0 & $0,411(71)$ & $2,775(9)$ & $0,191(70)$ & 5,22 & 0,200 \\
6,0 & $0,549(72)$ & $4,035(11)$ & $0,259(71)$ & --- & -- \\
\hline \hline
\end{tabular}

Observa-se pela Tabela 4.2.2-7 que os resultados obtidos por Nowotny e Meighzifene (Tabela 4.2.2-7 (c)) são equivalentes com as $\Delta$ CSR's obtidas com a filtração equivalente de W (Tabela 4.2.2-7 (b)). O programa computacional XCOMP5R baseado em um método semi-empírico utilizado no trabalho de Nowotny e Meighzifene (Nowotny \& Meghzifene, 2002) realiza a simulação de forma distinta em relação ao GEANT4, que é baseado no método de Monte Carlo, gerando resultados não compatíveis (Tabela 4.2.2-7 (a)).

Os resultados apresentados aqui mostram que procedimentos experimentais ou matemáticos que pretendem aproximar o efeito da rugosidade do ânodo pela simples inclusão de filtros não são válidos. 


\section{Conclusões}

De modo geral, o uso do GEANT4 na avaliação da influência da rugosidade na distribuição espectral de raios $\mathrm{X}$ em radiologia diagnóstica apresentou resultados satisfatórios. Além disso, o seu manuseio mostrou-se bastante versátil devido a sua modularidade e possibilidade de trabalhar em conjunto com outras aplicações computacionais desenvolvidas por terceiros. Por outro lado, a aplicação dos diversos recursos desta ferramenta computacional apresenta-se como uma tarefa bastante complexa, que requer longo tempo de aprendizado.

Os estudos prévios da formação da superfície rugosa (seção 3.1) demonstraram a complexidade para a realização de sua modelagem computacional. A avaliação de uma amostra de ânodo por um microscópio de força atômica demonstrou de uma forma mais precisa a rugosidade real do ânodo de um tubo de raios X, pois, até então, em estudos anteriores, para a medição da rugosidade dos ânodos foram utilizados rugosímetros com precisão de $1 \mu \mathrm{m}$ (Nowotny \& Meghzifene, 2002).

O modelo de crescimento da rugosidade utilizado (seção 3.2.1.1) propiciou bons resultados na modelagem geométrica da superfície rugosa mesmo utilizando formas geométricas simples (pirâmides). O emprego de uma modelagem mais complexa foi inviável principalmente devido à restrição em relação ao processamento e memória dos computadores atuais. Para uma modelagem mais próxima ao real, seria necessário o uso de diversas formas geométricas mais elaboradas para a formação da superfície rugosa.

Devido também à velocidade de processamento, armazenamento e memória dos computadores disponíveis, foi necessária a simulação com a aplicação de uma técnica de redução de variância para ser possível a obtenção dos resultados em tempo hábil (seção 3.3.4).

Foi demonstrado, por meio de simulação computacional com o Método de Monte Carlo, que há alteração da distribuição espectral com o aumento da rugosidade. Este fato também foi verificado com a utilização de um modelo computacional semi-empírico no estudo realizado por Nowotny e Meighzifene (Nowotny \& Meghzifene, 2002). Também foi verificado que com o aumento da rugosidade tanto os valores da energia média quanto 
os valores da primeira e segunda camada semi-redutora dos espectros também aumentaram. Este fato foi verificado anteriormente por Stears, Felmlee e Gray (Stears, Felmlee, \& Gray, 1986) e por Nagel (Nagel, 1988).

$\mathrm{Na}$ caracterização do feixe de raios $\mathrm{X}$ pela energia média e pela primeira e segunda camadas semi-redutoras mostraram que os espectros produzidos com ânodo rugoso e os espectros com filtração de $\mathrm{W}$ tornam-se incompatíveis com rugosidades mais elevadas. O espectro atenuado é proveniente de um espectro simulado por um ânodo sem rugosidade, ou seja, ambos os espectros têm a mesma natureza. No entanto, o efeito do aumento da rugosidade demonstrou ser diferente do aumento da filtração de W (ou da filtração inerente do tubo de raios X). Com o aumento da rugosidade ocorre o aumento dos picos característicos e diminuição da parte correspondente às energias mais baixas do bremsstrahlung do espectro não tendo grandes alterações em relação à sua forma original. Nos espectros com filtração de W, ocorre praticamente um corte em suas energias mais baixas. Só foi possível a verificação deste fato devido a simulação ser realizada sem nenhuma adição de filtração inerente tais como a filtração correspondente ao vidro do tubo de raios $\mathrm{X}$, do óleo isolante e da janela da cúpula de raios $\mathrm{X}$.

Comparando-os com os resultados de $\Delta$ CSR's calculados por método semiempírico por Nowotny e Meighzifene, verificou-se a equivalência em relação aos espectros atenuados com filtração de $\mathrm{W}$ e a divergência em relação aos espectros simulados por método de Monte Carlo. Provavelmente para a obtenção do espectro de radiação $\mathrm{X}$, a realização dos cálculos no método semi-empírico é semelhante ao modelo de atenuação do feixe por filtração de W.

Um fator limitante na utilização do método de Monte Carlo neste tipo de aplicação é o tempo de processamento computacional. Neste trabalho, para a aquisição dos espectros simulados, foram necessários diversos meses. Caso não houvesse esse fator limitante, como sugestão, seria interessante a avaliação de simulações com rugosidades abaixo de $0,5 \mu \mathrm{m}$ para a verificação do comportamento para rugosidades de tubos de raios $\mathrm{X}$ novos, além da realização da simulação com toda a filtração inerente ao tubo de raios X. Uma solução seria a utilização de grid para a computação distribuída com o GEANT4, na qual seria possível a realização do processamento de uma simulação em diversos computadores ao mesmo tempo (Ardizzone, et al., 2004). Para futuros estudos, também 
seria interessante realizar: a aplicação de modelos mais realísticos para a geração da superfície rugosa; geração de espectros simulados em outras faixas de energias; utilização de outros materiais e diferentes ângulos para o ânodo e avaliação da vida útil de um equipamento de raios $\mathrm{X}$ em termos da rugosidade. 


\section{Apêndice 1 - Alguns princípios básicos da teoria de probabilidades}

\subsection{Evento}

Um evento $E$ é o resultado obtido quando se realiza um experimento. O conjunto de todos os resultados possíveis é denominado espaço amostral $\Omega$.

\subsection{Probabilidade}

Probabilidade $P$ é uma função associada aos eventos que representa a freqüência relativa com que este evento ocorre numa série de $\mathrm{n}$ tentativas.

$$
P(E)=\lim _{\mathrm{n} \rightarrow \infty} \frac{\mathrm{n}_{E}}{\mathrm{n}}
$$

Tendo como axioma:

$$
P(\Omega)=1
$$

\subsection{Variável aleatória}

Variável aleatória é uma função que atribui um número real $X$ associada a um evento. A variável aleatória pode ser discreta ou contínua. É denominada variável aleatória discreta quando ela assume um número finito ou infinito enumerável de valores reais distintos $X_{1}, X_{2}, X_{3} \ldots$ A variável aleatória contínua é quando ela assume um número infinito qualquer não-enumerável de valores entre $X_{1}$ e $X_{2}$. 


\subsection{Função Distribuição Cumulativa}

A função distribuição cumulativa $F(x)$, também denominada função distribuição acumulada é a probabilidade que a variável aleatória $X$ possa assumir um valor menor que um número real $x$.

$$
F(x)=P(X \leq x)
$$

Sendo que $0 \leq F(x) \leq 1, F(-\infty)=0$ e $F(\infty)=1$

\subsection{Função Distribuição de Probabilidade}

A Função Distribuição de Probabilidade de uma variável aleatória discreta $X$ é definida de acordo com a seguinte função:

$$
\begin{gathered}
f(x)=\left\{\begin{array}{cc}
P\left(X=x_{i}\right) & \text { para } x=x_{i} \\
0 & \text { para } x \neq x_{i}
\end{array}\right. \\
F(x)=\sum_{x_{i} \leq x} f\left(x_{i}\right)
\end{gathered}
$$

\subsection{Função Densidade de Probabilidade}

A Função Densidade de Probabilidade de uma variável aleatória contínua $X$ é definida de acordo com a seguinte função:

$$
\begin{gathered}
f(x)=\lim _{\Delta x \rightarrow 0} \frac{P(x<X \leq x+\Delta x)}{\Delta x} \\
F(x)=\int_{-\infty}^{x} f(x) d x
\end{gathered}
$$


Se uma variável aleatória tem densidade dada por $f(x)$, a probabilidade de todo o espaço amostral é 1, ou seja:

$$
\int_{-\infty}^{\infty} f(x) d x=1
$$

\section{Apêndice 2 - Códigos utilizados na técnica de redução de variância}

\subsection{G4LowEnergyBremsstrahlungBias.cc}

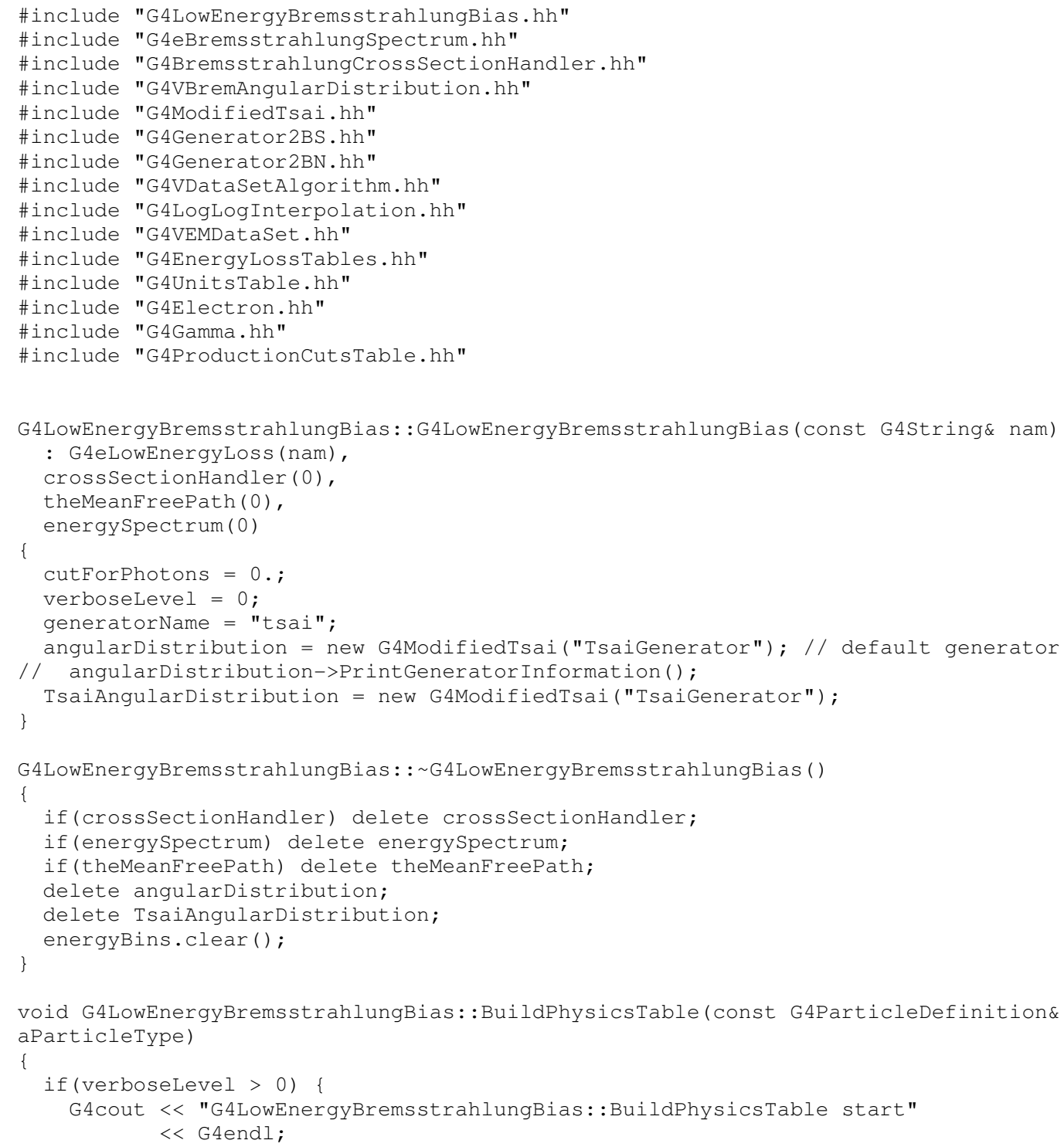




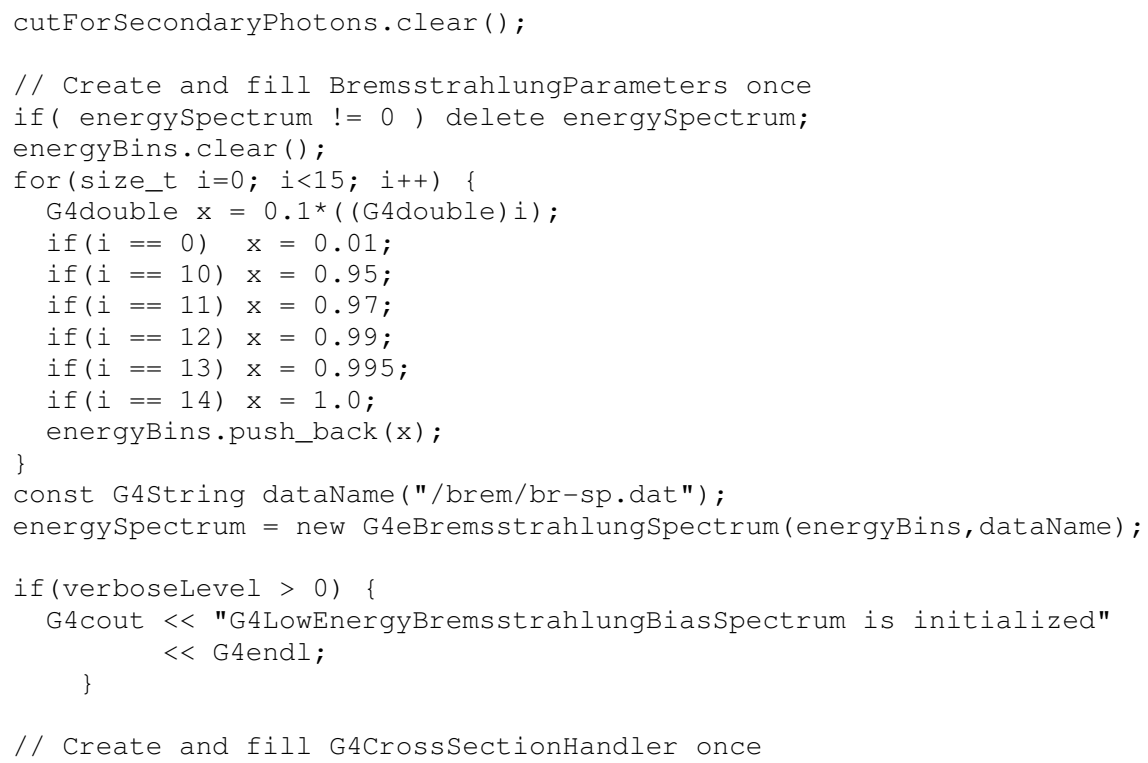

if( crosssectionHandler $!=0$ ) delete crosssectionHandler;

G4VDataSetAlgorithm* interpolation = new G4LogLogInterpolation();

G4double lowkineticEnergy = GetLowerBoundEloss();

G4double highKineticEnergy = GetUpperBoundEloss ();

G4int totBin = GetNbinEloss ();

crossSectionHandler = new G4BremsstrahlungCrossSectionHandler(energyspectrum, interpolation);

crossSectionHandler->Initialise(0, lowKineticEnergy, highKineticEnergy, totBin); crossSectionHandler->LoadShellData ("brem/br-cs-");

if (verboselevel $>0$ ) \{

G4cout $<<$ GetProcessName()

$<<$ " is created; Cross section data: " $<<$ G4endl.

crossSectionHandler->PrintData () ;

G4cout $<<$ "Parameters: "

$<<$ G4endl;

energyspectrum->PrintData () ;

// Build loss table for Bremsstrahlung

BuildLosstable (aParticleType);

if (verboselevel $>0)\{$

G4cout $<$ "The loss table is built"

$<$ G4endl;

\}

if (\&aParticleType==G4Electron: : Electron()) \{

RecorderofElectronProcess [CounterOfElectronProcess] = (*this).theLossTable; CounterofelectronProcess ++ ;

PrintInfoDefinition();

\} else \{

RecorderofPositronProcess [CounterofPositronProcess] = (*this).theLossTable; CounterofPositronProcess++;

// Build mean free path data using cut values

if ( theMeanFreePath $!=0$ ) delete theMeanFreePath;

theMeanFreePath = crossSectionHandler $->$

BuildMeanFreePathForMaterials (\&cutForSecondaryPhotons);

if (verboseLevel $>0)\{$

G4cout << "The MeanFreePath table is built" 


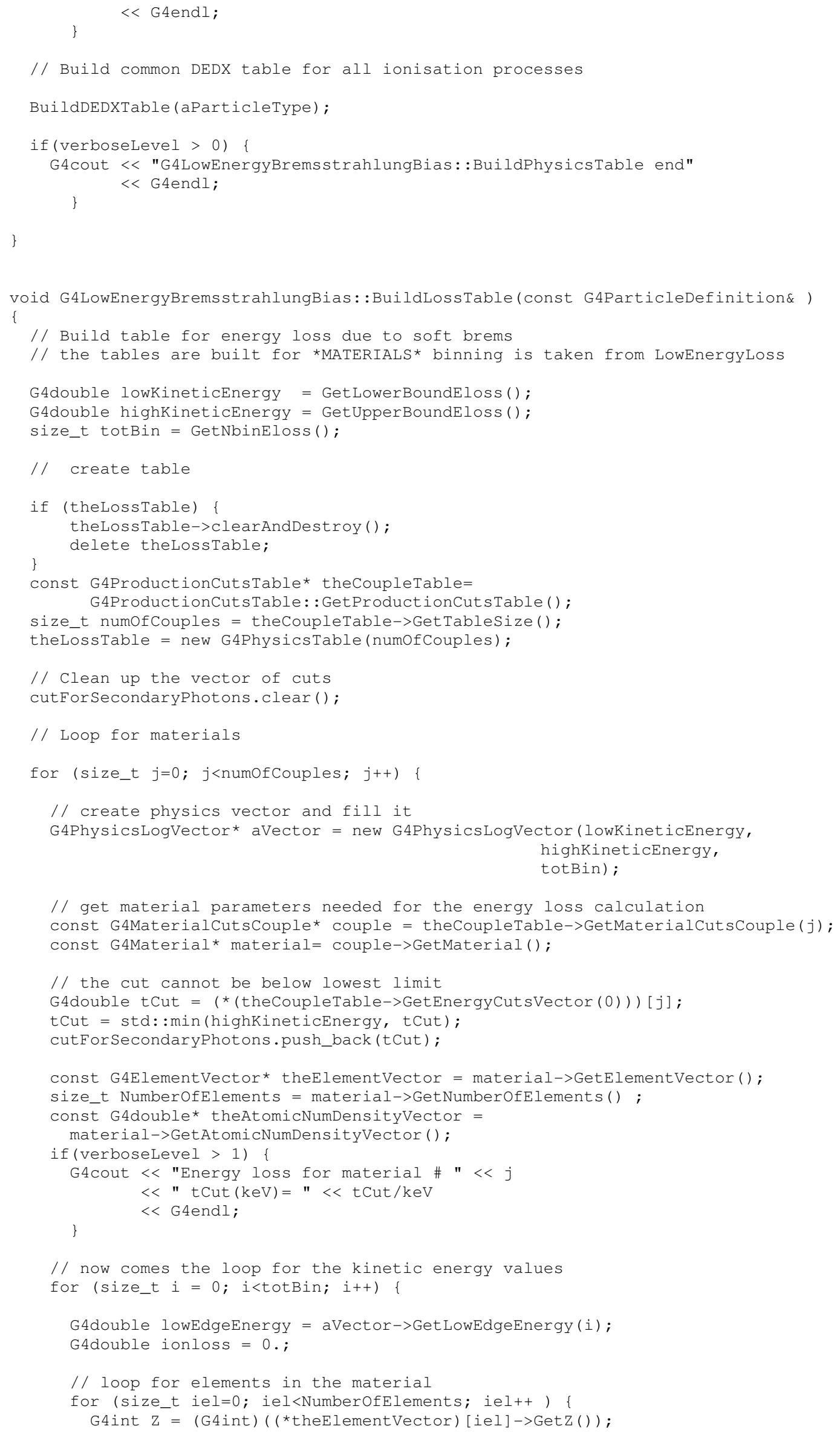




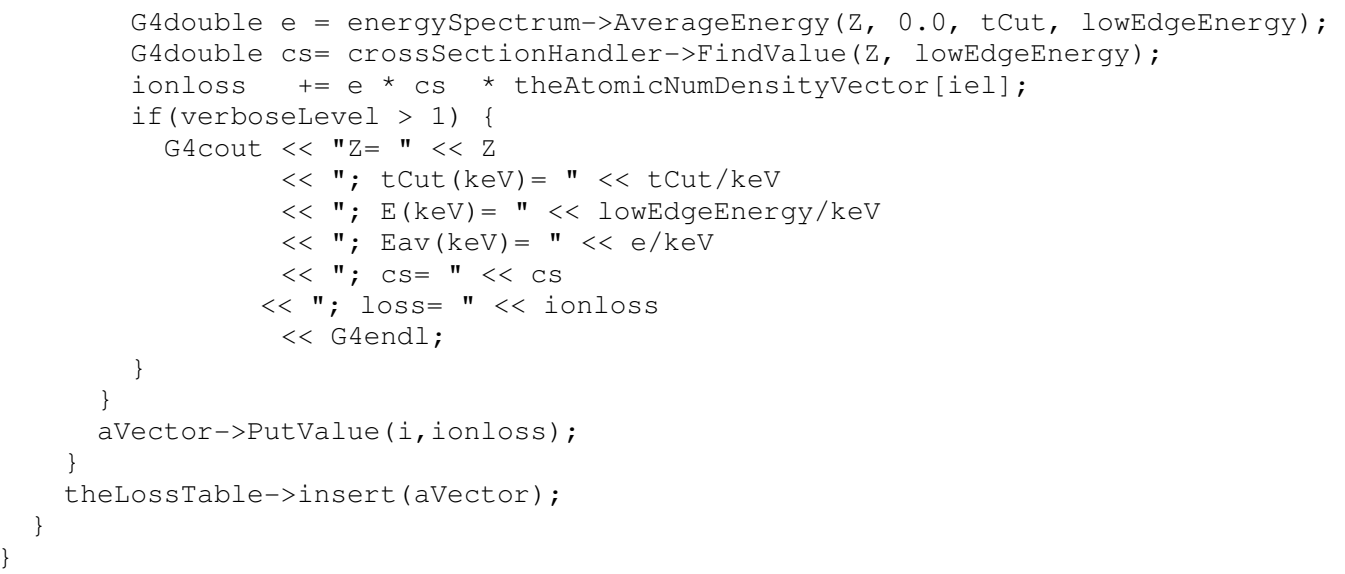

G4VParticleChange* G4LowEnergyBremsstrahlungBias: :PostStepDoIt(const G4Track\& track, const G4Step\& step)

aParticlechange. Initialize(track);

const G4MaterialCutsCouple* couple = track.GetMaterialCutsCouple();

G4double kineticEnergy = track. GetKineticEnergy ();

G4int index = couple->GetIndex ();

G4double tcut = cutForSecondaryPhotons [index];

// Control limits

if(tCut $>=$ kineticEnergy)

return G4VContinuousDiscreteProcess: :PostStepDoIt(track, step);

G4int $\mathrm{Z}=$ crossSectionHandler->SelectRandomAtom(couple, kineticEnergy);

G4double tGamma = energySpectrum->SampleEnergy ( $\mathrm{Z}$, tCut, kineticEnergy, kineticEnergy).

G4double totalEnergy = kineticEnergy + electron_mass_c2;

G4double finalEnergy = kineticEnergy - tGamma; // electron/positron final energy

G4double theta $=0$;

if ( (kineticEnergy $<1 * \mathrm{MeV} \& \& \mathrm{kineticEnergy}>1 * \mathrm{keV} \& \&$ generatorName $==" 2 \mathrm{bn} "))\{$ theta = angularDistribution->PolarAngle(kineticEnergy,finalEnergy, z); \}else \{

theta = TsaiAngularDistribution->PolarAngle(kineticEnergy,finalEnergy, Z); \}

G4double phi = twopi * G4UniformRand ();

G4double dirz = std: $: \cos ($ theta);

G4double sinTheta = std: :sqrt(1. - dirz*dirz);

G4double dirX = sinTheta*std: $\cos ($ phi);

G4double diry = sinTheta*std: :sin(phi);

G4ThreeVector gammaDirection (dirX, dirY, dirz);

G4ThreeVector electronDirection = track.GetMomentumDirection();

/ /

// Update the incident particle

//

gammaDirection.rotateUz (electronDirection);

// Kinematic problem

if (finalEnergy $<0$.) \{

tGamma $+=$ finalEnergy;

finalEnergy $=0.0$;

G4double momentum = std: :sqrt((totalEnergy + electron_mass_c2)*kineticEnergy);

G4double finalx = momentum*electronDirection.x() - tGamma*gammaDirection.x();

G4double finaly = momentum*electronDirection.y() - tGamma*gammaDirection.y();

G4double finalz = momentum*electronDirection.z() - tGamma*gammaDirection.z();

aParticlechange. SetNumberofSecondaries (1):

G4double norm $=1 . /$ std: : sqrt (finalX*finalX +finalY*finaly +finalz*finalz); 


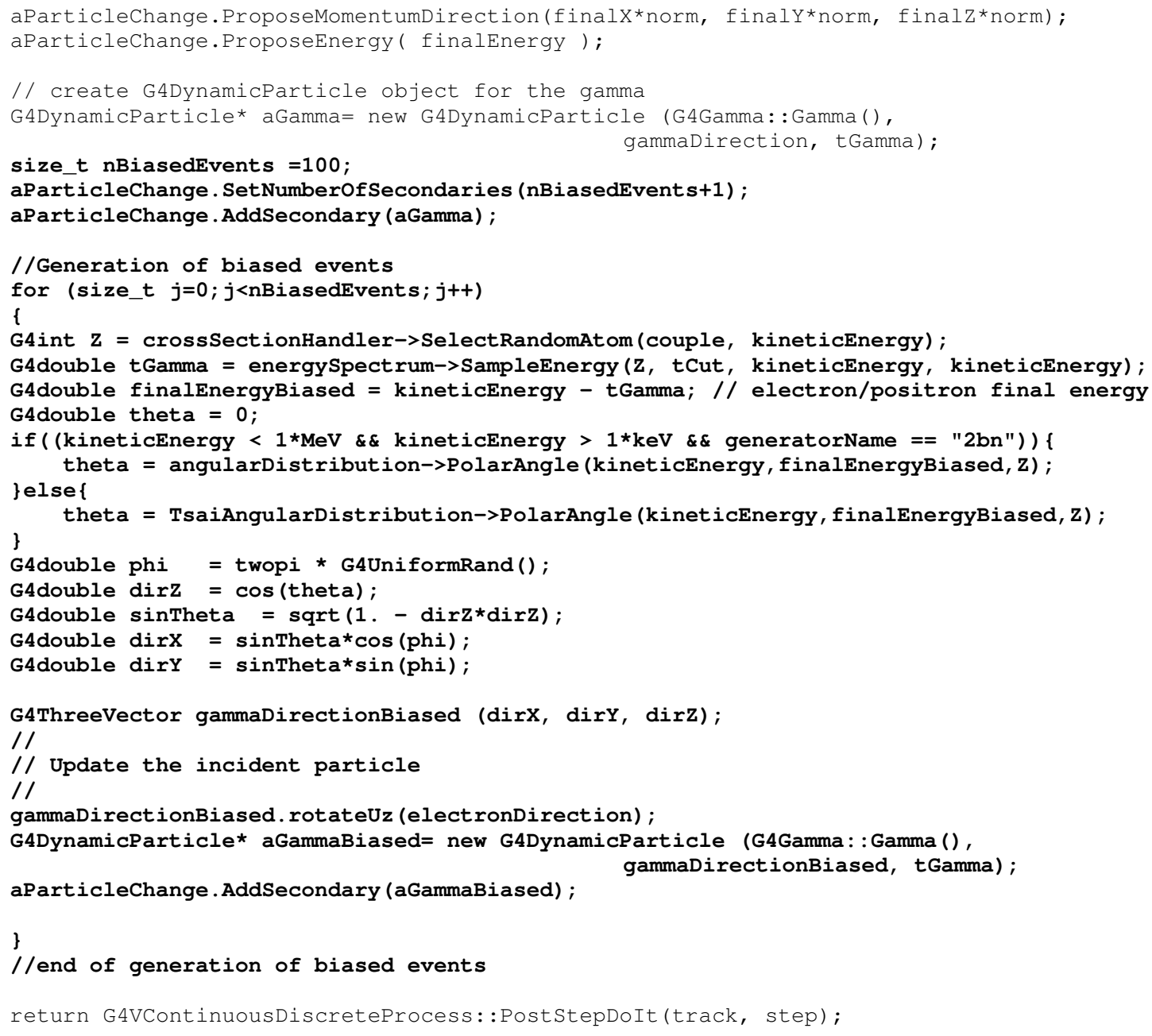


cutForPhotons = cut;

void G4LowEnergyBremsstrahlungBias: : SetAngularGenerator(G4VBremAngularDistribution* distribution)

\{

angularDistribution = distribution;

angularDistribution->PrintGeneratorInformation();

void G4LowEnergyBremsstrahlungBias: : SetAngularGenerator(const G4String\& name)

if (name $==$ "tsai")

\{

delete angularDistribution;

angularDistribution = new G4ModifiedTsai("TsaiGenerator");

generatorName = name;

else if (name $==$ "2bn")

\{

delete angularDistribution;

angularDistribution = new G4Generator2BN("2BNGenerator");

generatorName = name;

else if (name $==$ "2bs")

delete angularDistribution;

angularDistribution = new G4Generator2BS("2BSGenerator");

generatorName = name;

\}

1 se

G4Exception("G4LowEnergyBremsstrahlungBias: : SetAngularGenerator - generator does not exist");

angularDistribution->PrintGeneratorInformation();

\subsection{G4LowEnergyIonisationBias.cc}

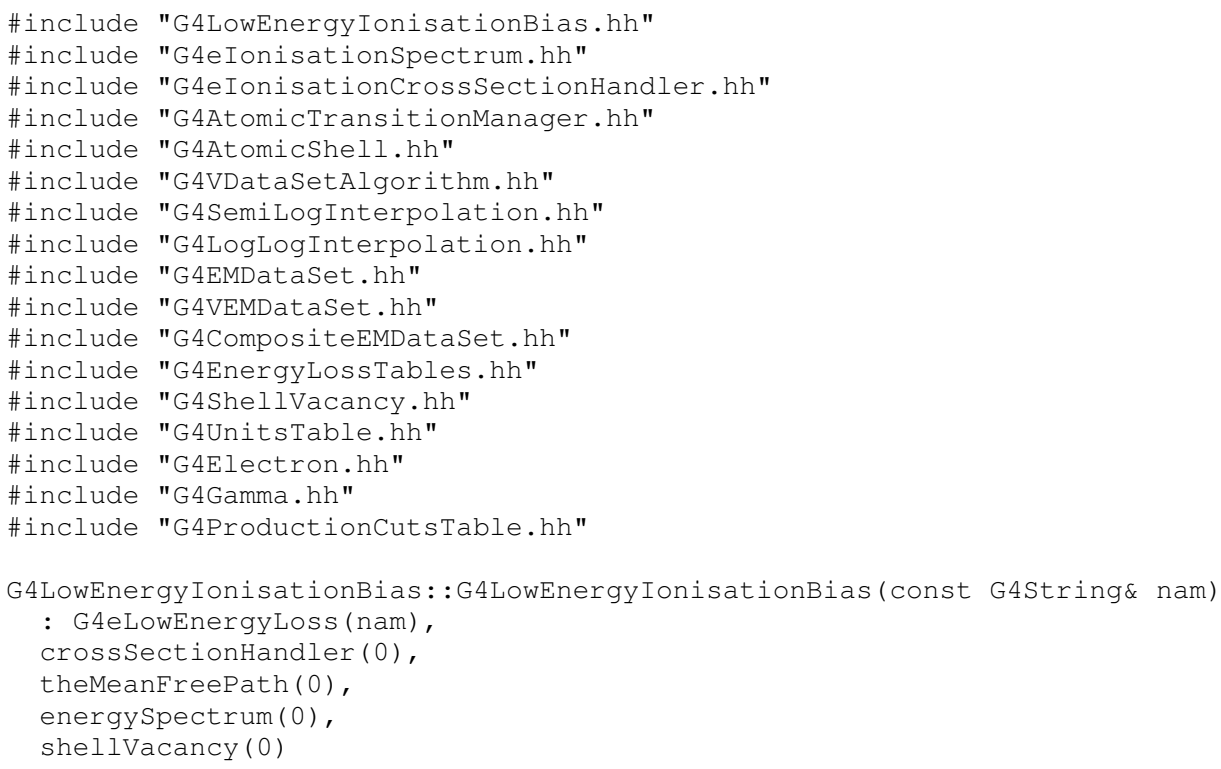


cutForPhotons $=250.0 * \mathrm{eV}$

cutForElectrons $=250.0 * \mathrm{eV}$;

\}

verboselevel $=0$;

G4LowEnergyIonisationBias: : G4LowEnergyIonisationBias()

\{

delete crossSectionHandler;

delete energyspectrum;

delete theMeanFreePath;

\}

delete shellVacancy;

void G4LowEnergyIonisationBias: :BuildPhysicsTable(const G4ParticleDefinition\& aParticleType)

if (verboseLevel $>0)\{$

G4cout $<<$ "G4LowEnergyIonisationBias: :BuildPhysicsTable start" $<<$ G4endl;

cutForDelta.clear();

// Create and fill IonisationParameters once

if( energyspectrum $!=0$ ) delete energyspectrum;

energySpectrum = new G4eIonisationSpectrum();

if (verboselevel $>0)\{$

G4cout $<<$ "G4VEnergySpectrum is initialized"

$<$ G4endl;

// Create and fill G4CrossSectionHandler once

if ( crossSectionHandler $!=0$ ) delete crosssectionHandler;

G4VDataSetAlgorithm* interpolation = new G4SemiLogInterpolation();

G4double lowkineticEnergy = GetLowerBoundEloss();

G4double highKineticEnergy = GetUpperBoundEloss();

G4int totBin = GetNbinEloss ()

crossSectionHandler = new G4eIonisationCrossSectionHandler(energyspectrum,

interpolation,

lowkineticEnergy,

highKineticEnergy,

crossSectionHandler->LoadShellData ("ioni/ion-ss-cs-");

totBin);

if (verboselevel $>0$ ) \{

G4cout $<<$ GetProcessName ()

$<<$ " is created; Cross section data: "

$<$ G4endl;

crossSectionHandler->PrintData( ) ;

G4cout $<<$ "Parameters: "

$<$ G4endl;

energyspectrum->PrintData();

// Build loss table for IonisationIV

BuildLosstable (aParticleType);

if (verboselevel $>0$ )

G4cout $<<$ "The loss table is built" $<<$ G4endl;

if (\&aParticleType==G4Electron: :Electron()) \{

RecorderOfElectronProcess [CounterOfElectronProcess] = (*this).theLossTable; CounterofElectronProcess ++

PrintInfoDefinition();

\} else \{ 


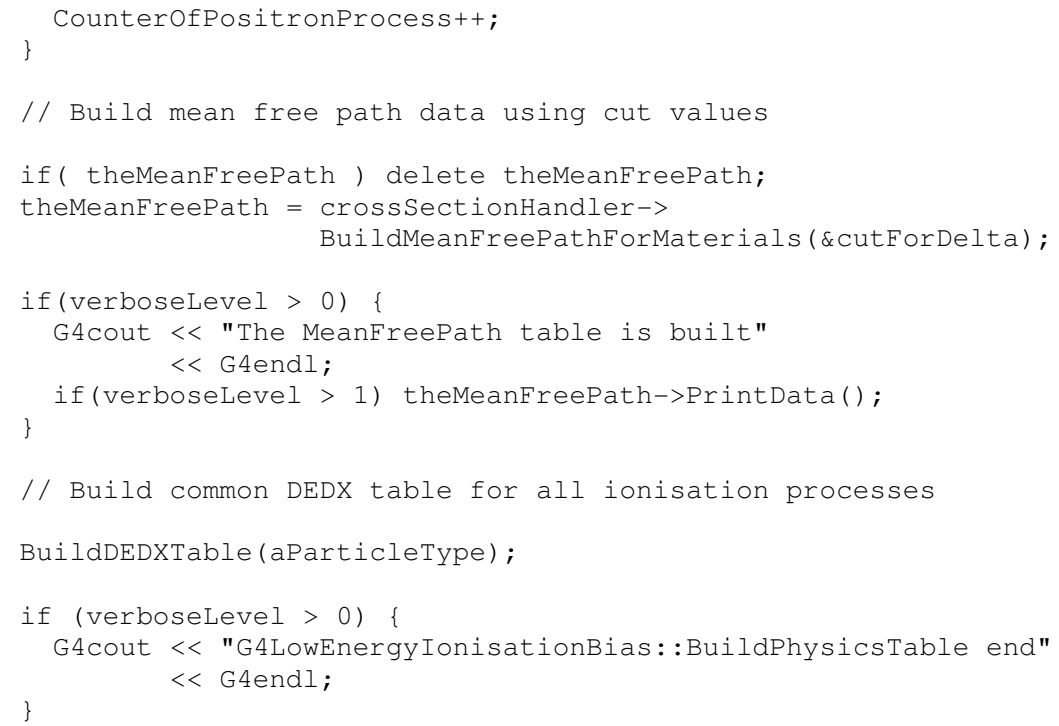




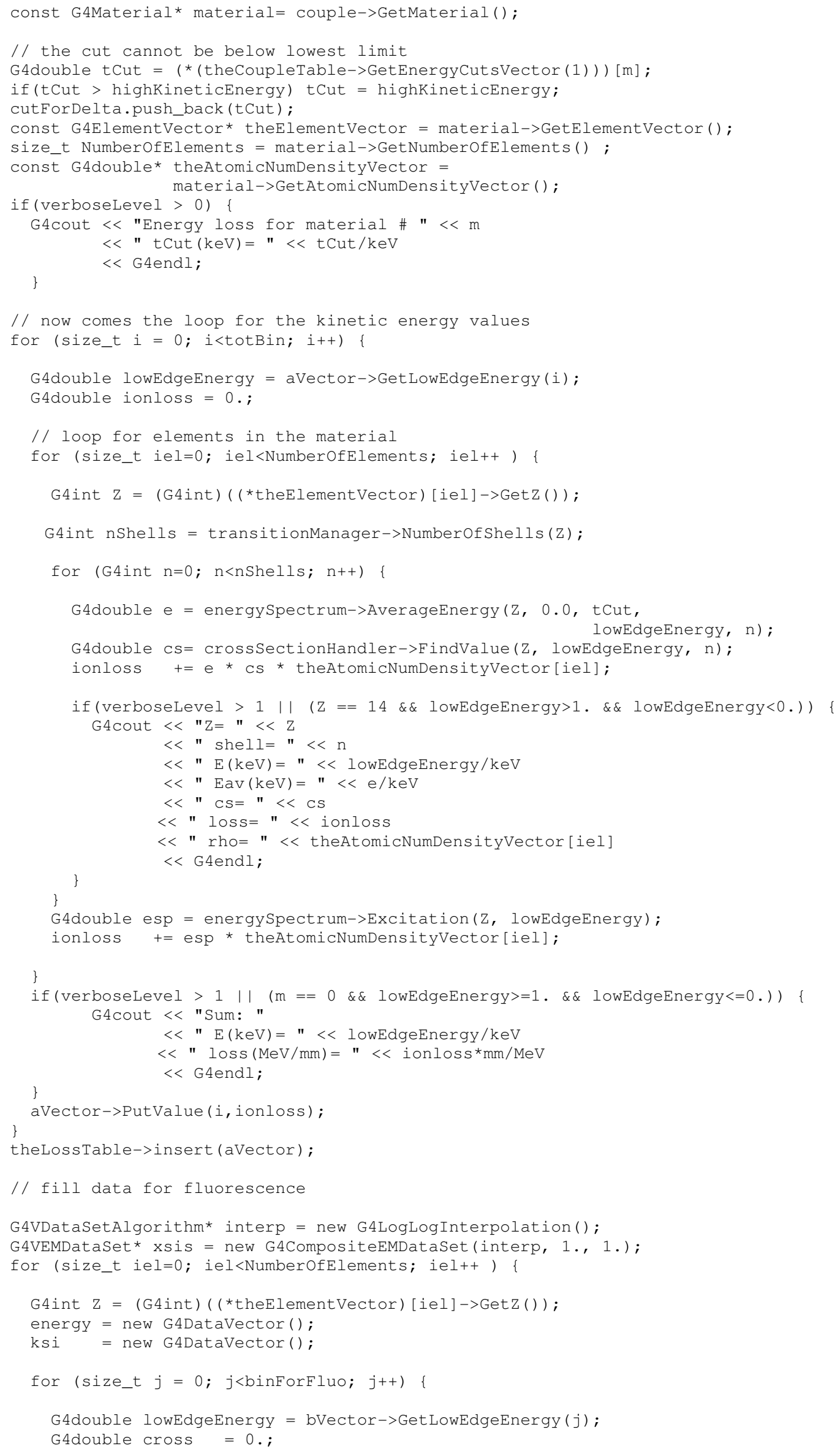




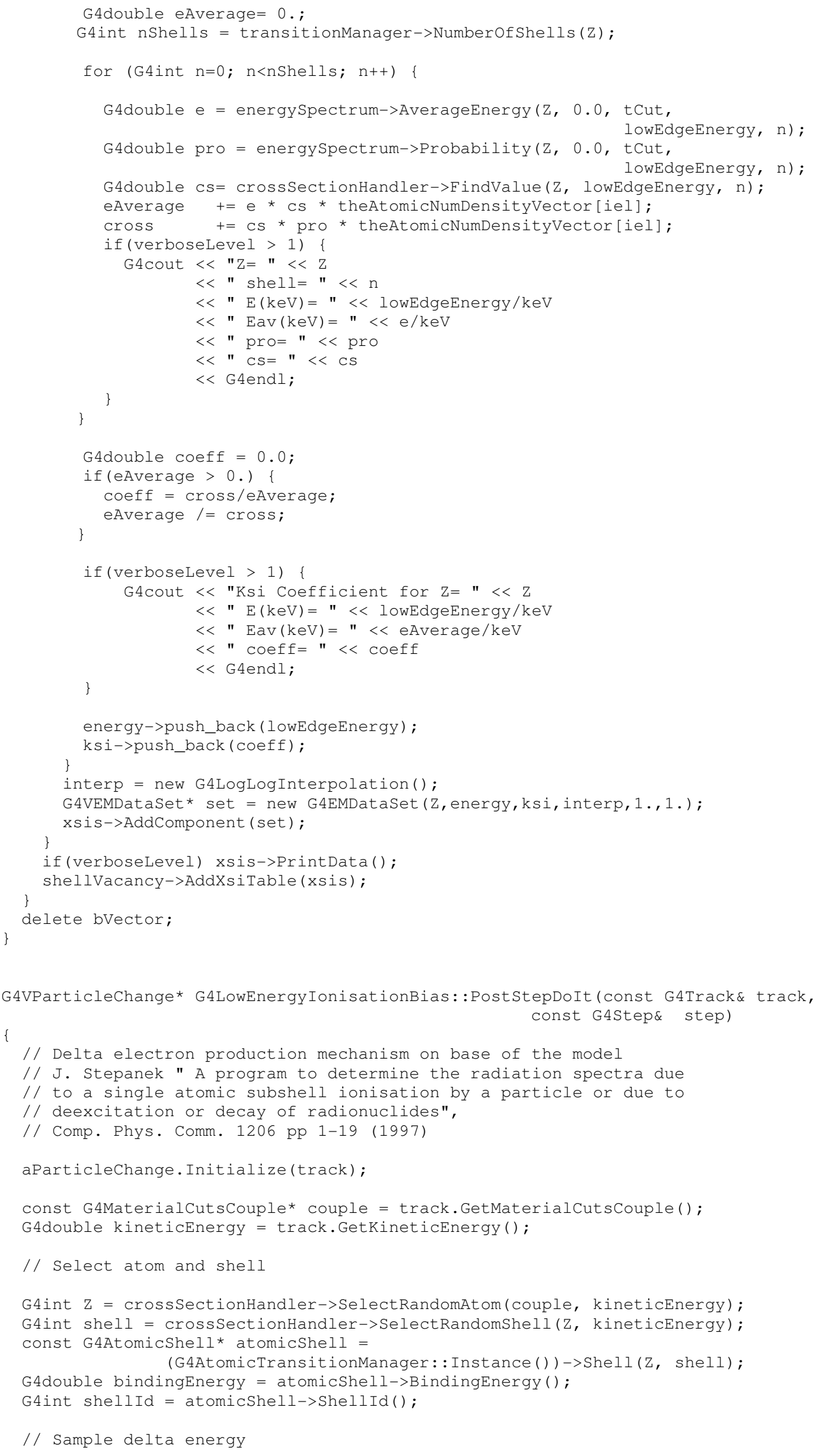




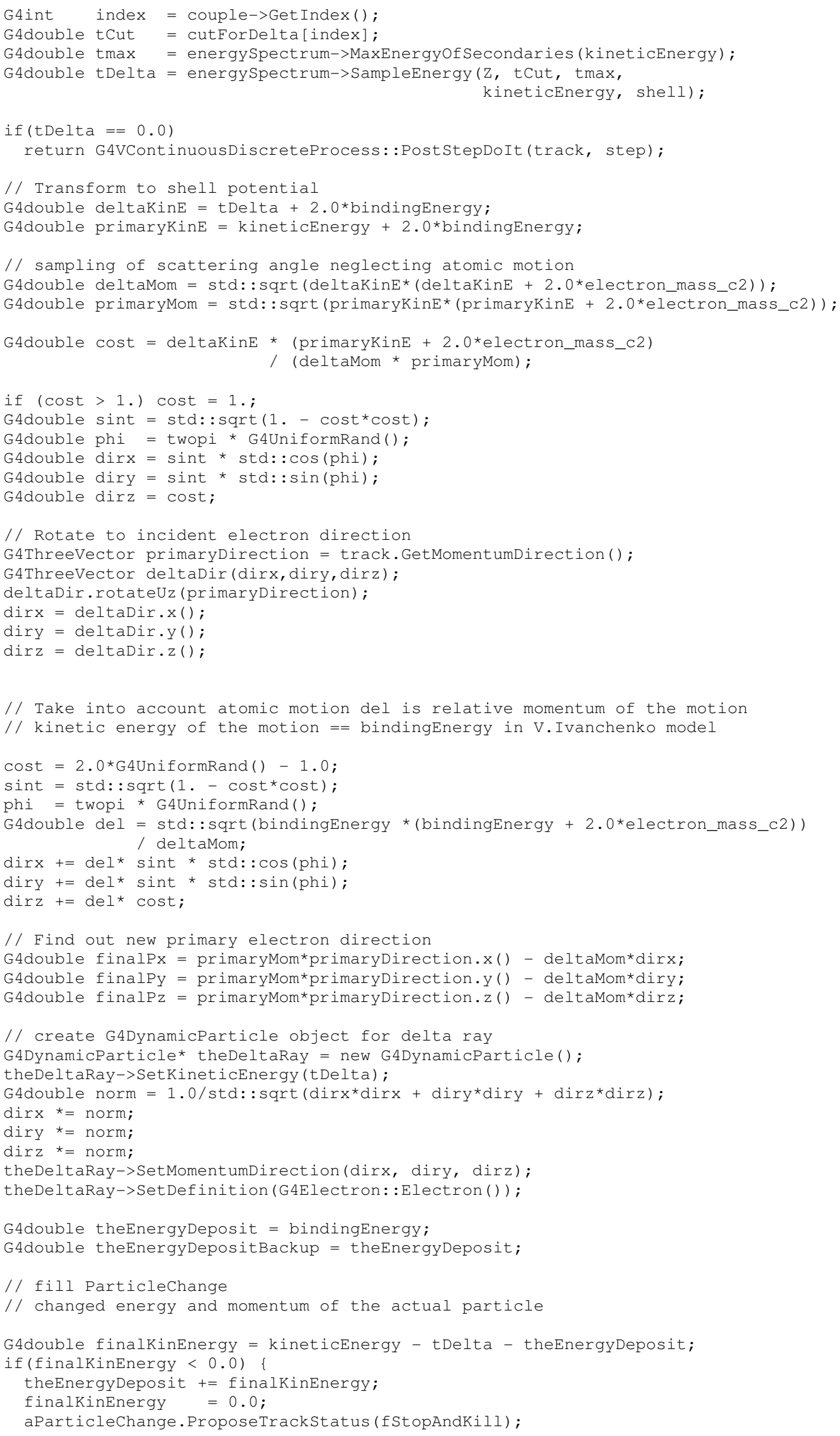




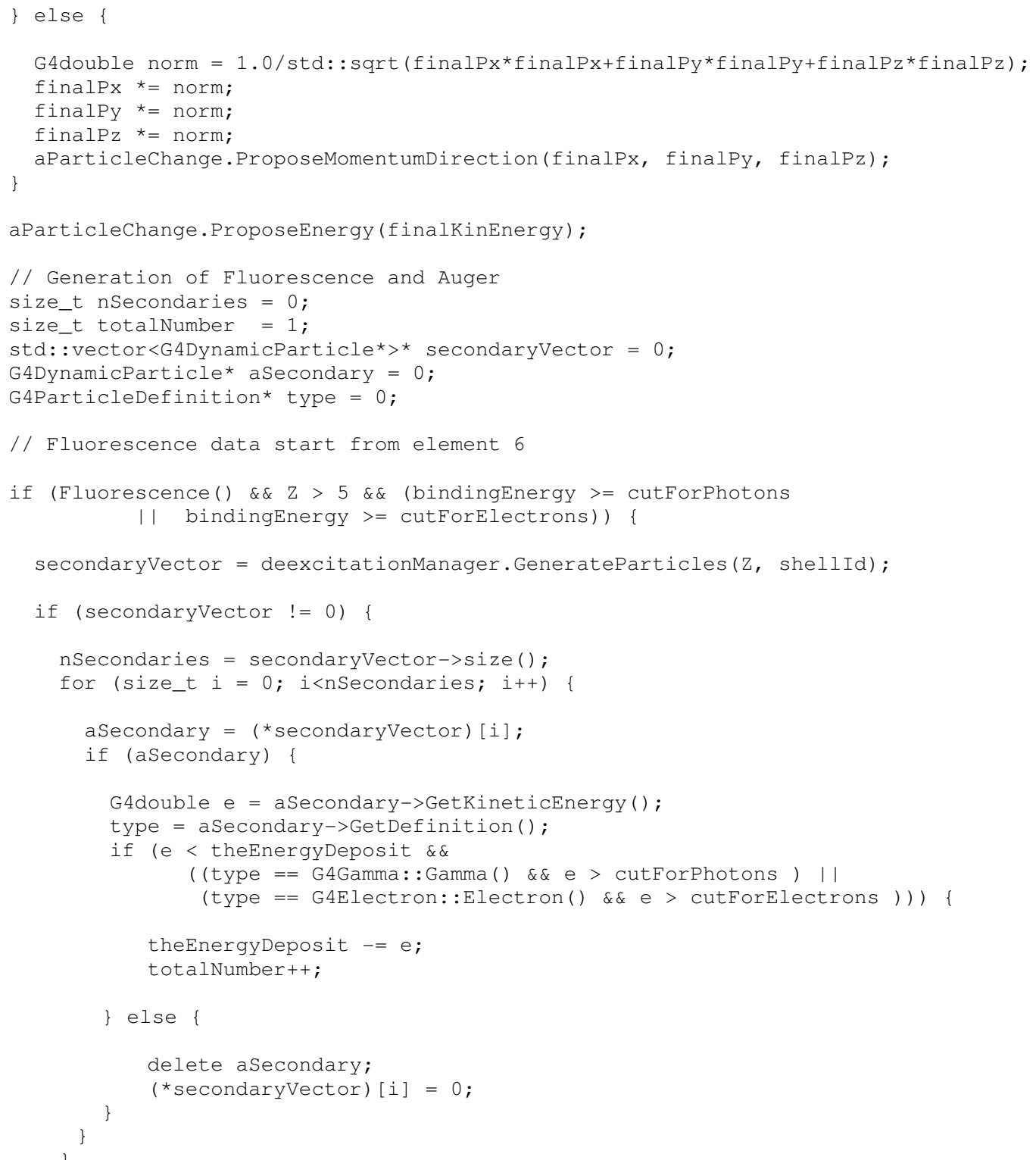

// Generation of Biased Fluorescence and Auger

size_t nSecondariesBias $=0$;

size_t ntBiasedSecondaries $=0$;

std: : vector $<$ G4DynamicParticle* $>*$ secondaryVectorBias $=0$;

std: : vector<G4DynamicParticle*>* secondaryVectorBiastotal = new

std: : vector<G4DynamicParticle*>;

size_t nBiasedEvents $=100$;

for (size_t $j=0 ; j<n B i a s e d E v e n t s ; j++$ )

\{

G4double theEnergyDepositBias = theEnergyDepositBackup;

// Fluorescence data start from element 6

if (Fluorescence() \&\& $\mathrm{Z}>5 \& \&$ (bindingEnergy $>=$ cutForphotons

| | bindingEnergy $>=$ cutForElectrons) ) (

secondaryVectorBias = deexcitationManager.GenerateParticles ( $\mathrm{z}$, shellId);

if (secondaryVectorBias $!=0)\{$

nSecondariesBias = secondaryVectorBias->size ();

for (size_t $i=0$; $i<$ nSecondariesBias; $i++)$ 


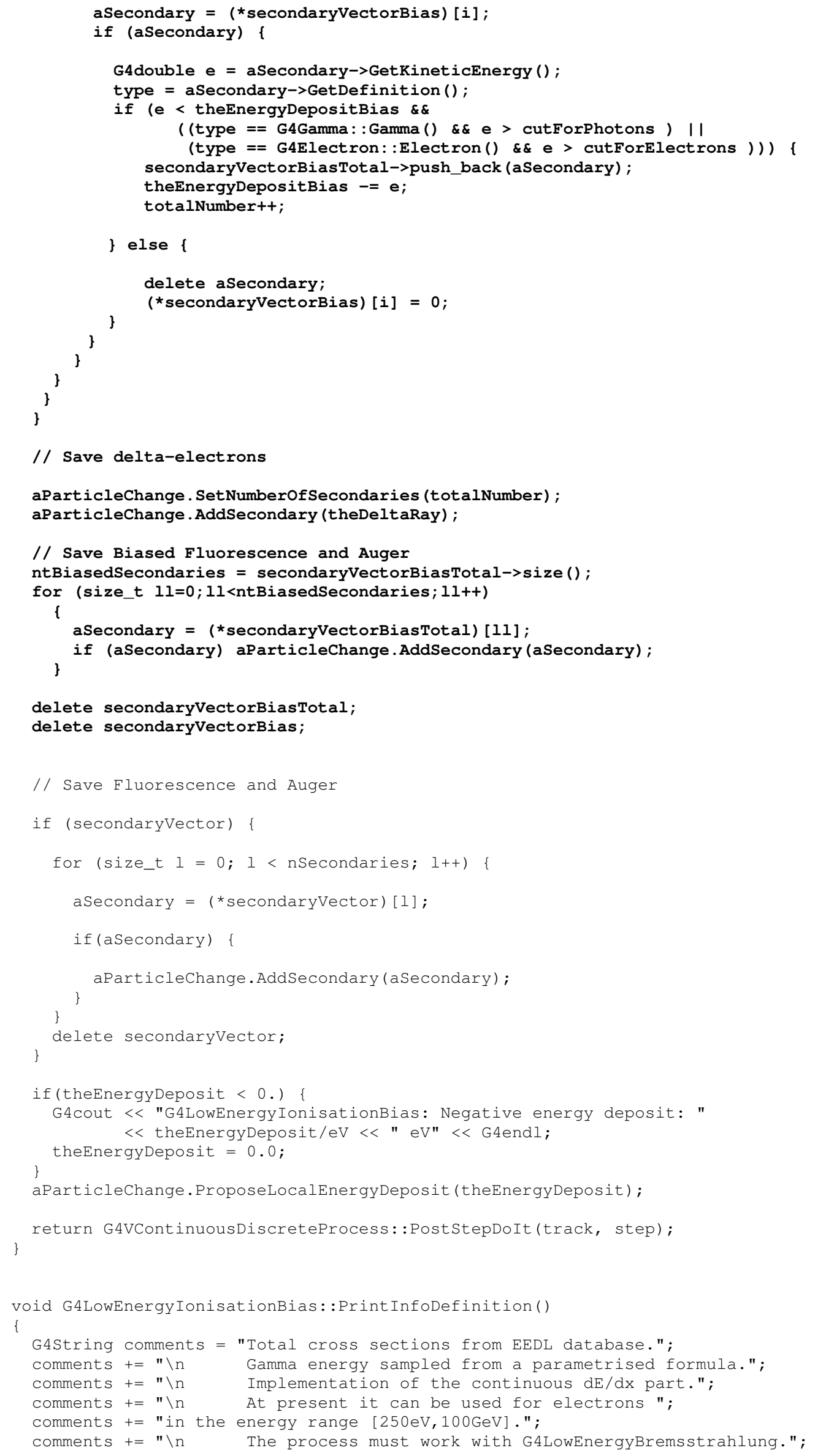



\}

G4cout $<$ G4endl $<$ GetProcessName ()$\quad<$ ": " $<$ comments $<$ G4endl;

G4bool G4LowEnergyIonisationBias: IsApplicable(const G4ParticleDefinition\& particle)

\{

return ( (\&particle == G4Electron: :Electron()) );

std: : vector $<$ G4DynamicParticle* $>*$

G4LowEnergy IonisationBias: DeexciteAtom(const G4MaterialcutsCouple* couple, G4double incidentEnergy,

G4double eLoss)

// create vector of secondary particles

const G4Material* material = couple->GetMaterial();

std: : vector $<$ G4DynamicParticle* $>$ * partVector $=$

new std: : vector $<$ G4DynamicParticle* $>$;

if(eLoss > cutForPhotons \&\& eLoss > cutForElectrons) \{

const G4AtomicTransitionManager* transitionManager =

G4AtomicTransitionManager: : Instance();

size_t nElements = material->GetNumberofElements().

const G4ElementVector* theElementVector = material->GetElementVector();

std: : vector $<$ G4DynamicParticle* $>$ * secVector $=0$;

G4DynamicParticle* aSecondary $=0$;

G4ParticleDefinition* type $=0$;

G4double e;

G4ThreeVector position;

G4int shell, shellid;

// sample secondaries

G4double eTot $=0.0$;

std: : vector $\langle\mathrm{G} 4$ int $>\mathrm{n}=$

shellVacancy->GenerateNumberofIonisations (couple,

for (size_t $i=0 ; i<n E l e m e n t s ; i++) \quad\{$

incidentEnergy, eLoss);

G4int $\mathrm{Z}=$ (G4int) ( (*theElementVector) [i]->GetZ());

size_t nVacancies $=\mathrm{n}[\mathrm{i}]$;

G4double maxE = transitionManager->Shell( $\mathrm{Z}, 0)->$ BindingEnergy () ;

if (nVacancies \&\& Z $>5$ \&\& (maxE>cutForPhotons | maxE>cutForElectrons)) \{

for (size_t $j=0 ; j<$ nVacancies; $j++$ ) \{

shell = crossSectionHandler->SelectRandomShell (Z, incidentEnergy);

shellId = transitionManager->Shell(Z, shell)->ShellId();

G4double maxeshell =

transitionManager->Shell(Z, shell)->BindingEnergy();

if (maxEShell>cutForPhotons || maxEShell>cutForElectrons ) \{

secVector = deexcitationManager.GenerateParticles (Z, shellId);

if ( secVector $!=0) \quad\{$

for (size_t $1=0 ; 1<$ secVector->size(); $1++)$

aSecondary $=\left({ }^{*}\right.$ secVector $)[1]$;

if (aSecondary $!=0) \quad\{$

e = aSecondary->GetKineticEnergy ();

type = aSecondary->GetDefinition();

if ( eTot $+e<=$ eLoss \&\&

(type == G4Gamma: :Gamma () \&\& e>cutForPhotons ) | |

(type == G4Electron: :Electron() \&\& e>cutForElectrons)) \{

eTot $+=e$; 


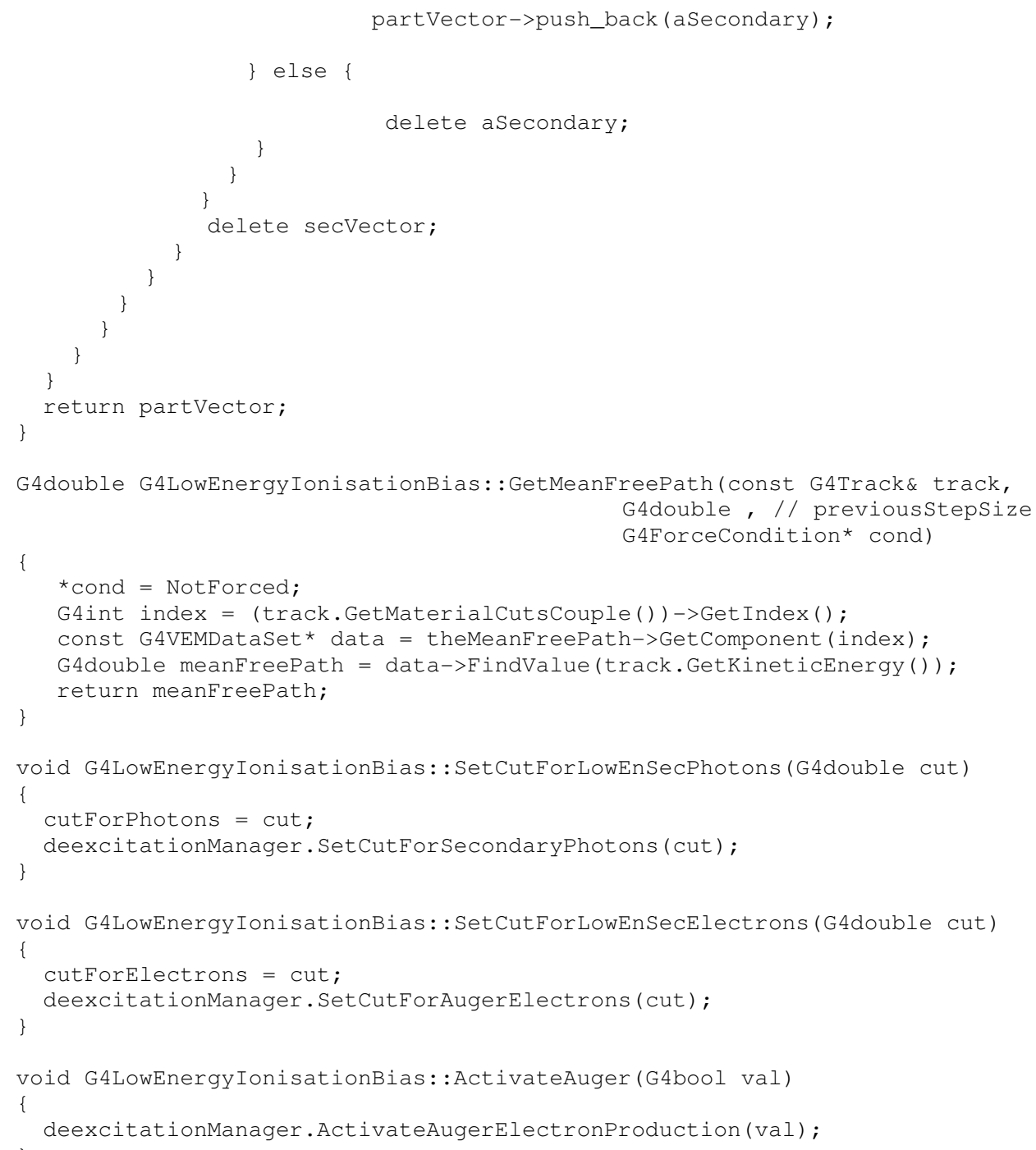




\section{Referências Bibliográficas}

Agostinelli, S., Allison, J., Amako, K., Apostolakis, J., Araujo, H., Arce, P., et al. (2003). GEANT4-a simulation toolkit. Nuclear Instruments and Methods in Physics Research A, $506,250-303$.

Allison, J., Amako, K., Apostolakis, J., Araujo, H., Arce Dubois, P., Asai, M., et al. (2006). Geant4 developments and applications. IEEE Transactions on Nuclear Science, 53 (1, part 2), 270- 278.

Allison, J., Asai, M., Barrand, G., Donszelmann, M., Minamimoto, K., Perl, J., et al. (2007). The Geant4 visualisation system. Computer Physics Communications , (In Press, Accepted Manuscript).

Amako, A., Guatelli, S., Ivanchencko, V., Maire, M., Mascialino, B., Murakami, K., et al. (2004). Validation of Geant4 electromagnetic Physics versus protocol data. Nuclear Science Symposium Conference Record, 4 (16-22), pp. 2115 - 2119. Rome, Italy. Andreo, P. (1991). Monte Carlo techniques in medical radiation Physics. Physics in Medicine and Biology , 36 (7), 861-920.

Ardizzone, V., Barbera, R., Cirrone, G. A., Cuttone, G., Di Rosa, E., Giorgio, E., et al. (2004). Monte Carlo simulation of a clinical beam line: GEANT4 and Grid technology approach. Proceedings of IEEE Nuclear Science Symposium Conference Record, 3, pp. 1824 - 1828. Rome, Italy.

Ay, M. R., Sarkar, S., Shahriari, M., Sardari, D., \& Zaidi, H. (Junho de 2005). Assessment of different computational models for generation of $x$-ray spectra in diagnostic radiology and mammography. Medical Physics , 32 (6), pp. 1660-1675.

Ay, M. R., Shahriari, M., Sarkar, S., Adib, M., \& Zaidi, H. (Outubro de 2004). Monte Carlo simulation of $\mathrm{x}$-ray spectra in diagnostic radiology and mammography using MCNP4C. Physics in Medicine and Biology, 49, pp. 4897-4917. 
Barabási, A.-L., \& Stanley, H. E. (1995). Fractal concepts in surface growth. New York, NY, USA: Press Syndicate of the University of Cambridge.

Barrand, G. (1997). OPACS and Geant4. Proceedings of Computing in High Energy Physics. Berlin, Germany.

Barrand, G. (2004). OpenScientist. Status of the project. Proceedings of Computing in High Energy and Nuclear Physics. Interlaken, Switzerland.

Barrand, G., Binko, P., Donszelman, M., Johnson, A., \& Pfeiffer, A. (2001). Abstract Interfaces for Data Analysis - Component architecture for data analysis tools. Proceedings of Computing in High Energy and Nuclear Physics. Beijing, China.

Beringer, J., Folger, G., Gianotti, F., Ribon, A., Wellisch, J. P., Barberis, D., et al. (2003). Validation of Geant4 hadronic Physics. Proceedings of IEEE Nuclear Science Symposium Conference Record, 1, pp. 494-498. Portland, USA.

Birch, R., \& Marshall, M. (1979). Computation of bremsstrahlung of x-ray spectra and comparision with spectra measured with a Ge (Li) detector. Physics in Medicine and Biology, 24 (3), pp. 505-517.

Bonifácio, D. A. (2007). Validação do Geant4 para a produção e detecção de raios X na faixa de energia de radiodiagnóstico. Dissertação (mestrado), Universidade de São Paulo, Instituto de Física, São Paulo.

Bonifácio, D. B., Murata, H. M., \& Moralles, M. (2005). Monte Carlo simulation of Xray spectra in diagnostic radiology and mammography using Geant4. International Nuclear Atlantic Conference - INAC. Santos: ABEN.

Booch, G. (1994). Object-Oriented analysis and design with applications (2nd ed.). Boston, MA, USA: Addison-Wesley.

Boone, J. M., \& Seibert, J. A. (Novembro de 1997). An accurate method for computergenerating tungsten anode x-ray spectra from 30 to $140 \mathrm{kV}$. Medical Physics, 24 (11), pp. 1661-1670. 
Boone, J. M., Fewell, T. R., \& Jennings, R. J. (Dezembro de 1997). Molybdenum, rhodium, and tungsten anode spectral models using interpolating polynomials with application to mammography. Medical Physics , 24 (12), pp. 1863-1874.

Bottaro, M. (2007). Estudo do envelhecimento de um tubo de raios X por métodos não invasivos. Dissertação (mestrado), Instituto de Pesquisas Energéticas e Nucleares, São Paulo.

Bushberg, J. T., Seibert, J. A., Leidholdt. Jr., E. M., \& Boone, J. M. (2002). The essential Physics of medical imaging (2nd ed.). Philadelphia, PA, USA: Lippincott Williams \& Wilkins.

CERN. (2007a). Geant4 User's Guide for Application Developers. Acesso em 26 de Outubro de 2007, disponível em http://geant4.web.cern.ch/geant4/UserDocumentation/UsersGuides/ForApplicationDevelo per/html/index.html

CERN. (2007b). Physics reference manual. Acesso em 26 de 10 de 2007, disponível em http://geant4.web.cern.ch/geant4/UserDocumentation/UsersGuides/PhysicsReferenceMan ual/html/index.html

CERN. (2007c). ROOT - An Oriented-Object analysis framework. Acesso em 26 de Outubro de 2007, disponível em http://root.cern.ch/

Chauvie, S., Guatelli, S., Ivanchenko, V., Longo, F., Mantero, A., Mascialino, B., et al. (2004). Geant4 low energy electromagnetic Physics. Proceedings of IEEE Nuclear Science Symposium Conference Record, 3 (16-22), pp. 1881 - 1885. Rome, Italy.

Chauvie, S., Guatelli, S., Mascialino, B., Pandola, L., Pia, M. G., Rodrigues, P., et al. (2006). Validation of Geant4 Bremsstrahlung models: first results. Proceedings of IEEE Nuclear Science Symposium Conference Record, (pp. 1511-1515). San Diego, USA.

Chytracek, R., McCormick, J., Pokorski, W., \& Santin, G. (2006). Geometry Description Markup Language for Physics simulation and analysis applications. IEEE Transactions on Nuclear Science, 53 (5, part 2), 2892- 2896.

Cooperman, G., Casanova, H., Hayes, J., \& Witzel, T. (2002). Using TOP-C and AMPIC to port large parallel applications to the computational grid. Proceedings of the $2 n d$ 
IEEE/ACM International Symposium on Cluster Computing and the Grid. Berlin, Germany.

Cosmo, G. (2001). Software process in Geant4. Proceedings of Computing in High Energy and Nuclear Physics, (pp. 469-472). Beijing, China.

Cosmo, G. (2004). The Geant4 geometry modeler. 2004 IEEE Nuclear Science Symposium Conference Record, 4, pp. 2196- 2198.

Cullen, D. E., Hubbell, J. H., \& Kissel, L. (1997). EPDL97: the Evaluated Photon Data Library, '97 version. UCRL-50400, vol.6, rev.5, Lawrence Livermore National Laboratory, Livermore, CA.

Dendy, P. P., \& Heaton, B. (1999). Physics for diagnostic radiology (2nd ed.). London, UK: Institute of Physics Publishing.

Dresser, M. (2003). Geometrical importance sampling in Geant4: from design to verification. CERN-OPEN-2003-048.

Edwards, S. F., \& Wilkinson, D. R. (1982). The surface statistics of a granular aggregate. Proceedings of the Royal Society of London. Series A, Mathematical and Physical Sciences , 381, 17-31.

Family, F., \& Vicsek, T. (1991). Dynamics of fractals surfaces. Singapore: World Scientific publishing Co. pte. Ltd.

Family, F., \& Vicsek, T. (1985). Scaling of the active zone in the Eden process on percolation networks and the ballistic deposition model. Journal of Physics A:

Mathematical and General, 18, L75-L81.

Fergunson, C. (2000). General purpose Source Particle Module for Geant4/SPARSET.

Technical note, University of Southampton, Physics and Astronomy Department, Southampton.

FreeHep. (2007a). JAS (Java Analysis Studio). Acesso em 26 de Outubro de 2007, disponível em http://jas.freehep.org

FreeHep. (2007b). WIRED. Acesso em 26 de Outubro de 2007, disponível em http://wired.freehep.org/ 
Guatelli, S., Mantero, A., Mascialino, B., Nieminen, P., Pia, M. G., \& Saliceti, S. (2004). Geant4 atomic relaxation. Nuclear Science Symposium Conference Record, 4 (16-22), pp. 2178-2181. Rome, Italy.

Hartmann, S. (1996). The World as a process: simulations in the natural and social sciences. In: R. Hegselmann, U. Mueller, \& K. G. Troitzsch (Eds.), Modeling and simulation in the social sciences from the Philosophy of science point of view (pp. 77100). Dordrecht, The Netherlands: Kluwer Academic Publishers.

Hubbell, J. H., \& Seltzer, S. M. (2004). Tables of X-Ray mass attenuation coefficients and mass energy-absorption coefficients (Version: 1.4). Acesso em 15 de Novembro de 2007, disponível em http://physics.nist.gov/xaamdi

IAEA. (23 de Abril de 2004). Absorbed Dose Determination in External Beam Radiotherapy: An International Code of Practice for Dosimetry based on Standards of Absorbed Dose to Water. TRS-398 (V.11b).

IAEA. (2007). Dosimetry in diagnostic radiology: an international code of practice. TRS457 .

ICRU. (Dezembro de 2005). Patient dosimetry for X Rays used in medical imaging. Journal of the ICRU, Report 74,50 (2).

IEC. (2005). Medical electrical equipment - Dosimetric instruments used for non-invasive measurement of X-ray tube voltage in diagnostic radiology. IEC 61627, Geneva.

Johns, H. E., \& Cunningham, J. R. (1983). The physics of radiology (4a. ed.). Springfield, Ill., USA: Charles C. Thomas Publisher.

Khan, A., Schofield, K., \& Wright, D. (2005). Validation of Geant4 electromagnetic and hadronic processes in the BaBar detector. Proceedings of IEEE Nuclear Science Symposium Conference Record, 2, pp. 844- 846. San Juan, Puerto Rico.

Kippen, R. M. (2004). The GEANT low energy Compton scattering (GLECS) package for use in simulating advanced Compton telescopes. New Astronomy Reviews, 48, pp. 221-225. 
Kramer, H. M., Selbach, H. J., \& Iles, W. J. (Fevereiro de 1998). The practical peak voltage of diagnostic X-ray generators. The British Journal of Radiology, 71, pp. 200209.

Mattos, T. G. (2005). Autômatos celulares e crescimento de interfaces rugosas.

Dissertação (mestrado), Universidade Federal de Minas Gerais, Instituto de Ciências Exatas, Departamento de Física, Minas Gerais.

Mattos, T. G., Moreira, J. G., \& Atman, A. P. (2006). A new method to study stochastic growth equations: application to the Edwards-Wilkinson Equation. Brazilian Journal of Physics, , 36 (3A), $746-749$.

McHaney, R. (1991). Computer simulation: a practical perspective. San Diego, CA, USA: Academic Press Professional, Inc.

Meakin, P. (1988). Fractals, scaling and growth far from equilibrium. Cambridge, UK: Cambridge University Press.

Meakin, P., Ramanlal, P., Sander, L. M., \& Ball, R. C. (1986). Ballistic deposition on surfaces. Physical Review A , 34 (6), 5091-5103.

Metropolis, N., \& Ulam, S. (1949). The Monte Carlo Method. 44 (247), 335-341.

Nagamatsu, M., Kodama, T., Uno, H., Yoshida, H., Ohtsubo, K., Tanaka, S., et al. (1998). GAG: GEANT4 Adaptive Graphical user interface. Proceedings of Computing in High Energy Physics. Chicago, USA.

Nagel, H. D. (1988). Limitations in the determination of total filtration of X-Ray tube assemblies. Physics in Medicine and Biology, 33 (2), 271-289.

Nelson, W. R., Hirayama, H., \& Rogers, D. W. (1985). The EGS4 code system. SLAC265, Stanford University, Stanford LinearAccelerator Center, Stanford, CA.

Ng, K. P., Kwok, C. S., \& Tang, F. H. (2000). Monte Carlo simulation of x-ray spectra in mammography. Physics in Medicine and Biology, 45, pp. 1309-1318.

Nowotny, R., \& Meghzifene, K. (2002). Simulation of the effect of anode surface roughness on diagnostic x-ray spectra. Physics in Medicine and Biology , 47, 3973-3983. 
Olsher, R. H. (Abril de 2006). A practical look at Monte Carlo variance reduction methods in radiation shielding. Nuclear Engineering and Technology, 38, pp. 225-230.

Peralta, L., Rodrigues, P., Trindade, A., \& Pia, M. G. (2005). A new low-energy bremsstrahlung generator for Geant4. Radiation Protection Dosimetry, 116, pp. 59-64.

Perkins, S. T., Cullen, D. E., \& Seltzer, S. M. (1991). Tables and graphs of electroninteraction cross-sections from $10 \mathrm{eV}$ to $100 \mathrm{GeV}$ derived from the LLNL Evaluated Electron Data Library (EEDL), Z=1-100. UCRL-50400, vol.31, Lawrence Livermore National Laboratory, Livermore, CA.

Perkins, S. T., Cullen, D. E., Chen, M. H., Hubbell, J. H., Rathkopf, J., \& Scofield, J. (1991). Tables and graphs of atomic subshell and relaxation data derived from the LLNL Evaluated Atomic Data Library (EADL), Z = 1 - 100. UCRL-50400, vol.30, Lawrence Livermore National Laboratory, Livermore, CA.

Pia, M. G. (2003). The Geant4 toolkit: simulation capabitiesand application results. Nuclear Physics B (Proceedings Supplements) , 125, 60-68.

Pressman, R. S. (2001). Software engineering a practitioner's approach (5th ed.). New York, NY, USA: McGraw Hill.

Rodrigues, P., Moura, R., Ortigão, C., Peralta, L., Pia, M. G., Trindade, A., et al. (August de 2004). Geant4 applications and developments for Medical Physics experiments. IEEE Transactions on Nuclear Science, 51, pp. 1412-1419.

Salvat, F., Fernández-Varea, J. M., \& Sempau, J. (2006). PENELOPE-2006, A Code System for Monte Carlo Simulation of Electron and Photon Transport. Workshop Proceedings. Barcelona, Spain: NEA No. 6222.

Shepard, S. J., Lin, P.-J. P., Boone, J. M., Cody, D. D., Fisher, J. R., Frey, G. D., et al. (2002). AAPM Report no. 74 - Quality control in diagnostic radiology. American Association of Physicists in Medicine. Medical Physics Publishing.

Sobol, I. M. (1994). A Primer for the Monte Carlo Method. Boca Raton, FL, USA: CRC Press, Inc. 
Sprawls, P. (1995). Physical Principles of Medical Imaging. Madison, Wisconsin, USA: Medical Physics Publishing.

Stears, J. G., Felmlee, J. P., \& Gray, J. E. (1986). Half-Value-Layer increase owing to tungstein buildup in the X-ray tube: fact or fiction. Radiology, 160 (3), 837-838.

Tanaka, S., \& Kawaguti, M. (1997). DAWN for Geant4 visualization. Proceedings of Computing in High Energy Physics. Berlin, Germany.

Tinslay, J., Faddegon, B. A., Perl, J., \& Asai, M. (junho de 2007). Verification of bremsstrahlung splitting in Geant4 for radiotherapy quality beams. Medical Physics , 34 (6), p. 2504.

Vold, M. J. (1959). A numerical approach to the problem of sediment volume. Journal of colloid science, $14,168-174$.

Wolbarst, A. B. (1993). Physics of radiology. Norwalk, Connecticut, USA: Appleton \& Lange.

X-5 Monte Carlo Team. (2005). MCNP - A General Monte Carlo N-Particle Transport Code Version 5. LA-UR-03-1987, LA-CP-03-0245, LA-CP-03-0284, Los Alamos National Laboratory, Diagnostics Applications Group.

Yamaguchi, C., Yamamoto, T., Terada, H., \& Akisada, M. (1983). Effect of tungsten absorption edge filter on diagnostic x-ray spectra, image quality and absorbed dose to the patient. Physics in Medicine and Biology , 28 (3), 223-232. 